\title{
El paisaje en el ordenamiento territorial prehispánico durante el periodo Medio, valle de Azapa, norte de Chile ${ }^{1}$
}

\author{
Iván Muñoz ${ }^{2}$ y Francisca Zalaquett ${ }^{3}$
}

\begin{abstract}
RESUMEN
El presente manuscrito es resultado de una extensa y detallada prospección arqueológica realizada en el valle de Azapa, Arica, Chile. Se hallaron 36 sitios arqueológicos correspondientes al periodo Medio, la gran mayoría cementerios, en deficiente estado de conservación. Esta información ha sido fundamental para analizar la relación espacial entre los asentamientos humanos prehispánicos y los recursos naturales, como las vertientes, en el contexto del ordenamiento territorial en el sector bajo del valle de Azapa. De la discusión generada en torno a los recursos hídricos, fuentes de aprovisionamiento y patrón de visibilidad, se concluye que las poblaciones del periodo Medio fueron grupos de pescadores y agricultores quienes habrían transformado el valle en un espacio agrícola cultivando entre otros productos maíz, ají, porotos, aprovechando al máximo los espacios habitables, construyendo campamentos y aldeas, las que estuvieron conectadas entre sí a través de caminos y espacios ceremoniales.
\end{abstract}

Palabras clave: Ordenamiento territorial, visibilidad, recursos hídricos.

\begin{abstract}
The work is the result of extensive and detailed archaeological research in the Azapa Valley of Arica, Chile. Thirty-six archaeological sites were discovered, predominantly cemeteries, all from the Middle period. From a conservation point of view, most sites have not been well preserved. This information has been fundamental for the analysis of the spatial relationship between the pre-hispanic human settlements and natural resources, such as watersheds, in the context of land use in the lower area of the Azapa Valley. From the discussion generated on water resources, energy sources and the pattern of visibility, the conclusion is that the populations from the Middle period were groups of fisherman and farmers, who likely transformed the valley into an agriculturarl region through the cultivation of corn, peppers and beans, among other products. The population made the most of the habitable areas by building camps and villages, which were connected interconnected by roads and ceremonial sites.
\end{abstract}

Key words: Territorial zoning, visibility, water resources.

\footnotetext{
1 Este artículo es producto de la investigación desarrollada en el proyecto Fondecyt 1130249. Se reconoce el apoyo del Convenio de Desempeño Universidad de Tarapacá-Mineduc. Se agradece la colaboración del Sr. José Raúl Rocha, encargado de la Oficina de Catalogación del Departamento de Antropología de las Universidad de Tarapacá con quien prospectamos el valle de Azapa, confeccionó las fichas de sitios, figuras y cuadros que ilustran el presente texto. Se agradece además la colaboración de Teresa Cañipa por la información proporcionada
}

sobre las colecciones del periodo Medio, y Wilfredo Faundes por la información sobre fuentes de aprovisionamiento lítico en la costa de Arica. Artículo recibido el 31 de marzo de 2014, aceptado el 30 de noviembre de 2014 y corregido el 23 de diciembre de 2014.

2 Departamento de Antropología, Universidad de Tarapacá (Chile). E-mail: imunoz@uta.cl

3 Instituto de Investigaciones Filológicas, Centro de Estudios Maya, Universidad Nacional Autónoma de México (México). E-mail: panchaahau@hotmail.com 
En un trabajo previamente publicado (Muñoz y Zalaquett, 2011), fueron presentados los resultados del análisis de los patrones de asentamiento durante el periodo Formativo en el valle de Azapa, tomando como eje la edificación de túmulos funerarios, estos datos fueron obtenidos mediante el desarrollo de una prospección arqueológica y arrojaron la existencia de una vinculación entre la ubicación de los túmulos y la presencia de afloramientos de agua (vertientes). El trabajo que se presenta a continuación, profundiza en el análisis de esa relación espacial existente entre los sitios de cementerio-aldeas y los lugares de disponibilidad de recurso hídrico en el valle de Azapa para el periodo Medio.

Prospecciones arqueológicas realizadas en el valle de Azapa por Dauelsberg (1959), Espoueys (1973), Goldstein y Muñoz (1991), Muñoz y Zalaquett (2011) han arrojado en los registros de superficie escasas evidencias sobre asentamientos habitacionales y pisos de ocupación doméstica para el periodo Medio (300 d.C.- 800 d.C.) por lo cual la información de cementerios ha pasado a ser fundamental para entender las estrategias organizativas de este período trascendental en la arqueología de este valle ya que por un lado, constituye el proceso de culminación y expansión del desarrollo agrario y por otro, es el momento de mayor influencia cultural de Tiwanaku.

Si consideramos que el poblamiento aldeano del valle, durante el periodo Medio, se extendía por más de mil años de desarrollo agrícola, el paisaje de estos valles se habría convertido en un referente clave para la construcción y expresión de la identidad del grupo (Muñoz, 2012). Es así que los cementerios surgen entre las evidencias que, al parecer, alcanzaron mayor representatividad en el contexto de la identidad, estos fueron reconocidos y mantenidos por la comunidad como puntos de evocación de la memoria, por lo tanto, como un transmisor de la cultura de estos agricultores de los valles occidentales. Constituyeron verdaderos monumentos en cuyo alrededor, en espacios de terrazas, levantaron sus recintos habitacionales y áreas productivas (chacras). Bajo esta perspectiva, los espacios fúnebres fueron relevantes en el contexto de la estructuración del paisaje social.
Por otro lado, en la perspectiva territorial, la irrupción de las prácticas funerarias caracterizadas por la inhumación de los cuerpos en fosas subterráneas, explicaría el surgimiento de una tradición funeraria en la que los antepasados se habrían convertido en argumentos de derecho para regular el acceso y uso de territorios complejos (Muñoz, 2012). Entre los elementos formales que dibujan el paisaje durante el período Medio, la arquitectura funeraria conformada por tumbas cavadas en fosas, al parecer constituyó un cambio significativo en el proceso de complejización aldeana en los valles, su estilo constructivo al parecer obedece a una nueva concepción del espacio y el tiempo; reflejando de buena manera la artificialización de la naturaleza que tal vez se constituyó como una vía de primer orden para acceder a la dimensión simbólica, dado el carácter ideológico y político, que subyacía en las prácticas funerarias de las poblaciones del período Medio.

Ahora bien, Cabuza se constituye como la población que caracteriza este periodo en el valle de Azapa, de acuerdo con los trabajos de Focacci (1982), Berenguer y Dauelsberg (1989), Rivera y Kolata (2004) entre otros, esta se caracterizaría por a) presentar un fuerte desarrollo de la economía agrícola, con énfasis en los cultivos de maíz, ají y frutícolas, b) intensidad del tráfico caravanero representado en el arte rupestre c) depósito de ofrendas y objetos suntuarios en los entierros, siguiendo el antiguo patrón de las poblaciones locales, integrando además a este patrón algunos objetos e íconos que recuerdan el ceremonialismo de Tiwanaku: orejeras de plata, gorros de cuatro puntas, decorados con una gran variedad de motivos y colores, además de vasijas y cucharas de maderas finamente trabajadas, portando íconos de personajes míticos. d) empleo de instrumentos musicales usados en ritos relacionados con el pago de la tierra y el floreo de animales, e) depósito además de piezas y objetos vinculados a prácticas psicotrópicas.

Sobre quienes fueron estas poblaciones Cabuza, estudios recientes señalan que no correspondería a una población colonizadora vinculada con Tiwanaku (Berenguer 2000, Chacama 2004), sino más bien, se trataría de una población local con influencias estilís- 
ticas provenientes del núcleo de Moquegua (Uribe y Agüero, 2001) ${ }^{4}$.

De la información que nos ha arrojado la prospección arqueológica e investigaciones previas, el objetivo de la presente investigación apunta a definir las características de los patrones de asentamientos desarrollados durante el periodo Medio en el valle de Azapa, norte de Chile. Para tal efecto se describen los asentamientos de dicho periodo y se comparan con los asentamientos del periodo Formativo, especialmente los cementerios de túmulos, vinculados con los inicios del proceso agrícola. También se discute la relación de los cementerios del período Medio con los recursos de agua de vertientes. Finalmente se analiza y discute la relación visual entre asentamientos y el entorno con el objeto de determinar las posibles relaciones entre los grupos asentado en el valle y su ordenamiento territorial.

La metodología estuvo enfocada en base a una prospección - directa e indirecta- y el análisis espacial de los asentamientos. La información recogida fue sistematizada en base a un registro de datos, la cual fue la base para la confección de planos e inventario de los sitios prospectados.

\section{Reflexiones teóricas}

El concepto de Paisaje ha estado vinculado a la geografía y a su desarrollo desde principios del siglo XIX, si bien es cierto los primeros antecedentes de la noción de Paisaje pueden ser rastreados hasta el siglo XVII, vinculados a las artes plásticas, no es sino hasta que la geografía se consolida como una disciplina científica positiva que el concepto toma mayor relevancia (Villafáñez, 2011). Durante las primeras décadas del siglo XX, la escuela francesa entendió el concepto como "el reflejo de un estilo particular de la organización espacial" y posteriormente como un

\footnotetext{
4 Esta hipótesis se apoyaría en el estudio de análisis dentarios realizados por Sutter (2000) quien señala que no habría diferencias notables en las poblaciones que ocuparon la zona de Arica por varios miles de años destacando una ocupación continua, hipótesis que contradice el planteamiento de Rothammer y Santoro (2001) quienes señalan la presencia de individuos de origen altiplánico, interactuando durante el periodo Medio en el valle de Azapa.
}

elemento esencial para "entender las relaciones entre las sociedades humanas y el medio geográfico (Villafáñez, 2011: 137-8). Avanzada la segunda mitad del siglo XX los cambios paradigmáticos propios de una disciplina en evolución llevaron a la revisión del concepto, el surgimiento de la nueva geografía en la década de 1960, "llevó a la sustitución del término de "paisaje" por el de "espacio", concepto más adecuado a las exigencias [...] de este nuevo marco teórico" (Villafáñez, 2011: 138). Actualmente, el paisaje se entiende como una construcción social y cultural, intrínsecamente e indivisiblemente vinculado a una plataforma física, en palabras de Nogué y San Eugenio Vela (2011: 27):

"El paisaje es, a la vez, una realidad física y la representación que culturalmente se hace de ella; la fisonomía externa y visible de una determinada porción de la superficie terrestre y la percepción individual y social que genera; un tangible geográfico y su interpretación intangible".

Coincidentemente con esta última definición, desde la arqueología del paisaje -disciplina ampliamente influenciada por la nueva geografía ${ }^{5}$ - el concepto paisaje es definido como un "producto sociocultural creado por la objetivación, sobre el medio y en términos espaciales, de la acción social tanto de carácter material como imaginario" (Criado Boado, 1999: 5). Se establecen además tres elementos del concepto paisaje: a) el espacio físico-medioambiental de la acción humana, este aspectos es solo posible de estudiar por la arqueología con la ayuda de otras disciplinas como la geografía, b) el espacio social o construido por los seres humanos y donde se desarrollan las relaciones de los individuos, c) el espacio simbólico, donde es posible decodificar la forma en cómo los seres humanos se apropian de la naturaleza (Criado Boado,

\footnotetext{
5 Villafáñez (2011) señala que la arqueología del paisaje desarrolló el interés por los espacios gracias a los aportes de la nueva geografía, esta a su vez recibió la influenciada de diversas teorías económicas, es así que "Estas posturas, tomadas por la nueva arqueología, permitieron que los sitios arqueológicos comenzaran a confeccionarse, verse e interpretarse como algo más allá que puntos en un mapa, guiados por ciertos métodos operativos." (Villafáñez, 2011: 141).
} 
1999). Este último punto es fundamental para el entendimiento del concepto actual de paisaje, desde la geografía social y cultural, el paisaje es más que todo una manera de ver, es un complejo sistema de signos y símbolos, que requiere, para entenderlo, comprender a su vez sus representaciones no como imágenes estáticas, "sino como imágenes constitutivas de sus significaciones" (Nogué y San Eugenio Vela, 2011: 27), de esta manera los autores señalan que el paisaje puede ser leído como un texto.

Como se expresó anteriormente, los estudios de arqueología del paisaje plantean la dinámica relacional que posee el hombre en torno a las construcciones mentales que hace de su paisaje y cómo forja normas y directrices para que se mantenga de acuerdo a escalas de pretensión espacial y temporal (Criado Boado, 1993, 1999; Anschuetz et al., 2001). Uno de los elementos característicos de estos estudios dice relación con la visibilidad, entendiéndose esta por los resultados de la acción social, sean más, menos o nada visibles ${ }^{6}$.

En el caso de los asentamientos del período Medio del valle de Azapa, donde las evidencias mayoritarias corresponden a cementerios, estos posiblemente estuvieron relacionados con los orígenes, con los antepasados, y por lo tanto, debieron haber sido parte fundamental de la memoria de los agricultores, convirtiéndose como lo señalan Knapp y Ashmore (1999) y Kaulicke (2001) entre otros, en un referente clave para la construcción y expresión de la identidad del grupo. Por otro lado, al construirse las tumbas en los mismo espacios donde anteriormente, en el periodo Formativo, se construyeron los túmulos, cercanos a los lugares donde ha-

\footnotetext{
6 Desde el punto de vista de las estrategias de visibilización del paisaje Criado Boado (1993) distingue cuatro principales, los que en su conjunto constituyen una expresión de visualización total: a) Inhibición: ausencia de actitud consciente de visibilización de los resultados y efectos de la acción humana. b) Ocultación: estrategia consciente de invisibilizacion de los efectos y resultados de la acción. c) Exhibición: estrategia consciente de la visibilizacion de los efectos de la acción y d) Monumentalización; estrategia consciente de visibilizacion y exhibición de los resultados, agregando pretensiones de permanecía en el tiempo.
}

bía agua (vertientes), estos recursos hídricos pasaron a constituirse en espacios claves en la estructuración del paisaje social de los agricultores del período Medio. Junto a estos recursos de agua, las terrazas con amplia visibilidad, teniendo como referente algunos hitos geográficos, fueron los lugares preferidos para asentarse. A partir de estos elementos demarcatorios como el agua, la tierra y los cerros, las poblaciones aldeanas del periodo Medio habrían ordenado, conceptualizado y transformado el paisaje del valle en la configuración de sus territorios sociales.

En la actualidad las perspectivas provenientes de la geografía, sociología y la antropología, como la teoría de la práctica han abierto los conceptos a comprender los lugares como espacios dinámicos, donde las personas crean y son limitadas por estructuras que marcan su vida, donde experimentan y actúan dentro de su sociedad, teniendo roles significativos en esta. Bourdieu (1977) establece que las grandes estructuras de una sociedad influencian en las prácticas diarias. Habla sobre la agencia entendida como la acción por la cual las cosas son logradas por los individuos, operando con reflexión y conocimiento de su sociedad. Esta se ubica en estructuras que facilitan sus acciones ya que necesitan de medios por los cuales trabajar, siendo estos materiales, simbólicos, hasta tradiciones de expresión social. La efectividad de la movilización de tales recursos en la práctica depende del poder del agente sobre esos recursos y de su experiencia para comunicarse efectivamente, por lo tanto pasa a ser un poder para actuar y no un poder sobre otro. A nivel arqueológico estas posturas cobran gran importancia, ya que permiten visualizar a la sociedad escribiendo su identidad en el registro arqueológico a través de las acciones de sus miembros. Al mismo tiempo, la práctica hace la memoria, las experiencias pasadas, expectativas, deseos y un compromiso comunicativo con los otros. A través de las prácticas Ilevadas a cabo por el cuerpo y la materialidad del habitus, las prácticas sociales aparecen ordenadas a través del tiempo y del espacio. Las condiciones materiales facilitaban la práctica en el tiempo, por esta razón el control territorial que comienza a manifestarse por medio de las construcciones de montículos durante el período Formativo y continúa en el período Medio con la 
construcción de los cementerios en fosas siguiendo el planteamiento de Isbell (1997) y Dillehay (2000) entre otros, puede entenderse a través de la legitimación de una localidad determinada donde yacen los restos de los antepasados, lográndose con esto establecer fronteras territoriales manejadas a través de un enfoque ideológico. De tal manera que, el estudio de las prácticas mortuorias y contextos funerarios en los valles de Arica, constituye la base para inferir aspectos de la organización social, territorial y la demografía de los grupos de agricultores prehispánicos del periodo Medio. Interpretar el concepto de paisaje bajo las posturas actuales en geografía aplicadas en los estudios de patrón de asentamiento prehispánicos, permite visibilizarlo como un elemento esencial en la formación de identidades territoriales, como un espacio lleno de significado, que refleja y es parte de la constitución de un grupo cultural en un tiempo determinado (Nogué y San Eugenio Vela, op. cit. 26), es una propuesta interdisciplinaria que retroalimenta las investigaciones arqueológicas actuales. Por esta razón, se incluyen elementos de visibilidad en los estudios de patrón de asentamiento, los que permiten una visión más dinámica, considerando elementos materiales e inmateriales en la determinación de relación entre los asentamientos durante el periodo Medio.

La construcción de montículos destinados a enterratorios, en una primera etapa del desarrollo aldeano, y la posterior práctica de inhumación de cuerpos en fosas cercanas a estos montículos, plantean una clara legitimación y manejo del paisaje con una continuidad y permanencia, asociada a grupos de pescadores, que delimitan su paisaje en el caso del periodo Formativo de forma exhibición y monumentalización como plantea Criado Boado, a pasar a una estrategia más íntima de apego al territorio por medio de entierros en fosas, relacionados con una inserción en el paisaje natural y sus creencias, respetando los túmulos como culto a los antepasados, no claramente relacionados por vía consanguínea. Estos grupos de pescadores al adentrarse al valle al mismo tiempo que demarcaron una expansión territorial, fortalecieron relaciones y contactos con otros grupos aldeanos entre ellos algunos influenciados por Tiwanaku, con los que al parecer compartieron cultos.

\section{El medio natural}

El valle de Azapa forma parte de un conjunto mayor conocido como los valles mesotérmicos, que en el sur del Perú y norte de Chile nacen a partir de los cursos de agua cuyo origen según Espina (1971) se hallan en la cordillera de los Andes. Sus coordenadas en la desembocadura y naciente de valle, que alcanzan una Longitud aproximada de $87 \mathrm{~km}$ son: desembocadura río San José: 19k 361.420E - 7957.580N (Fuente: cartografía IGM Arica 0-12 escala 1/50.000, edición 2006). Naciente valle de Azapa-quebrada de Livilcar: $19 \mathrm{k}$ 433.934E- 7961.715N (Fuente: cartografía IGM Belén A-015 escala 1/50.000, edición 2004). El valle de Azapa es alimentado por el río San José, que nace en la cordillera central y que logra llegar en forma intermitente hasta la costa, debido a la infiltración de aguas en el curso inferior de la quebrada (Keller, 1946). El caudal aumenta en los meses de enero y febrero, por las lluvias en las regiones cordilleranas y altiplánicas; este aumento de agua habría sido aprovechado para el regadío de tierras haciendo posible un aumento de la producción agrícola, como consecuencia de una mayor superficie cultivada (Muñoz, 1980).

Una mirada del valle de Azapa descrita para el siglo XVI por el jesuita Vázquez de Espinosa (1619) y comentada por Crom (1995/1996), reconoce un valle de suelos pedragosos donde brotan una serie de ojos de agua en algunos sectores del valle como $\mathrm{Hu}$ magata, el sector comprendido entre quebrada del Diablo y Saucache y la costa de Arica, específicamente el sector de La Chimba. Señala que debido a la formación de estos ecosistemas húmedos hubo una vegetación permanente, los cuales fueron escenarios vitales para que se asentaran grupos humanos en su entorno, aprovechando las terrazas fluviales de amplia visibilidad, quienes tenían como propósito implementar y desarrollar el sistema agrícola, tal como lo reflejan las evidencias arqueológicas que describiremos, especialmente en el sector medio del valle.

\section{Metodología de análisis espacial}

El área de prospección arqueológica del valle de Azapa estuvo delimitada desde la 
costa al sector de Cabuza, abarcando un total de $24 \mathrm{~km}$. En una primera fase, se realizó una Prospección Indirecta basada en el análisis de fotografías aéreas, cartografía del Instituto Geográfico Militar (IGM) y en la Información Geográfica Satelital (Google Earth). Posteriormente, se realizó una Prospección Directa con el objeto de contrastar y completar la información obtenida a través de la prospección Indirecta, se realizaron mapas arqueológicos detallados con los datos registrados a través de fichas estandarizadas. Finalmente, se aplicó la técnica de Prospección Intensiva dirigida a los lugares para los cuales no existe información satelital, por lo tanto, se recorrieron las laderas de los valles antes mencionados.

Dentro de la metodología para el análisis de los sistemas de asentamiento se realizó un estudio morfológico del paisaje. Dicho análisis se concretó en mapas morfológicos y diagramas formales que muestran la topografía del terreno y que permiten visualizar los emplazamientos de los sitios, las características de visibilidad y acceso.

Como una forma de complementar la información descrita, se incorporan dos cuadros; el Cuadro $\mathrm{N}^{\circ} 1$ tiene como objeto respaldar la información obtenida en terreno a través de excavaciones y registros realizados anteriormente. El Cuadro $N^{\circ} 2$ proporciona la totalidad de los registros obtenidos en la prospección del año 2013. En este cuadro se describen las coordenadas de ubicación, alturas, tipos de sitios y estado de conservación. Además se dan a conocer dimensiones aproximadas a partir de evidencias y vestigios superficiales considerando área, perímetro y hectáreas. Sin embargo, por las condiciones actuales que presentan los sitios (deficiente conservación) dimensiones más precisas requiere de estudios con aplicación de georradar y excavaciones.

\section{La prospección del valle de Azapa}

Reconocimiento y excavación de tumbas en el valle de Azapa fueron realizadas por el equipo del Museo Regional de Arica (MRA) a fines de la década del cincuenta y cuyos resultados fueron publicados en Dauelsberg en los años 1959 y 1961. Resultado de esta prospección Dauelsberg plantea un modelo cronológico que enfatiza la definición de un período Formativo caracterizado por la fase Alto Ramírez y la configuración de una secuencia cerámica para la región de Arica, que ha servido como columna vertebral para el área centro sur andina El material arqueológico forma parte de las colecciones del Museo Arqueológico San Miguel de Azapa (MASMA). Otros reconocimientos fueron realizados por Espoueys (1973) y Focacci (1983) cuyos resultados son parte del catálogo de sitios de los valles de Arica publicado en 1973 y de publicaciones donde describen una serie de cementerios claves para entender aspectos ceremoniales, tecnológicos y económicos de las poblaciones prehispánicas del período Medio en el valle de Azapa. En 1991, Goldstein y Muñoz, realizaron una extensa prospección en el valle de Azapa que abarcó desde el km 1 al 26, parte de ese reconocimiento se halla en Goldstein (1995/1996) donde describe una mayor información de sitios domésticos, además problematiza la interacción de establecimientos agrarios autóctonos, colonias Tiwanaku e intercambio de larga distancia con otras identidades como Wari (Muñoz y Santos, 1995).

El año 2008, Muñoz y Zalaquett (2011) al estudiar los cementerios de túmulos, reconocen un patrón de asentamiento durante el periodo Formativo representado por conjuntos de túmulos que se distribuyen a lo largo del valle, construidos sobre terrazas y faldeos de cerros cercanos a los lugares de vertientes y humedales. Este estudio se basa en una prospección extensiva e intensiva con el propósito de determinar la ubicación de los túmulos, definir su distancia con los recursos de agua, medir el grado de ocupación del área de los complejos de túmulos y determinar el grado de visualización entre los distintos sectores de túmulos.

\section{Ubicación y registros de los sitios}

El segmento prospectado abarcó desde la desembocadura del río San José hasta el km 24, valle de Azapa denominado sector puntilla de Cabuza alcanzando los 500 m.s.n.m. En todo este segmento localizamos $18 \mathrm{sec}$ tores, los que fueron determinados a partir de las evidencias culturales y morfológicas propias de los asentamientos prehispánicos 
del periodo Medio, además de una estrecha relación con los ecosistemas de humedad. El número y dimensiones de cada sector se describen en la Figura $N^{\circ} 1$, Sectorización de los asentamientos del período Medio. Por otro lado para las denominaciones de los sectores se consideró la información obtenida de la cartografía IGM referidos a la toponimia del valle.

Figura $\mathrm{N}^{\circ} 1$

Sectorización de los asentamientos del periodo Medio, en el valle de Azapa, según prospección arqueológica año 2013

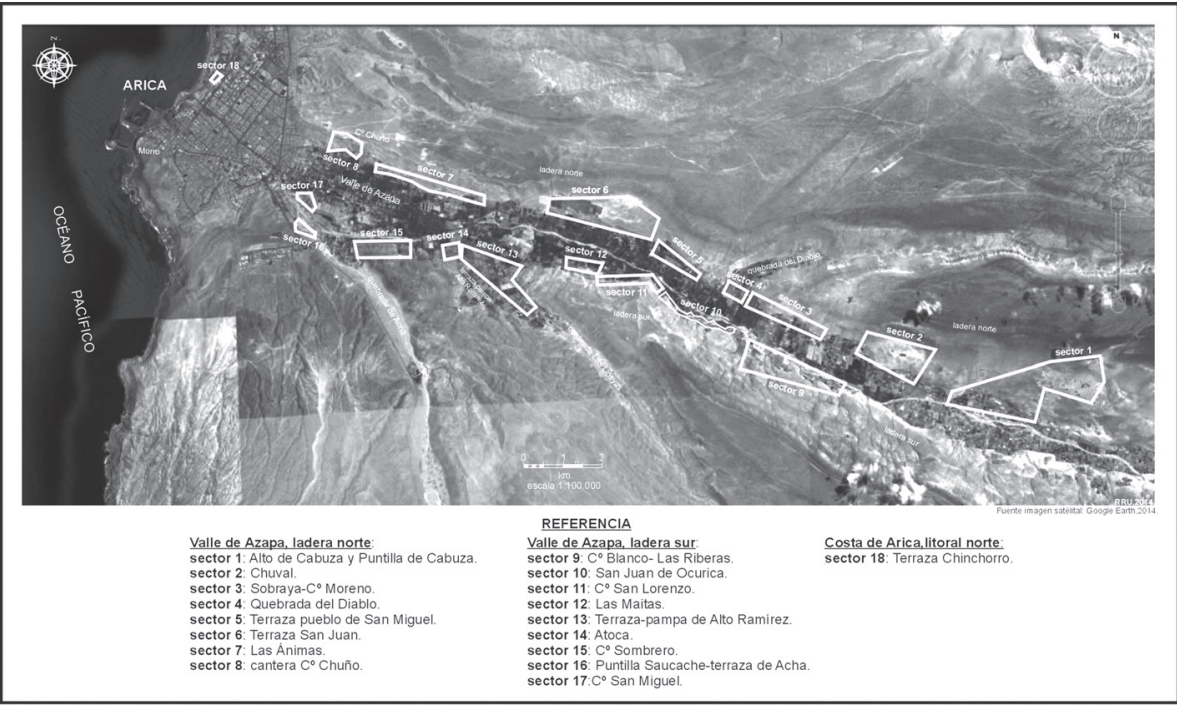

Fuente: Elaboración propia.

En la ladera norte se determinaron ocho sectores con ocupación del periodo Medio. El primer sector correspondió a lo que hemos denominado La Puntilla y Alto Cabuza, en el sector La Puntilla registramos restos de tumbas cavadas al piso, de planta circular. Estas fosas distribuidas en un radio de acción de $1330 \mathrm{~m}^{2}$ fueron parte de los cementerios Az-1 y Az-2. Allí sobre superficie constatamos restos de osamentas humanas, además de fragmentos de túnica listada fina tejida en colores azul, rojo, café y blanco. También se hallaron fragmentos de cerámica con formas de olla y restos de mazorcas de maíz. En las colecciones del Museo Arqueológico San Miguel de Azapa (MASMA) registros proveniente de Az-1 corresponden a objetos textiles como una manta con teñido de amarra tai day, un casco guerrero confeccionado en fibra vegetal, cerámicas con forma de puco, kero y jarro pato estilos que según Dauelsberg (1972) se relacionan con componentes estilísticos Cabuza, Sobraya y Tiwanaku. En Az-2 entre las piezas excepcionales se halla el registro de una máscara de un felino.

En este mismo sector se ubica el sitio Az103, corresponde a un cementerio en cuya superficie del terreno se pueden visualizar difusas depresiones de planta circular que corresponderían a fosas funerarias, se observan restos de osamentas humanas, mazorcas, alfarería fragmentada y restos de textilería. En la colección Manuel Blanco Encalada (CMBE), se tiene registro de 103 contextos fundamentalmente fragmentos de cerámica vinculados a los estilos Cabuza, Tiwanaku y Charcollo, además de dos gorros de cuatro puntas policromos. En el sector Alto de Cabuza se localizó un pequeño cementerio conformado por fosas cistadas, construidas muy próximas entre sí. Junto a estas se hallaron restos de osamentas humanas blanquecinas y clastos que corresponden a la arquitectura de bóvedas mortuorias. 
El segundo sector corresponde al Chuval, ubicado entre el sector Alto Cabuza y Cerro Moreno-Sobraya. Allí se haya el cementerio Az-141, corresponde a un asentamiento funerario ubicado en cotas cercanas a la cima de ladera. Focacci en la década de los ochenta excavó 55 tumbas con un registro de 398 objetos, donde notoriamente se destacan elementos culturales Cabuza, Sobraya y Tiwanaku. Las tumbas están constituidas por fosas de planta circular, algunas presentan cámaras mortuorias cistadas, los cuerpos están enfardados con prendas manufacturadas en lana, con diseños polícromos. En la tumba 53, la ofrenda dispone de un mazo con cabezal lítico y los restos de una camisa recamada en plumas.

El tercer sector prospectado corresponde al área que comprende desde Sobraya a Cerro Moreno; allí registramos evidencias de los cementerios Az-3, Az-4 y Az-5. Az-3 corresponde a un asentamiento funerario ubicado en recodo de las cotas de base de ladera norte y plano de valle inmediato. Este asentamiento está constituido por fosas de forma circular. La dispersión en el terreno de clastos angulados indica el uso de técnica constructiva con revestimiento en las paredes de cámaras mortuorias. En la superficie del terreno se haIlaron 5 fragmentos de cerámica con formas de keros y jarra, estilo Cabuza; 1 fragmento de borde de labio de vaso, estilo Tiwanaku, presenta como decoración una estrella de 4 puntas con círculo concéntrico central y 4 círculos concéntricos en los costados de la estrella, también se registra un fragmento de túnica, decorado con listas verticales de colores rojo, verde y amarillo realizados en faz de urdimbre. Junto a estos fragmentos de cerámica y tejidos decorados se hallaron restos de cerámica y textiles sin decoración, además de mazorcas y chalas de maíz. También se registraron restos de osamentas humanas de adultos e infantes, muy erosionadas. Vinculado a este cementerio, en las colecciones del MASMA y de la Colección Manuel Blanco Encalada (CMBE) hemos registrado objetos confeccionados para posibles acciones bélicas, como un mazo lítico horadado, un carcaj o costal de cuero de camélido conteniendo en su interior astiles con puntas de flechas junto a una máscara con rostro de felino. Según Espoueys (1973) el sitio presentaba varios petroglifos, y dos grandes bloques de piedras tacita, con varias oquedades.
Az-4 corresponde a un complejo de petroglifos conformado por seis bloques de gran volumen. La interpretación general de los elementos figurativos comprenden trazos lineales verticales no profundos, con segmentos adosados en sentido oblicuo $45^{\circ}$ a $50^{\circ}$ para representar posiblemente una especie vegetal. Otras figuras corresponden a círculos concéntricos, alineados entre sí en sentido horizontal y vertical, realizados en talla más profunda; también reconocemos puntos y espirales conformando figuras geométricas. Finalmente se observan horadaciones de formas cilíndricas talladas en bloques de superficies planas y alisadas, se reconocen como piedras tacitas. Finalmente registramos el sitio Az-5 corresponde a un cementerio disturbado, se haya distribuido en cotas de base y faldeos de ladera norte sobre los asentamientos. En la colección Manuel Blanco Encalada, (CMBE) los registros de inventario de este sitio señalan una diadema tumiforme de oro vinculada a la fase Cabuza.

Siguiendo la misma ladera norte registramos un cuarto sector el que corresponde al cauce de la quebrada del Diablo en su confluencia hacia la caja del valle de Azapa. Allí se ubica el cementerio Az-143 el que se halla ampliamente disturbado observándose una serie de osamentas humanas, distribuidas a lo largo del cementerio, corresponden a fosas hechas en un terreno arenoso de cauce de río con presencia esporádica de clastos y cantos rodado, los que son parte de la estratigrafía natural del sector. En la superficie de las tumbas removidas se hallan fragmentos de cerámica, tejidos muy deteriorados y restos de zuros de maíz. Algunas sepulturas presentan las losas de canto a medio enterrar, otras muestran formas cilíndricas u ovaladas. Focacci en la década de 1980 excavó diez sepulturas que contenían algunos fardos funerarios semidestruidos, registrando 118 objetos que se hallan en los depósitos del MASMA. La cerámica mayormente corresponde al tipo denominado Tiahuanaco V (Focacci, 1982).

Entre el sector de cerro Moreno y el poblado de San Miguel de Azapa, se ubica un quinto sector denominado terraza Pueblo de San Miguel, allí se ubicaba el asentamiento Az-6, excavado por Focacci (1990: 69-124), corresponde a un cementerio cuyos cuerpos fueron depositados en fosas construidas en 
medio de un pedregal. Fueron excavadas 206 sepulturas, con un registro de 1.153 objetos, correspondientes a las fases Maytas-Chiribaya y San Miguel, también se examinaron 50 contextos funerarios asociados a la fase Cabuza. Según Focacci, sus ofrendas rituales parecen vincularse con los cultos felínicos, de la fertilidad y de los antepasados a través del culto a las huacas y de la práctica del consumo de alucinógenos. Junto a esta área de entierro se halló un pequeño basural, en el que se observaron abundantes restos de zuros de maíz, calabazas, frejoles, hueso de camélidos y de cuyes, restos de pescados y conchas de mariscos, que evidencian una actividad agrícola complementada con los recursos de la costa y de camélidos. Añade Focacci que entre sus ofrendas se destacan camisas recamadas con plumas, un mazo de piedra, un casco guerrero, trenzados triangulares de pelo humano, camisas con mangas, gorros de cuatro puntas, una punta de picana de bronce.

Por su parte, Dauelsberg (1959) señala que en un nivel de mayor de altura donde se ubicaba este cementerio se hallaron restos de muros de caña asociadas a desperdicios de ocupación doméstica. Le asigna a estos restos la sigla de Az-98. En la actualidad ambos espacios -cementerio y habitaciones- están cercados con plantaciones y galpones en su interior, además no hay registros de colecciones de este sitio.

El sitio Az-74, se ubica en la terraza de origen fluvial emplazada en la confluencia de la quebrada del Diablo hacia la caja de valle y adosado a cotas de base de ladera. La superficie del terreno presenta una decena de depresiones de forma circular, cercanas entre sí y asociadas a un conjunto de piedras de regular tamaño. Estos rasgos -fosas y piedrascorresponden a evidencias de sepulturas construidas en técnica de cistas. Hay registros de fragmentación de una manta de color café claro muy deteriorada.

En el poblado de San Miguel, adosado a la ladera norte se hallan los sitios mayoritariamente estudiados por el Departamento de Antropología de la Universidad de Tarapacá, Az-70 y Az-71, este último corresponde a un cementerio estudiado por Focacci (1980) y Santoro (1980). El sitio se halla en medio del actual cementerio cristiano del pueblo de San Miguel de Azapa. De acuerdo a descripciones históricas, su posición geográfica ocuparía cotas de ladera en un área de 96 m de este a oeste y de $84 \mathrm{~m}$ orientados de norte a sur. (Plano: Distribución de sepulturas sitios Az-70 y Az-71, MASMA 1977-1979). Las tumbas según Santoro (1981) corresponden a los periodos Intermedio Temprano, Medio y comienzos del Intermedio Tardío. En Azapa71B, Santoro excavó restos de ocupaciones doméstica y funeraria; a las sepulturas más tempranas le denominó Fase Azapa. El total de tumbas registradas fueron 607 .

Hacia el oeste de la terraza Pueblo de San Miguel, específicamente en la parcela 27, donde se halla el Museo San Miguel de Azapa (MASMA), registramos el cementerio Az115, excavado por el Departamento de Antropología en varias etapas, el último el año 2004. Los registros excavados corresponden a 252 contextos funerarios. Las tumbas intactas suman 27 y las alteradas 225. Por otro lado, 46 aparecen depositadas en cestos. Un rasgo particular de este cementerio es la presencia de ofrendas en miniatura entre ellas cerámicas, tejidos, dardos, entre otros elementos (Focacci, 1983, Muñoz, 1995/1996).

El sexto sector reconocido corresponde a la terraza de San Juan, donde se halla la red eléctrica de alta tensión Iquique-Arica; corresponden a evidencias funerarias, enterratorios con esteras, asociadas a pequeños montículos conformados por bloques líticos de gran volumen aglutinados, alcanzan una altura promedio de $50 \mathrm{~cm}$ sobre superficie. Estas evidencias se encuentran dispersos en un plano extenso, superando los $4 \mathrm{~km}$ de extensión en un eje de este a oeste. Entre las evidencias halladas en superficie, registramos mazorcas de maíz, restos de tejidos de lana y huesos de camélidos. Otro sitio de carácter funerario registrado en la base de la terraza, en la parcela de propiedad del Sr. Olivares, corresponde a un cementerio tipo cestos urnas de distintos tamaños. En él se recuperaron una docena de cestos urnas algunos de ellos muy deteriorados por el personal del MASMA y Consejo de Monumentos Nacionales.

El séptimo sector reconocido en la ladera norte, corresponde al sector de las Ánimas, donde hemos registrado con la sigla Az-148 (Parcela Eusebio Roque) dos asentamientos 
funerarios. El primero corresponde a cestos urnas dispuestos en pisos arenosos sobre una altura de 20 m; estas tumbas están dispersas en una pendiente agresiva, muy susceptible a la erosión. Están asociadas a un extenso complejo de túmulos, algunos de ellos fuertemente disturbados por la maquinaria agrícola. En este mismo sector en cotas de mediana altura $y$ en un plano estrecho, se encuentra un asentamiento de arte rupestre (petroglifos) donde observamos figuras zoomorfas, geométricas y antropomorfas.

El octavo sector corresponde a la cantera de $C^{a}$ Chuño, el año 1991 se constataron vestigios de un complejo de cementerios de túmulos asociados a figuras de arte rupestre (petroglifos). En la actualidad esta reserva arqueológica ubicada en la parcela Familia Bu-Antun casi ha desaparecido como consecuencia del desarrollo agrícola.

En la ladera sur se prospectaron nueve sectores con ocupaciones del periodo Medio. El Noveno sector corresponde al espacio que va desde cerro Blanco a las Riberas, allí registramos Az-145, corresponde a un cementerio donde las tumbas tipo cistas se ubica en la cima y cárcavas de dos cerros. En la superficie se hallan restos dispersos de material cerámico, los que presentan engobes rojos con decoración en círculos de color negro. En la cima del cerro menor, llamada por Focacci waka chica se recolectan 6 fragmentos de cerámica muy erosionados de bordes de labio y cuello, con engobe rojo y decoración en negro. Otro sitio ubicado en este sector fue Az-147, en la actualidad totalmente alterado por labores agrícolas. Correspondió a un cementerio descrito por Espoueys (1973) registrándose una serie de fragmentos de cerámica vinculado con el estilo Cabuza y Sobraya, además de fragmentos de tejidos multicolores y restos de cestería con formas de puco y plato.

El décimo sector corresponde a San Juan de Ocurica, donde registramos el cementerio Az-140, el que se halla muy disturbado. Está constituido por una serie de fosas donde fueron depositados cuerpos con las piernas flexionadas. En la superficie hallamos osamentas humanas muy erosionadas de color blanquecinas, restos de mantas de lana, esteras y maderos.
El undécimo sector corresponde a San Lorenzo, allí hemos registrados los cementerios Az-75, Az-76, Az-79 y el asentamiento poblacional Az-11; Az-75 y Az-76, fueron excavados por Focacci (1983) y Muñoz y Focacci (1985) y Muñoz (2004), los contextos estudiados se vinculan a la fase Maitas-Chiribaya y San Miguel. Az-75 se ubica en la ladera sur en dirección oeste a la reserva arqueológica de Az-11, en cotas de medio faldeo. Dicho cementerio está conformado por fosas cavadas al piso de forma circular muy próximas entre sí. En este cementerio se exhumaron 136 tumbas con un total de 998 registros. Se destacan algunos objetos como dos figuras antropomorfas confeccionadas en madera con gorros de cuatro puntas y un brazalete de oro. En nuestra reciente prospección, en la superficie de estas fosas hallamos cinco fragmentos de túnicas de lana de color café y cinco fragmentos textiles, de hilada fina, de color café oscuro, tres fragmentos de cerámica de forma globular, un fragmento de olla con restos de tizne, zuros de maíz y un fragmento de Cucurbitácea sp. El cementerio Az-76 presenta similitudes con Az-75, en él Focacci excavó 49 tumbas, registrando 321 objetos fragmentados correspondientes a las fases Cabuza y MaytasSan Miguel.

El sitio Az-79, se ubica en espacios que corresponden a predios y urbanizaciones rurales, se detectaron restos de piso habitacional y algunos fragmentos de cerámica que podrían estar relacionados con ocupaciones prehispánicas vinculadas al período Medio. De este sitio hay 10 objetos -fragmentación de cerámica- provenientes de la colección Manuel Blanco Encalada, vinculadas con la fase Maytas y San Miguel.

Az-11 fue excavado por Muñoz y Focacci (1985), Muñoz (2004a y b). Se cuenta con una cantidad de 1883 registros de fragmentos y piezas completas en los inventarios del MASMA. Corresponde a un asentamiento poblacional de carácter residencial-administrativo, construido en cotas de cima de un promontorio que se adentra en dirección a la caja del río San José en 140 m y se adosa en la base de cerro San Lorenzo, constituyente de la ladera sur del valle de Azapa. La distribución espacial de 42 muros de contención cuantificados y diseñados en modelo arquitectónico de planta rectangular, ocupan toda 
la topografía desde cotas de cima y se prolongan a cotas inferiores detectando diferencias de altura en sectores agrestes de 5 a 7 metros, (oeste-este-norte), mientras que en otros difieren en dos metros (sur). Esta particularidad de planificación urbana, a cierta distancia se observan 5 a 6 niveles aterrazados. Hacia las pendientes del promontorio, los muros poseen mayor extensión y altura, finiquitando en sus vértices y en sentido perpendicular, segmentos de pircados que determinan un espacio de ocupación. Áreas destinadas a actividades domésticas, económicas, tecnológicas y rituales se planificaron a partir de la estructuración de terraplenes.

El duodécimo sector de la ladera norte, lo constituye Las Maytas, allí se hallan los sitios Az-13 que corresponde a restos de un cementerio donde se rescató el cuerpo de un joven sin cráneo, además de fragmentos de cerámica correspondientes a los estilos Cabuza y Maytas. En la Colección Manuel Blanco Encalada se registra el hallazgo de un tupu de plata. En nuestra prospección registramos 6 recintos pequeños de forma circular, presentan muros construidos en base a bloques líticos. Asociado a estos recintos se hallaron seis fragmentos de cerámica decorada, correspondientes a los estilos Cabuza y Tiwanaku, ocho fragmentos de cerámica sin decoración y una lasca de calcedonia.

El sector de la Terraza, pampa de Alto Ramírez, constituye el decimotercer sector, es un espacio donde se concentró la mayor población prehispánica desde los inicios del desarrollo agrícola, entre ellos, medio centenar de túmulos ubicado en el sector de Pampa del Viento. Algunos de estos montículos como Az-122, Az-Az-84, (14), 17, fueron estudiados por Focacci, Rivera, Muñoz y Santoro; son antecedentes importantes que marcan la temprana presencia de pescadores en tránsito hacia la agricultura. Sin embargo, los sitios más representativo del periodo Medio son el cementerio Az-84 (Az-14), en su nivel medio (Santoro, 1980) y parte de la aldea Az83, especialmente lo que tiene relación con la ocupación fechada entre el 560 d.C. al 710 d.C. (Rivera, 1983). De este sitio en el MASMA se halla un total de 151 fragmentos de piezas, la gran mayoría objetos de cerámicas sin decoración y dos fragmentos de gorros de cuatro puntas.
Otro sitio ubicado en esta terraza corresponde al cementerio Az-80 vinculado al periodo Medio. El hallazgo de fosas semicubiertas con arena, indica que las tumbas fueron cavadas al piso. En la superficie se hallaron dos fragmentos de cerámica con forma de tazón y kero, presentan engobe rojo con decoración lineal en negro recordando el estilo Cabuza. En los registros del MASMA, se halla el ejemplar de un gorro de cuatro puntas policromo en buen estado de conservación. Este cementerio se ubica en el mismo espacio donde se construyeron un conjunto de túmulos (Muñoz, 2012).

El decimocuarto sector corresponde a Atoca, el sitio Atoca 1, conocida como la Waka de Atoca (Muñoz y Santos, 1995) se ubica en una cárcava conformada por dos cerros que miran hacia el borde noroeste de la pampa de Alto Ramírez. Corresponde a un conjunto de tumbas tipo cista, halladas debajo de una capa de guano. Tanto las tumbas como los cuerpos y ofrendas presentan una intensa remoción (Muñoz y Santos, 1995). Ahora bien en los alrededores de estas tumbas fueron hallados dos camélidos adultos con la ausencia del cráneo. El material reconocido en la superficie está muy fragmentado y corresponde a cerámica; dentro de los estilos se ha reconocido Tiwanaku-Wari. Ahora bien, en el cerro que se ubica al sureste, se halla la construcción de uno de los geoglifos más grande del sector bajo del valle de Azapa representado con la figura de un camélido. Este pequeño cementerio sumado al geoglifo se le han denominado las siglas Az-19 y 20.

Adentrándonos al sector de cerro Sombrero nos encontramos con el decimoquinto sector que comprende los sitios Az- 21, los registros de de la colección Manuel Blanco Encalada, señalan 37 objetos, proveniente de recolección superficial realizada en este asentamiento vinculado al periodo Tiwanaku. Entre los hallazgos se destacan dos miniaturas de balsas confeccionas tejidas en fibra de totora.

El decimosexto sector corresponde a la puntilla Saucache, específicamente la terraza de Acha, allí se halla el cementerio Acha -1 vinculado a poblaciones aldeanas del periodo Medio. Está conformado por 30 fosas aglutinadas en un área de 20 metros por 20 
metros aproximadamente. Este asentamiento funerario está emplazado en niveles bajos de una suave loma que se aproxima a la ribera oeste de la terraza. La composición superficial de los estratos está dada por tierra y arena fina matizadas con piedrecillas, susceptible a la erosión natural y antrópica. Los antecedentes culturales recopilados de superficie corresponden a osamentas humanas y restos de cabellera, fragmentos de alfarería, restos de tecnología a telar, restos de mazorcas de maíz y conchas de moluscos y cantos rodados que fueron parte de la arquitectura funeraria.

El decimoséptimo sector corresponde a el cerro San Miguel, allí registramos el sitio Az-24, el que se haya totalmente saqueado pero donde se reconocen la presencia de componentes cerámicos y textiles de la fase Alto Ramírez, Cabuza y Maytas. Para este sitio Dauelsberg (1959) señala haber encontrado uno de los dos únicos canales de riego arqueológicos conocidos en Azapa, los que fueron registrados nuevamente el año 2000 por Rocha y Briones. Este canal se vinculaba con la vertiente existente en la parcela de la familia Ordóñez. En los registros de la colección Manuel Blanco Encalada se encuentran seis objetos de las fases Maytas y Chiribaya. Señalemos que en Az-21 y Az-24, las tumbas y entierros vinculados con el periodo Medio se construyeron alrededor de asentamientos previos como los túmulos funerarios.
Otros sitios registrados en este sector corresponde a Az-105, de él hay un registro de 153 piezas fragmentadas asociadas a las fases Chiribaya, Cabuza y Maytas. Según Espoueys (1973) se hallaron algunos perros y sapos como parte de las ofrendas, además de cuyes, estos últimos en tumbas de lactantes, los cuerpos de estos animales estaban intactos y sujetos del cuello por finos cordeles. En este mismo cerro se halla además el sitio Az-27, corresponde a un asentamiento residencial, ubicado en los faldeos del cerro San Miguel, se observan restos de basuras, en el sector central y cima del cerro, se observan estratos compuestos por fibras vegetales. Hay dispersión de fragmentos de alfarería utilitaria sin decoración, se registraron 2 fragmentos de cerámica decorada, uno con trazos negros sobre el engobe, en la cara interior del fragmento, al parecer corresponde a un recipiente con forma de plato. Otros restos culturales corresponden a lascados de cuarzo, además de algunos restos óseos de moluscos (choro zapato y macha).

El decimoctavo sector se ubica en la terraza de Chinchorro sector Industrial de la maestranza FFCC Arica-La Paz, en él se haya el asentamiento sitio Borde Terraza Chinchorro 3, donde se encontraron fragmentos de cerámica, textil, cordelería, restos malacológicos, óseos de origen animal y maderas. Entre los fragmentos cerámicos figura un fragmento de kero (tazón) de engobe rojo con decoración en negro.

Cuadro $\mathrm{N}^{\circ} 1$

Resumen de sitios del periodo Medio, valle de Azapa, según registro de Colecciones Arqueológicas, Museo Arqueológico San Miguel de Azapa (MASMA) y Colecciones Manuel Blanco Encalada (CMBE)

\begin{tabular}{|c|c|c|c|c|c|c|}
\hline$N^{\circ}$ & Sitio & $\begin{array}{l}\text { Cantidad de } \\
\text { tumbas }\end{array}$ & Registros & Colección & Fase/estilo & Periodo \\
\hline 1 & AZ1 & 5 Tumbas & 63 & $\begin{array}{l}\text { CMBE/ } \\
\text { MASMA }\end{array}$ & Cabuza, Sobraya, Tiwanaku & Medio \\
\hline 2 & AZ2 & Sin Referencia & 13 & MASMA & Cabuza & Medio \\
\hline 3 & AZ3 & Cuadrículas & 429 & CMBE & $\begin{array}{l}\text { Maytas, Cabuza, Chiribaya, So- } \\
\text { braya, Tiwanaku }\end{array}$ & Medio \\
\hline 4 & AZ4 & Sin Referencia & 1 & $\mathrm{CMBE}$ & Cabuza & Medio \\
\hline 5 & AZ5 & Sin Referencia & 2 & $\begin{array}{l}\text { CMBE/ } \\
\text { MASMA }\end{array}$ & Cabuza & Medio \\
\hline
\end{tabular}


Continuación Cuadro Nº 1

\begin{tabular}{|c|c|c|c|c|c|c|}
\hline $\mathrm{N}^{\circ}$ & Sitio & $\begin{array}{c}\text { Cantidad de } \\
\text { tumbas }\end{array}$ & Registros & Colección & Fase/estilo & Periodo \\
\hline 6 & AZ141 & 55 Tumbas & 398 & MASMA & Cabuza, Sobraya, Tiwanaku & Medio \\
\hline 7 & AZ143 & 10 Tumbas & 118 & MASMA & Tiwanaku & Medio \\
\hline 8 & AZ103 & Sin Referencia & 103 & CMBE & Cabuza, Tiwanaku, Charcollo & Medio \\
\hline 9 & AZ105 & Sin Referencia & 153 & $\mathrm{CMBE}$ & Chiribaya, Cabuza Tardío, Maytas & Medio \\
\hline 10 & AZ115 & 252 Contextos & 300 & MASMA & Alto Ramírez -Pre Tiwanaku & Medio \\
\hline 11 & AZ13 & Sin Referencia & 39 & CMBE & Maytas, Cabuza & Medio \\
\hline 12 & AZ21 & Superficial & 37 & CMBE & Tiwanaku & Medio \\
\hline 13 & AZ24 & Sin Referencia & 6 & CMBE & Maytas, Maytas Chiribaya & Medio \\
\hline 14 & AZ80 & Superficial & 4 & CMBE & Tiwanaku & Medio \\
\hline 15 & AZ83 & Superficial & 151 & $\begin{array}{l}\text { CMBE/ } \\
\text { MASMA }\end{array}$ & Alto Ramírez, Cabuza, Tiwanaku & $\begin{array}{l}\text { Form/ } \\
\text { Medio }\end{array}$ \\
\hline 16 & AZ6 & 206 Tumbas & 1153 & MASMA & $\begin{array}{l}\text { Cabuza, Sobraya, Maytas, Tiwa- } \\
\text { naku }\end{array}$ & $\begin{array}{l}\text { Medio/ } \\
\text { PIT }\end{array}$ \\
\hline 17 & AZ71 & Sin Referencia & 150 & CMBE & $\begin{array}{l}\text { San Miguel, Taltape, Maytas, } \\
\text { Cabuza }\end{array}$ & $\begin{array}{l}\text { Medio/ } \\
\text { PIT }\end{array}$ \\
\hline 18 & AZ71A & 200 Tumbas & 886 & MASMA & $\begin{array}{l}\text { Cabuza, Sobraya, Maytas, Maytas } \\
\text { Chiribaya, Tiwanaku, San Miguel, } \\
\text { Gentilar, Chiribaya, Charcollo }\end{array}$ & $\begin{array}{l}\text { Medio/ } \\
\text { PIT }\end{array}$ \\
\hline 19 & AZ71B & 607 Tumbas & 1000 & MASMA & $\begin{array}{l}\text { Azapa, San Miguel Temprano y } \\
\text { Medio }\end{array}$ & Medio \\
\hline 20 & AZ75 & 136 Tumbas & 998 & MASMA & $\begin{array}{l}\text { Maytas, Charcollo, Maytas } \\
\text { Chiribaya, Cabuza, San Miguel, } \\
\text { Taltape }\end{array}$ & $\begin{array}{l}\text { Medio/ } \\
\text { PIT }\end{array}$ \\
\hline 21 & AZ76 & 49 Tumbas & 321 & MASMA & $\begin{array}{l}\text { Maytas /Chiribaya, Taltape, Char- } \\
\text { collo, Pocoma, Gentilar, Taltape, } \\
\text { San Miguel, Tumilaca }\end{array}$ & $\begin{array}{l}\text { Medio/ } \\
\text { PIT }\end{array}$ \\
\hline 22 & AZ79 & Sin Referencia & 10 & CMBE & Maytas y San Miguel & $\begin{array}{l}\text { Medio/ } \\
\text { PIT }\end{array}$ \\
\hline 23 & AZ11 & $\begin{array}{l}43 \\
\text { R.Habitacion, } 19 \\
\text { Tumba }\end{array}$ & 1883 & MASMA & $\begin{array}{l}\text { Alto Ramírez, Maytas y San } \\
\text { Miguel }\end{array}$ & $\begin{array}{l}\text { Medio/ } \\
\text { PIT }\end{array}$ \\
\hline 24 & AZ140 & 131 Tumbas & 917 & MASMA & $\begin{array}{l}\text { Pocoma, San Miguel, Maytas } \\
\text { Chiribaya }\end{array}$ & $\begin{array}{l}\text { Medio/ } \\
\text { PIT }\end{array}$ \\
\hline 25 & PLM9 & 39 Tumbas & 510 & MASMA & $\begin{array}{l}\text { Cabuza, Sobraya, Maytas, Chi- } \\
\text { ribaya, San Miguel, Gentilar, } \\
\text { Taltape, Charcollo }\end{array}$ & $\begin{array}{l}\text { Medio/ } \\
\text { PIT }\end{array}$ \\
\hline 26 & AZ113 & Sin Referencia & 1 & & Cabuza & $\begin{array}{l}\text { Medio/ } \\
\text { PIT }\end{array}$ \\
\hline 27 & AZ19 & Superficial & 6 & MASMA & Cabuza, Tiwanaku & Medio \\
\hline 28 & AZ145 & Superficial & 3 & MASMA & Cabuza & Medio \\
\hline
\end{tabular}

Fuente: Elaboración propia. 


\begin{tabular}{|c|c|c|c|c|c|c|c|c|c|c|}
\hline 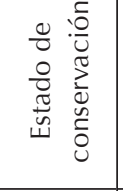 & 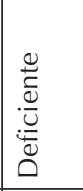 & 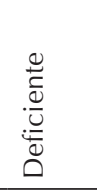 & 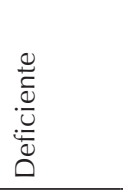 & 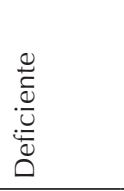 & 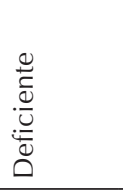 & 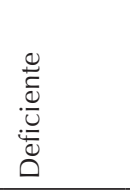 & 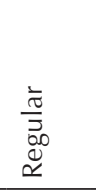 & 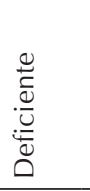 & 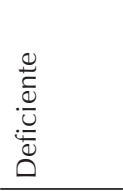 & 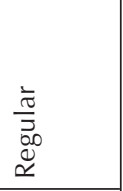 \\
\hline 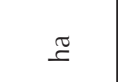 & $\stackrel{m}{\circ}$ & $\stackrel{\tilde{0}}{0}$ & $\stackrel{\curvearrowright}{-}$ & $\bar{\sigma}$ & $\stackrel{\infty}{\circ}$ & $\frac{\alpha}{\omega}$ & $\bar{\sigma}_{i}$ & $\frac{9}{0}$ & $\frac{\pi}{\circ}$ & $\overline{0}$ \\
\hline 芯 & 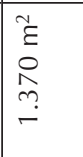 & $\begin{array}{l}\text { है } \\
\text { Dे } \\
\text { ले }\end{array}$ & 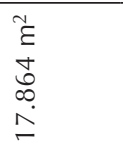 & $\begin{array}{l}\text { है } \\
\text { ปे } \\
\stackrel{-}{-}\end{array}$ & $\begin{array}{l}\text { है } \\
\tilde{N} \\
\infty\end{array}$ & $\frac{0}{s}$ & 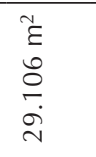 & 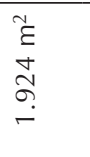 & $\begin{array}{l}\stackrel{N}{E} \\
\text { Q } \\
\stackrel{+}{-}\end{array}$ & $\begin{array}{l}\tilde{N} \\
\Xi \\
\infty \\
\infty \\
-\end{array}$ \\
\hline 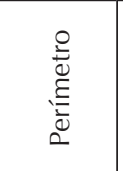 & $\frac{\dot{\varepsilon}}{\stackrel{m}{\sigma}}$ & $\begin{array}{l}\varepsilon \\
\dot{T} \\
\stackrel{R}{\Lambda}\end{array}$ & \begin{tabular}{l}
$\varepsilon$ \\
$\sigma$ \\
\multirow{\gamma}{F}{}
\end{tabular} & 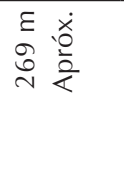 & $\begin{array}{l}\varepsilon \\
o \\
\stackrel{-}{-}\end{array}$ & $\frac{\alpha}{\omega}$ & $\begin{array}{l}\varepsilon \\
\infty \\
\nwarrow\end{array}$ & $\begin{array}{l}\varepsilon \\
i \\
\stackrel{n}{L}\end{array}$ & $\begin{array}{l}\varepsilon \\
\stackrel{\Omega}{-}\end{array}$ & $\begin{array}{l}\varepsilon \\
\frac{1}{3}\end{array}$ \\
\hline 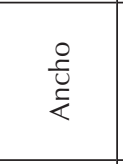 & $\begin{array}{l}E \\
0 \\
i n \\
\bar{m} \\
\bar{m}\end{array}$ & $\begin{array}{l}\varepsilon \\
8 \\
\dot{m} \\
\square\end{array}$ & $\begin{array}{l}\varepsilon \\
0 \\
\infty \\
\infty\end{array}$ & $\begin{array}{l}\varepsilon \\
\sim \\
\infty \\
\infty \\
\infty\end{array}$ & $\begin{array}{l}E \\
0 \\
\dot{+} \\
\dot{+}\end{array}$ & $\frac{\alpha}{s}$ & 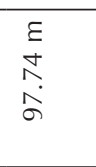 & $\begin{array}{l}\varepsilon \\
\varepsilon \\
\vdots \\
\qquad ? \\
\bar{m}\end{array}$ & $\begin{array}{l}E \\
+ \\
\infty \\
\stackrel{1}{\perp} \\
\perp\end{array}$ & $\begin{array}{l}\varepsilon \\
\sigma \\
\sigma \\
O \\
\sigma\end{array}$ \\
\hline $\begin{array}{l}\stackrel{\infty}{\infty} \\
\stackrel{D}{\Xi}\end{array}$ & 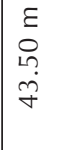 & $\begin{array}{l}\varepsilon \\
\dot{0} \\
\dot{0} \\
\dot{0} \\
m\end{array}$ & 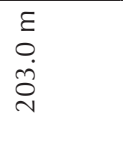 & 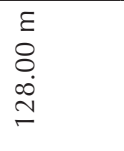 & $\begin{array}{l}\varepsilon \\
\varepsilon \\
o n \\
o n \\
o n\end{array}$ & $\frac{a}{\omega}$ & $\begin{array}{l}\varepsilon \\
\delta \\
\infty \\
\dot{\alpha} \\
\stackrel{\sigma}{v}\end{array}$ & $\begin{array}{l}\frac{\varepsilon}{\varepsilon} \\
\stackrel{0}{c} \\
\dot{\sigma}\end{array}$ & $\begin{array}{l}\varepsilon \\
E \\
0 \\
\dot{R} \\
0\end{array}$ & 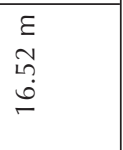 \\
\hline 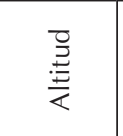 & 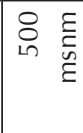 & 吕 & 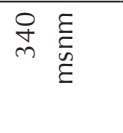 & 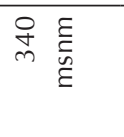 & 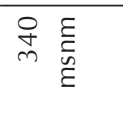 & 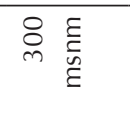 & $\stackrel{\stackrel{\leftrightarrow}{+}}{\sim} \underset{E}{E}$ & $\stackrel{P}{\sim} \underset{\Xi}{E}$ & $\begin{array}{ll}\stackrel{\circ}{\mathscr{\sigma}} \\
\stackrel{5}{5} \\
\end{array}$ & 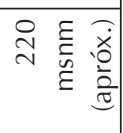 \\
\hline 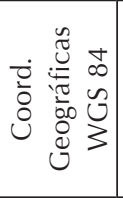 & 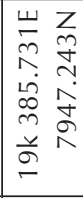 & 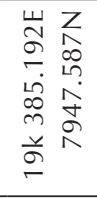 & 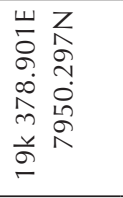 & 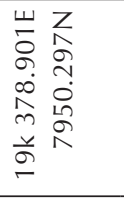 & 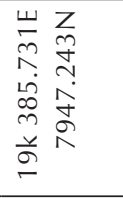 & 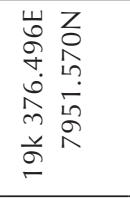 & 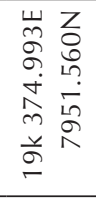 & 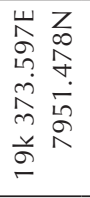 & 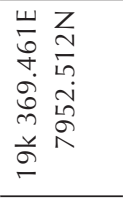 & 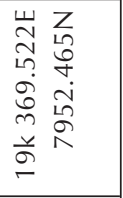 \\
\hline$\stackrel{\varrho}{\stackrel{2}{=}}$ & 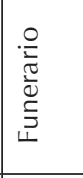 & 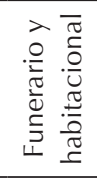 & 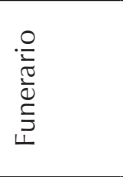 & $\begin{array}{l}\frac{0}{\grave{\nu}} \\
\frac{0}{2} \\
\stackrel{0}{\alpha}\end{array}$ & 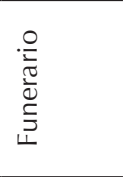 & 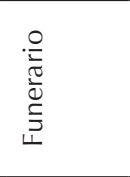 & $\begin{array}{l}\frac{0}{0} \\
\frac{\pi}{0} \\
\frac{0}{0}\end{array}$ & 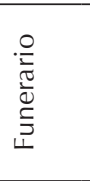 & 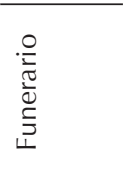 & 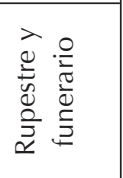 \\
\hline $\begin{array}{l}0 \\
\frac{8}{0} \\
\frac{0}{2} \\
0 \\
\end{array}$ & $\begin{array}{l}\stackrel{0}{\bar{z}} \\
\frac{0}{2}\end{array}$ & $\frac{\circ}{\overline{\bar{\theta}}}$ & $\begin{array}{l}\frac{0}{\overline{0}} \\
\frac{0}{z}\end{array}$ & $\begin{array}{l}\frac{0}{\overline{0}} \\
\frac{0}{2}\end{array}$ & $\begin{array}{l}\frac{0}{\bar{z}} \\
\frac{0}{2}\end{array}$ & $\begin{array}{l}\frac{0}{\overline{0}} \\
\frac{\dot{0}}{2}\end{array}$ & $\frac{0}{\frac{0}{0}}$ & $\begin{array}{l}\frac{0}{\overline{0}} \\
\frac{0}{2}\end{array}$ & $\begin{array}{l}\frac{0}{\overline{0}} \\
\frac{0}{2}\end{array}$ & $\begin{array}{l}\stackrel{0}{\overline{0}} \\
\frac{0}{2}\end{array}$ \\
\hline 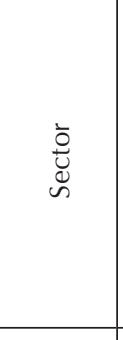 & 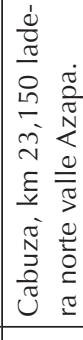 & 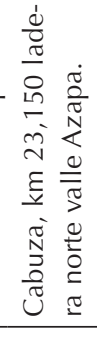 & 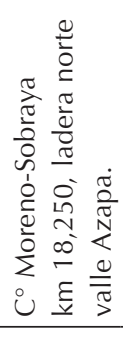 & 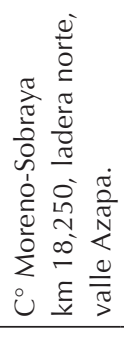 & 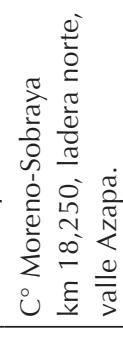 & 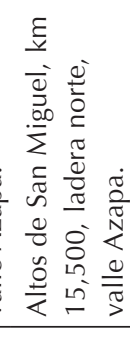 & 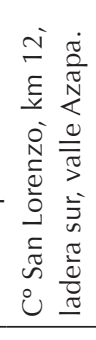 & 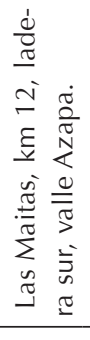 & 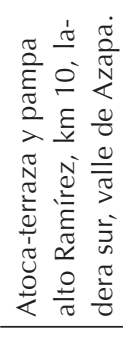 & 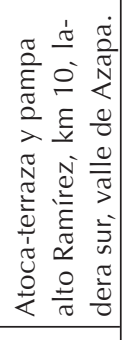 \\
\hline$\stackrel{\circ}{\stackrel{n}{n}}$ & $\underset{⿱ 亠}{\mathbb{N}}$ & $\underset{\mathbb{N}}{\mathbb{N}}$ & $\underset{\mathbb{N}}{\stackrel{M}{K}}$ & $\underset{⿱}{\mathbb{Z}}$ & 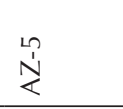 & $\begin{array}{l}\stackrel{0}{1} \\
\mathbb{2}\end{array}$ & 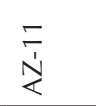 & $\underset{\dot{N}}{\frac{m}{x}}$ & 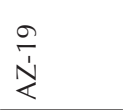 & $\begin{array}{l}\stackrel{N}{N} \\
\underset{\mathbf{N}}{2}\end{array}$ \\
\hline
\end{tabular}




\begin{tabular}{|c|c|c|c|c|c|c|c|c|c|}
\hline 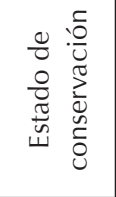 & 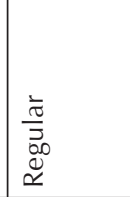 & 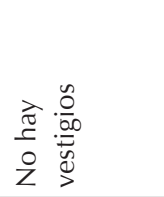 & 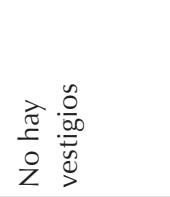 & 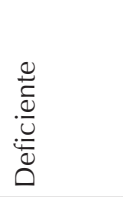 & 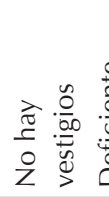 & & 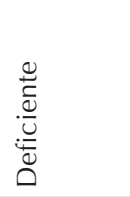 & 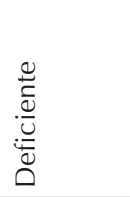 & 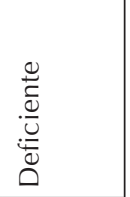 \\
\hline 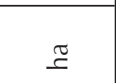 & $\frac{\circ}{0}$ & $\begin{array}{l}8 \\
0 \\
0\end{array}$ & $\begin{array}{l}8 \\
0 \\
0\end{array}$ & $\begin{array}{l}\infty \\
\stackrel{\infty}{0} \\
\stackrel{1}{0}\end{array}$ & $\begin{array}{ll}\varepsilon \\
0\end{array}$ & $\begin{array}{l}\qquad \stackrel{2}{\circ} \\
0\end{array}$ & $\begin{array}{l}\text { Oे } \\
\text { Ln } \\
0\end{array}$ & $\begin{array}{l}0 \\
\end{array}$ & 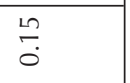 \\
\hline 莡 & $\begin{array}{l}\tilde{E} \\
\bar{g} \\
\bar{O}\end{array}$ & $\begin{array}{l}\varepsilon \\
8 \\
0 \\
0\end{array}$ & $\begin{array}{l}\varepsilon \\
8 \\
0 \\
0\end{array}$ & $\begin{array}{l}\text { है } \\
\text { ลे } \\
0 \\
\text { ปे }\end{array}$ & $\begin{array}{l}\varepsilon \\
\circ\end{array}$ & $\begin{array}{l}\text { है } \\
\text { है }\end{array}$ & $\begin{array}{l}\text { है } \\
\text { Nै } \\
\text { Dै }\end{array}$ & $\begin{array}{l}\tilde{E} \\
\tilde{E} \\
\Phi\end{array}$ & $\begin{array}{l}\text { है } \\
\text { है } \\
\text { Бू }\end{array}$ \\
\hline 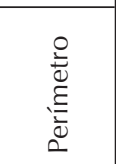 & $\begin{array}{l}E \\
\stackrel{E}{I} \\
\end{array}$ & $\begin{array}{l}\varepsilon \\
8 \\
8 \\
0\end{array}$ & $\begin{array}{l}\varepsilon \\
8 \\
8 \\
0\end{array}$ & $\begin{array}{l}\varepsilon \\
\infty \\
\stackrel{\nu}{\sim}\end{array}$ & $\begin{array}{l}\varepsilon \\
\vdots \\
0\end{array}$ & $\begin{array}{l}\varepsilon \\
\mathbb{\infty} \\
\stackrel{\sim}{N}\end{array}$ & $\begin{array}{l}E \\
+ \\
m \\
m\end{array}$ & $\begin{array}{l}\varepsilon \\
\sim \\
\sigma \\
\sigma\end{array}$ & 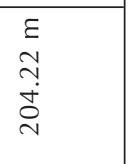 \\
\hline$\frac{8}{\grave{U}}$ & \begin{tabular}{|l|}
$E$ \\
$\vdots$ \\
$\omega$ \\
$\omega$ \\
$\omega$ \\
$\sim$ \\
\end{tabular} & $\begin{array}{l}\varepsilon \\
\Xi \\
0 \\
0\end{array}$ & $\begin{array}{l}\varepsilon \\
8 \\
0 \\
0\end{array}$ & 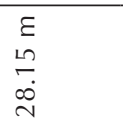 & $\begin{array}{ll}\varepsilon \\
0\end{array}$ & $\begin{array}{l}E \\
\bar{\sigma} \\
\sigma \\
\sigma\end{array}$ & $\begin{array}{l}\varepsilon \\
0 \\
\dot{\tilde{n}}\end{array}$ & $\begin{array}{l}\varepsilon \\
\underline{\omega} \\
m \\
\stackrel{\nu}{N}\end{array}$ & $\begin{array}{l}\varepsilon \\
\qquad \\
f \\
\stackrel{-}{-}\end{array}$ \\
\hline 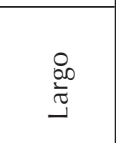 & 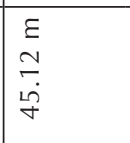 & $\begin{array}{l}\varepsilon \\
8 \\
8 \\
0\end{array}$ & $\begin{array}{l}\varepsilon \\
8 \\
8 \\
0\end{array}$ & 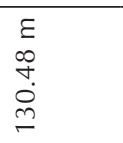 & $\begin{array}{ll}\varepsilon \\
0\end{array}$ & $\begin{array}{l}\varepsilon \\
\\
0 \\
\dot{0} \\
\llcorner\end{array}$ & 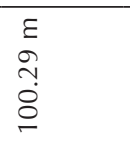 & 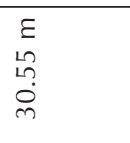 & $\begin{array}{l}E \\
E \\
b \\
0 \\
\infty \\
\infty\end{array}$ \\
\hline 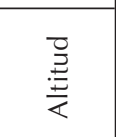 & 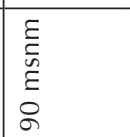 & 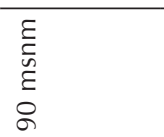 & 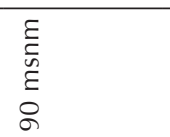 & 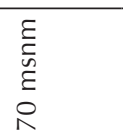 & 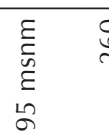 & 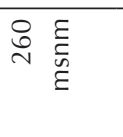 & 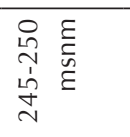 & 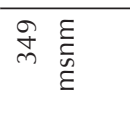 & $\begin{array}{ll}\circ & \varepsilon \\
\bar{m} & \frac{1}{\omega} \\
& \varepsilon\end{array}$ \\
\hline 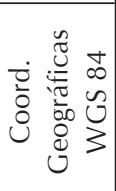 & 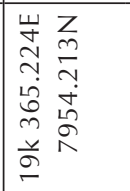 & 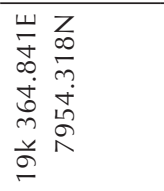 & 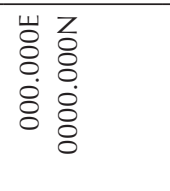 & 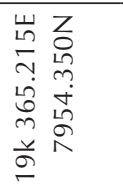 & 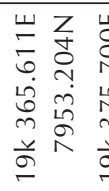 & 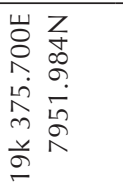 & 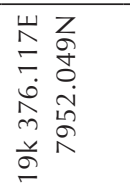 & 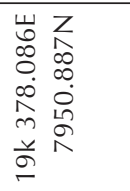 & 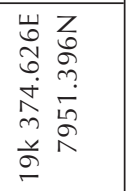 \\
\hline 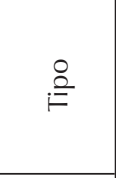 & 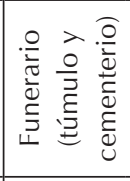 & 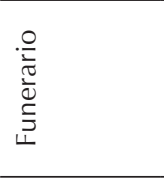 & $\begin{array}{l}\frac{0}{0} \\
\frac{\pi}{0} \\
\frac{0}{0}\end{array}$ & 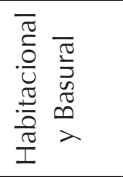 & $\begin{array}{l}\frac{0}{0} \\
\frac{\pi}{0} \\
0\end{array}$ & 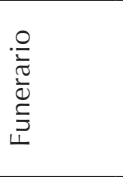 & 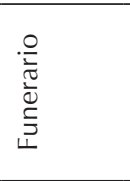 & 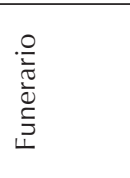 & 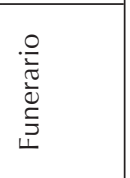 \\
\hline $\begin{array}{l}\frac{0}{\circ} \\
\frac{0}{\bar{U}} \\
0 .\end{array}$ & $\begin{array}{l}\frac{0}{0} \\
\frac{10}{2}\end{array}$ & $\begin{array}{l}\frac{0}{\overline{0}} \\
\frac{\Phi}{z}\end{array}$ & $\begin{array}{l}\frac{.0}{0} \\
\frac{0}{2}\end{array}$ & $\begin{array}{l}\frac{0}{\overline{0}} \\
\frac{\mathscr{d}}{2}\end{array}$ & $\frac{\circ}{i}$ & $\begin{array}{l}\frac{0}{0} \\
\frac{0}{2}\end{array}$ & $\begin{array}{l}\frac{0}{\overline{0}} \\
\frac{0}{z}\end{array}$ & $\begin{array}{l}\frac{0}{\overline{0}} \\
\frac{\Phi}{2}\end{array}$ & $\begin{array}{l}\frac{0}{\overline{0}} \\
\frac{0}{2}\end{array}$ \\
\hline 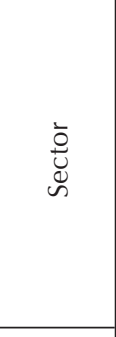 & 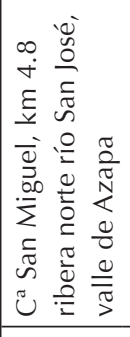 & 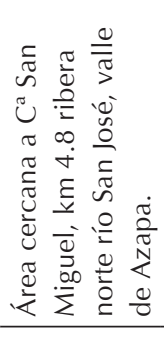 & 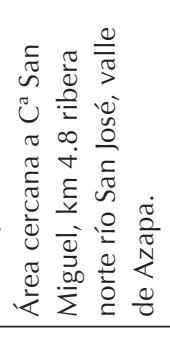 & 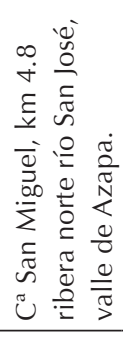 & 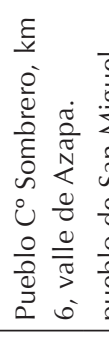 & 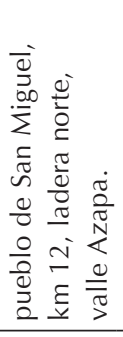 & 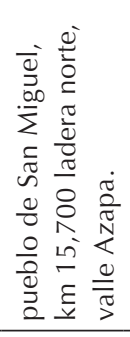 & 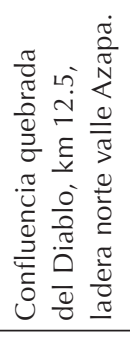 & 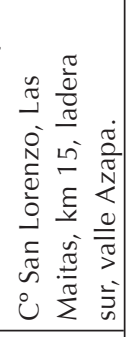 \\
\hline$\stackrel{\circ}{*}$ & $\underset{\substack{\alpha \\
N}}{\mathbb{N}}$ & $\underset{\stackrel{L}{N}}{\stackrel{N}{<}}$ & İ & \begin{tabular}{l}
$\hat{N}$ \\
\multirow{2}{*}{}
\end{tabular} & 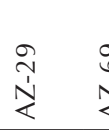 & 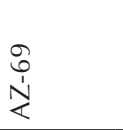 & 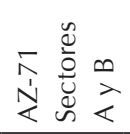 & 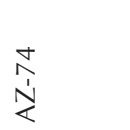 & $\begin{array}{l}\stackrel{2}{\Lambda} \\
\stackrel{1}{<}\end{array}$ \\
\hline
\end{tabular}




\begin{tabular}{|c|c|c|c|c|c|c|c|c|c|c|}
\hline 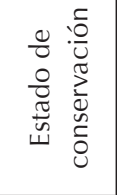 & 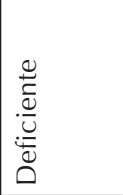 & 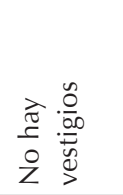 & 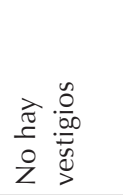 & $\begin{array}{l}\frac{\bar{c}}{5} \\
\stackrel{0}{0} \\
\stackrel{4}{4}\end{array}$ & 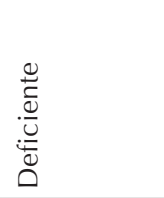 & 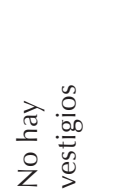 & 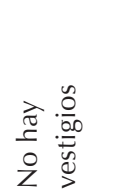 & 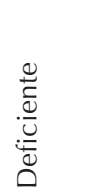 & 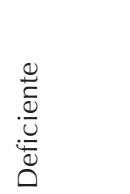 & 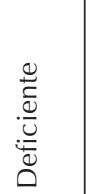 \\
\hline 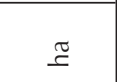 & $\begin{array}{ll}0 \\
\end{array}$ & $\stackrel{\circ}{\circ}$ & $\stackrel{\circ}{\circ}$ & $\stackrel{\frac{10}{?}}{\circ}$ & $\stackrel{\circ}{0}$ & 0 & 0 & 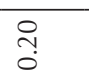 & $\stackrel{\Xi}{\check{0}}$ & $\begin{array}{c}0 \\
0 \\
0 \\
0\end{array}$ \\
\hline 苞 & 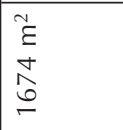 & $\begin{array}{l}\text { Eี } \\
0\end{array}$ & $\begin{array}{l}\text { है } \\
\text { - }\end{array}$ & 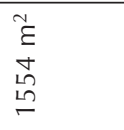 & $\begin{array}{l}\text { है } \\
\text { है }\end{array}$ & $\begin{array}{l}\text { है } \\
\text { है }\end{array}$ & $\begin{array}{l}\text { है } \\
\text { है }\end{array}$ & 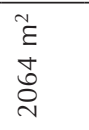 & $\begin{array}{l}\text { Eี } \\
\stackrel{L}{\square} \\
\dot{\Xi}\end{array}$ & $\begin{array}{l}\text { है } \\
\infty \\
\tilde{N} \\
\infty\end{array}$ \\
\hline 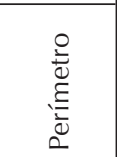 & $\begin{array}{l}\varepsilon \\
\stackrel{m}{v}\end{array}$ & $\varepsilon$ & $\varepsilon$ & $\begin{array}{l}\varepsilon \\
\infty \\
\infty \\
\infty \\
\infty \\
\square \\
\square\end{array}$ & $\begin{array}{l}\varepsilon \\
0\end{array}$ & $\begin{array}{l}\xi \\
\text { Eे } \\
0\end{array}$ & $\varepsilon$ & $\begin{array}{l}\varepsilon \\
\hat{N}\end{array}$ & $\begin{array}{l}\varepsilon \\
\Sigma \\
\check{L}\end{array}$ & $\begin{array}{l}\varepsilon \\
\varepsilon \\
\bar{m}\end{array}$ \\
\hline $\begin{array}{l}0 \\
\frac{\mathcal{U}}{\mathrm{K}} \\
\frac{\mathrm{T}}{2}\end{array}$ & \begin{tabular}{|l|}
$E$ \\
$\sigma$ \\
$\sigma$ \\
$\sigma$ \\
$\sigma$
\end{tabular} & $\varepsilon$ & $\varepsilon$ & $\begin{array}{l}\varepsilon \\
\infty \\
\sim \\
\tilde{\nu}\end{array}$ & $\begin{array}{l}E \\
\varepsilon\end{array}$ & $\begin{array}{l}\varepsilon \\
0\end{array}$ & $\begin{array}{l}\varepsilon \\
0\end{array}$ & $\begin{array}{l}\varepsilon \\
\varepsilon \\
ٌ \\
\\
\dot{J}\end{array}$ & $\begin{array}{l}\varepsilon \\
\text { ह } \\
\stackrel{\omega}{\sim}\end{array}$ & 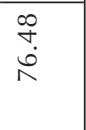 \\
\hline \begin{tabular}{l}
0 \\
$\infty$ \\
\multirow{J}{J}{}
\end{tabular} & $\begin{array}{l}\varepsilon \\
\varepsilon \\
0 \\
\tilde{\omega} \\
\infty \\
\infty\end{array}$ & $\begin{array}{l}E \\
\sigma\end{array}$ & $\begin{array}{l}\varepsilon \\
\end{array}$ & $\begin{array}{l}\varepsilon \\
\infty \\
\stackrel{0}{0} \\
\stackrel{0}{0}\end{array}$ & $\begin{array}{l}E \\
\sigma\end{array}$ & $\begin{array}{l}\varepsilon \\
0\end{array}$ & $\begin{array}{l} \\
\end{array}$ & 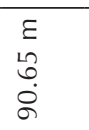 & $\begin{array}{l}\varepsilon \\
\\
\dot{L} \\
\dot{L}\end{array}$ & $\begin{array}{l}\stackrel{0}{\dot{n}} \\
\stackrel{=}{=}\end{array}$ \\
\hline 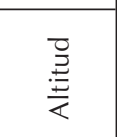 & 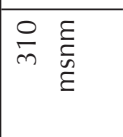 & 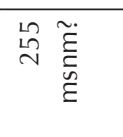 & 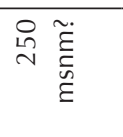 & ¿ & $\stackrel{\text { 号 }}{\sim} \underset{\square}{\square}$ & ¿ & 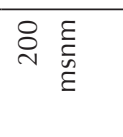 & 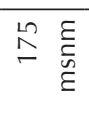 & 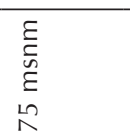 & 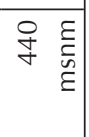 \\
\hline 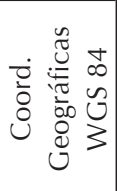 & 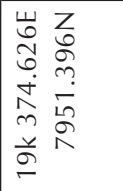 & 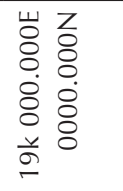 & 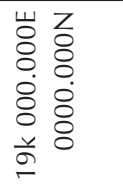 & 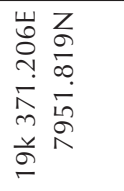 & 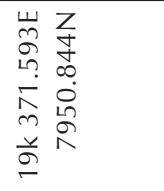 & 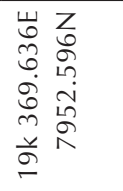 & 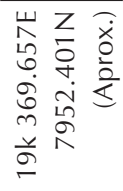 & 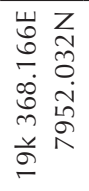 & 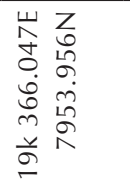 & 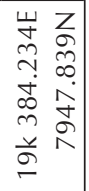 \\
\hline$\stackrel{\varrho}{\stackrel{2}{F}}$ & 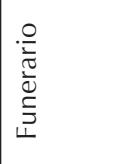 & 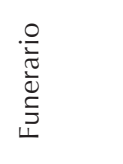 & 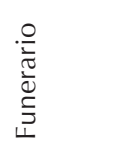 & 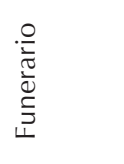 & 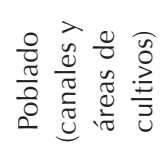 & 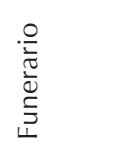 & 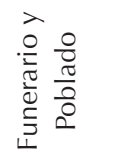 & 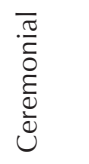 & 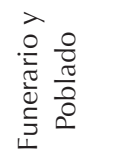 & 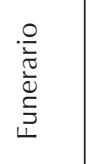 \\
\hline $\begin{array}{l}\frac{0}{0} \\
\frac{0}{\bar{U}} \\
0\end{array}$ & $\frac{0}{\frac{0}{0}}$ & $\frac{\stackrel{\circ}{\bar{j}}}{\frac{0}{2}}$ & $\begin{array}{l}\frac{0}{\overline{0}} \\
\frac{0}{z}\end{array}$ & $\begin{array}{l}\frac{0}{\bar{j}} \\
\frac{0}{z}\end{array}$ & $\begin{array}{l}\frac{0}{\overline{0}} \\
\frac{\otimes}{2}\end{array}$ & $\frac{\circ}{\frac{0}{0}}$ & $\frac{\circ}{\frac{0}{0}}$ & $\begin{array}{l}\frac{0}{\overline{0}} \\
\frac{\Phi}{2}\end{array}$ & $\frac{\circ}{\frac{0}{0}}$ & $\begin{array}{l}\frac{0}{\bar{l}} \\
\frac{0}{2}\end{array}$ \\
\hline $\begin{array}{l}\overline{\bar{u}} \\
\stackrel{u}{n} \\
\omega\end{array}$ & 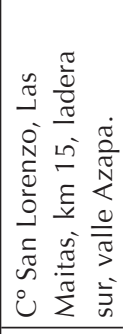 & 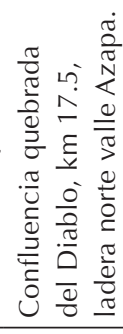 & 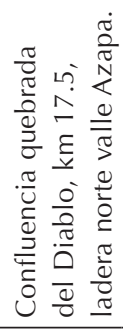 & 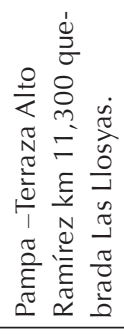 & 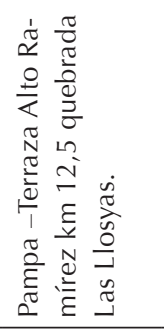 & 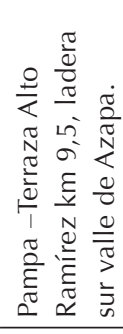 & 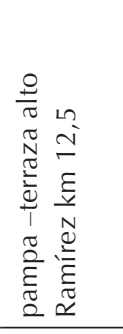 & 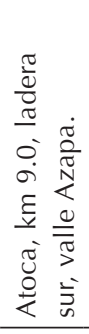 & 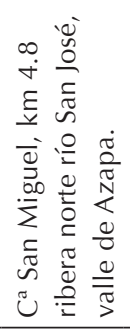 & 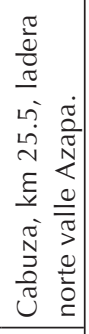 \\
\hline$\stackrel{\ominus}{=}$ & $\begin{array}{l}0 \\
\hat{1} \\
\mathbf{1}\end{array}$ & $\begin{array}{l}\stackrel{\infty}{\hat{1}} \\
\stackrel{1}{<}\end{array}$ & \begin{tabular}{l}
$\Omega$ \\
$\hat{1}$ \\
\multirow{2}{*}{}
\end{tabular} & $\begin{array}{l}\infty \\
\infty \\
\stackrel{1}{<}\end{array}$ & 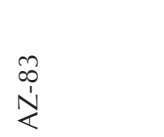 & 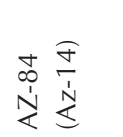 & $\begin{array}{l}\bar{\alpha} \\
\stackrel{u}{\alpha}\end{array}$ & 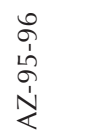 & $\begin{array}{l}\hat{a} \\
\stackrel{u}{\alpha}\end{array}$ & $\begin{array}{l}\overline{0} \\
\frac{1}{\alpha}\end{array}$ \\
\hline
\end{tabular}




\begin{tabular}{|c|c|c|c|c|c|c|c|c|c|c|c|}
\hline 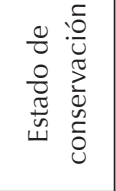 & 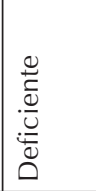 & 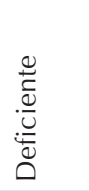 & 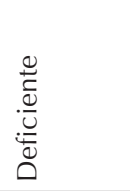 & 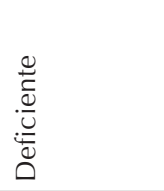 & 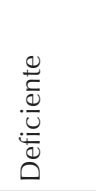 & 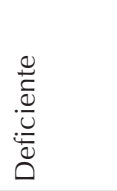 & 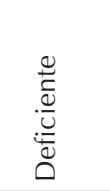 & 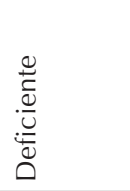 & 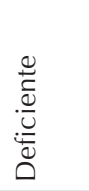 & 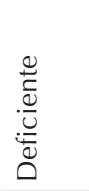 & 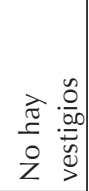 \\
\hline 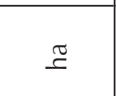 & \begin{tabular}{|l|}
$\varepsilon$ \\
$O$ \\
0
\end{tabular} & $\begin{array}{l}\bar{\sigma} \\
\dot{0}\end{array}$ & $\begin{array}{l}\text { Oे } \\
\stackrel{0}{0}\end{array}$ & $\begin{array}{l}\hat{0} \\
\dot{0}\end{array}$ & 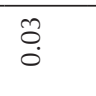 & $\stackrel{m}{\circ}$ & $\stackrel{0}{0}$ & 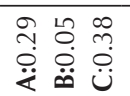 & $\begin{array}{l}\infty \\
\infty \\
0 \\
0\end{array}$ & $\begin{array}{l}\infty \\
0 \\
0\end{array}$ & \\
\hline$\stackrel{\widetilde{J}}{\stackrel{\Sigma}{K}}$ & $\begin{array}{l}\varepsilon \\
0 \\
0\end{array}$ & $\begin{array}{l}\text { है } \\
\stackrel{+}{\llcorner}\end{array}$ & 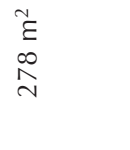 & 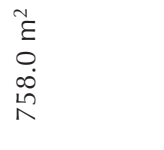 & 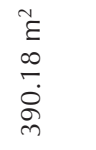 & $\begin{array}{l}\text { है } \\
\text { ठे } \\
\text { है }\end{array}$ & 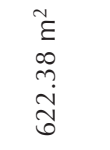 & 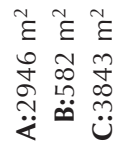 & $\begin{array}{l}\text { है } \\
\text { Jै } \\
\stackrel{\infty}{\infty}\end{array}$ & 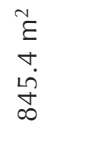 & $\begin{array}{l}\text { है } \\
\text { है }\end{array}$ \\
\hline 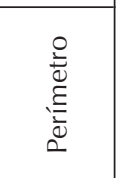 & $\begin{array}{l}E \\
\\
0 \\
0\end{array}$ & $\begin{array}{l}\varepsilon \\
\infty \\
\tilde{N} \\
n\end{array}$ & $\begin{array}{l}\varepsilon \\
\frac{\varepsilon}{\pi} \\
\stackrel{\pi}{0}\end{array}$ & $\begin{array}{l}\varepsilon \\
\stackrel{o}{q} \\
\square\end{array}$ & $\begin{array}{l}\varepsilon \\
\Re \\
\infty \\
\infty \\
\wedge\end{array}$ & 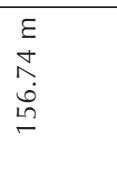 & $\begin{array}{l}\varepsilon \\
o \\
0 \\
\dot{0} \\
=\end{array}$ & 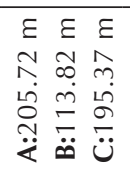 & $\begin{array}{l}\varepsilon \\
\infty \\
0 \\
\zeta \\
\end{array}$ & $\begin{array}{l}\varepsilon \\
m \\
\dddot{o} \\
\stackrel{0}{0}\end{array}$ & 0 \\
\hline 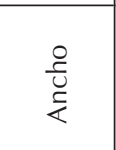 & $\begin{array}{l}\varepsilon \\
0 \\
0\end{array}$ & 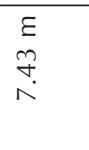 & 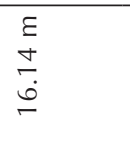 & 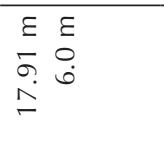 & $\begin{array}{l}\varepsilon \\
\sigma \\
D \\
m \\
m\end{array}$ & $\begin{array}{l}\varepsilon \\
0 \\
\dot{\sim} \\
\end{array}$ & $\begin{array}{l}\varepsilon \\
\delta \\
0 \\
\infty \\
-\end{array}$ & 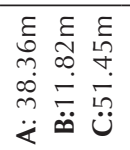 & 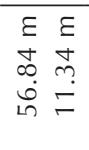 & $\begin{array}{l}\varepsilon \\
\infty \\
\sim \\
\sim \\
\sim\end{array}$ & $\begin{array}{l}\varepsilon \\
\end{array}$ \\
\hline $\begin{array}{l}0 \\
\stackrel{0}{0} \\
\text { J }\end{array}$ & $\begin{array}{l}E \\
0 \\
0 \\
0\end{array}$ & 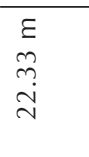 & 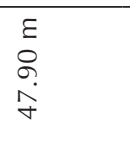 & 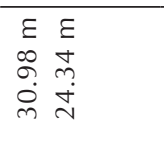 & $\begin{array}{l}E \\
E \\
\dot{\sigma} \\
\dot{\sigma}\end{array}$ & $\begin{array}{l}\varepsilon \\
E \\
\dot{m} \\
\dot{H} \\
\stackrel{L}{n}\end{array}$ & $\begin{array}{l}E \\
\circ \\
\llcorner \\
\dot{m} \\
\dot{m}\end{array}$ & 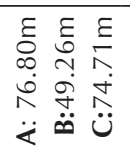 & 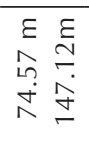 & $\begin{array}{l}\varepsilon \\
0 \\
\dot{m} \\
\end{array}$ & $\begin{array}{l}\varepsilon \\
\varepsilon \\
0\end{array}$ \\
\hline 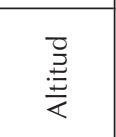 & 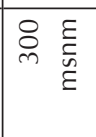 & 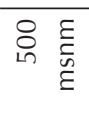 & 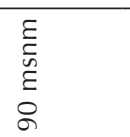 & 品 & 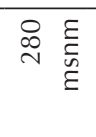 & 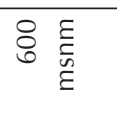 & 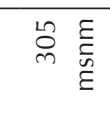 & 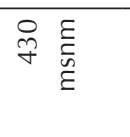 & 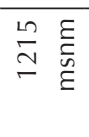 & 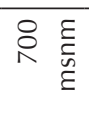 & 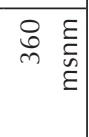 \\
\hline 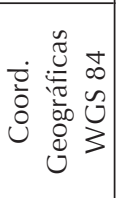 & 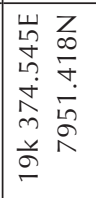 & 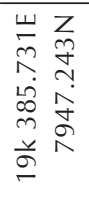 & 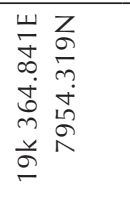 & 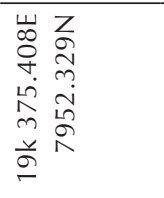 & 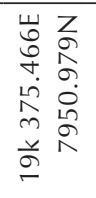 & 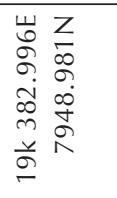 & 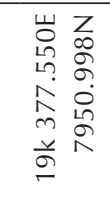 & 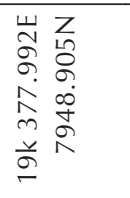 & 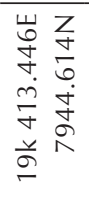 & 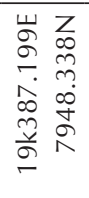 & 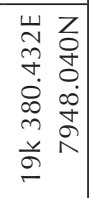 \\
\hline 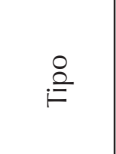 & 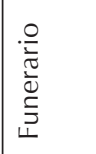 & 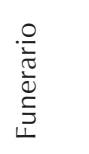 & 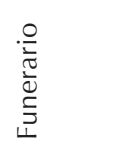 & 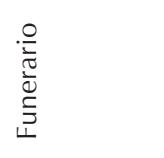 & $\begin{array}{l}\frac{0}{\frac{\pi}{\pi}} \\
\frac{\pi}{2} \\
5 \\
5\end{array}$ & 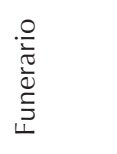 & $\begin{array}{l}\stackrel{\circ}{\frac{\pi}{\pi}} \\
\frac{\pi}{0} \\
5 \\
5\end{array}$ & 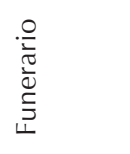 & 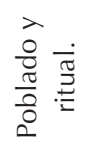 & 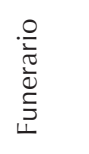 & 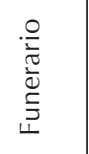 \\
\hline $\begin{array}{l}\frac{0}{\circ} \\
\frac{0}{\bar{V}} \\
0 .\end{array}$ & $\begin{array}{l}\frac{0}{\bar{U}} \\
\frac{0}{2}\end{array}$ & $\begin{array}{l}\frac{0}{0} \\
\frac{0}{2}\end{array}$ & $\begin{array}{l}\frac{0}{\bar{d}} \\
\frac{0}{2}\end{array}$ & $\begin{array}{l}\frac{0}{\overline{0}} \\
\frac{0}{2}\end{array}$ & $\begin{array}{l}\frac{0}{\overline{0}} \\
\frac{\mathrm{U}}{2}\end{array}$ & $\begin{array}{l}\frac{0}{\overline{0}} \\
\frac{0}{2}\end{array}$ & $\begin{array}{l}\frac{.0}{0} \\
\frac{0}{z}\end{array}$ & $\begin{array}{l}\frac{0}{\overline{0}} \\
\frac{\Phi}{2}\end{array}$ & $\begin{array}{l}\frac{0}{0} \\
\frac{0}{2}\end{array}$ & $\begin{array}{l}\frac{0}{\overline{0}} \\
\frac{0}{z}\end{array}$ & $\begin{array}{l}\stackrel{\circ}{\overline{0}} \\
\frac{0}{\Sigma}\end{array}$ \\
\hline 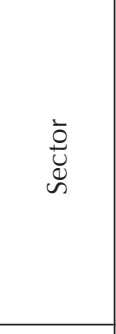 & 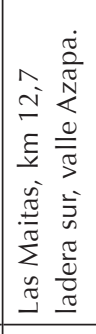 & 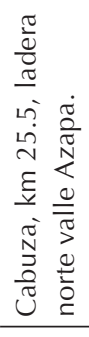 & 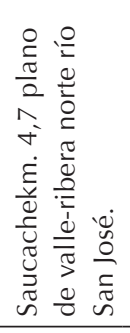 & 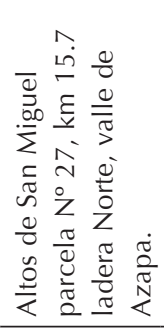 & 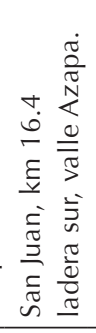 & 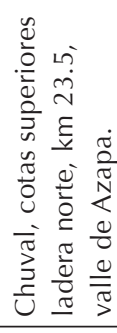 & 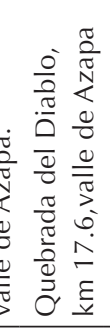 & 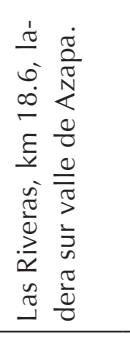 & 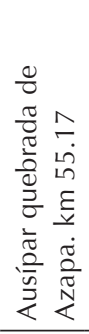 & 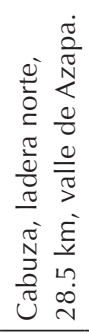 & 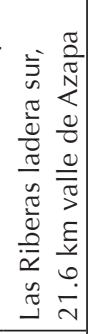 \\
\hline 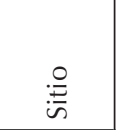 & $\begin{array}{l}\frac{1}{0} \\
\frac{1}{\alpha}\end{array}$ & $\begin{array}{c}0 \\
\frac{1}{1} \\
\frac{1}{<}\end{array}$ & $\frac{n}{\frac{10}{\grave{1}}}$ & 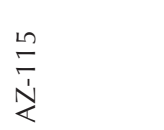 & 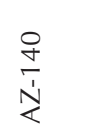 & $\frac{\bar{J}}{\frac{\bar{x}}{\alpha}}$ & 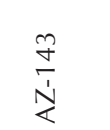 & 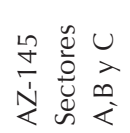 & $\frac{\bar{\pi}}{\stackrel{\overline{2}}{\frac{2}{2}}}$ & $\stackrel{\substack{N \\
\ominus}}{\stackrel{D}{<}}$ & 主 \\
\hline
\end{tabular}




\begin{tabular}{|c|c|c|c|c|c|}
\hline 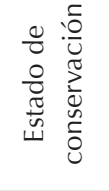 & 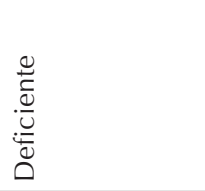 & 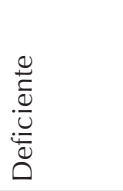 & 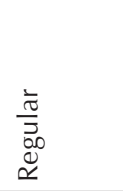 & 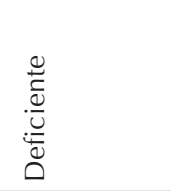 & 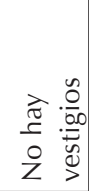 \\
\hline$\Xi$ & $\stackrel{2}{\circ}$ & 0 & ¿্. & $\begin{array}{l}\stackrel{L}{n} \\
\text { On }\end{array}$ & $\stackrel{\circ}{\circ}$ \\
\hline 蛋 & $\begin{array}{l}\text { है } \\
\text { हे } \\
\text { రू } \\
\text { tै }\end{array}$ & 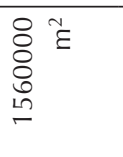 & 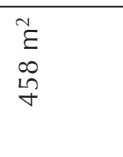 & $\begin{array}{l}\text { है } \\
\text { ปิ } \\
\stackrel{\text { ป }}{ }\end{array}$ & $\begin{array}{l}\varepsilon \\
\sigma\end{array}$ \\
\hline 迹 & $\begin{array}{l}\varepsilon \\
\pm \\
\text { Do } \\
\dot{\alpha}\end{array}$ & 0 & 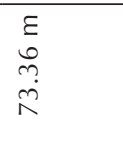 & $\begin{array}{l}\varepsilon \\
\omega \\
\tilde{\sim}\end{array}$ & $\begin{array}{l}\varepsilon \\
\sigma\end{array}$ \\
\hline 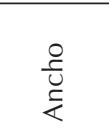 & $\begin{array}{l}\varepsilon \\
\tilde{m} \\
\grave{\nu} \\
\stackrel{v}{q}\end{array}$ & $\begin{array}{l}\varepsilon \\
\varepsilon \\
8 \\
\infty\end{array}$ & $\begin{array}{l}\varepsilon \\
\hat{f} \\
\stackrel{\sim}{\dot{v}}\end{array}$ & $\begin{array}{l}\varepsilon \\
0 \\
\dot{0} \\
\dot{m}\end{array}$ & $\begin{array}{l}\varepsilon \\
\sigma\end{array}$ \\
\hline 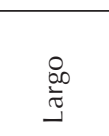 & $\begin{array}{l}\varepsilon \\
g \\
\qquad \\
\bar{m}\end{array}$ & $\begin{array}{l}\varepsilon \\
0 \\
0 \\
\stackrel{0}{\sigma} \\
\sigma\end{array}$ & $\begin{array}{l}\varepsilon \\
\infty \\
\tilde{N} \\
\stackrel{N}{N}\end{array}$ & $\begin{array}{l}\varepsilon \\
\circ \\
\dot{R} \\
\end{array}$ & $\begin{array}{l}\varepsilon \\
\varepsilon \\
0\end{array}$ \\
\hline 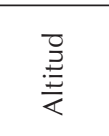 & 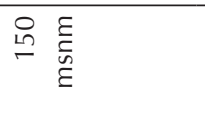 & 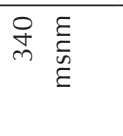 & 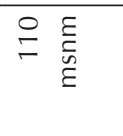 & 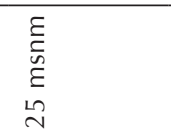 & 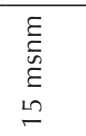 \\
\hline 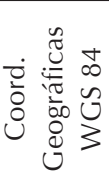 & 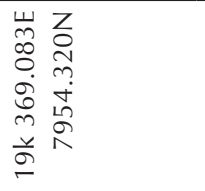 & 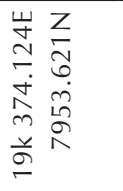 & 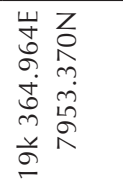 & 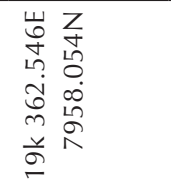 & 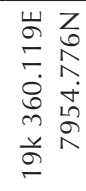 \\
\hline$\stackrel{\circ}{\stackrel{2}{F}}$ & 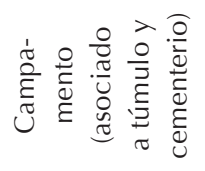 & 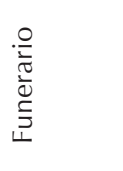 & 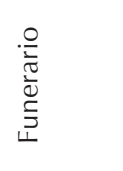 & $\begin{array}{l}\frac{0}{0} \\
\frac{\pi}{0} \\
\frac{0}{0}\end{array}$ & 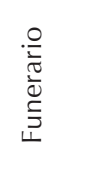 \\
\hline $\begin{array}{l}\frac{0}{8} \\
\frac{0}{\bar{D}} \\
0\end{array}$ & $\begin{array}{l}\frac{0}{0} \\
\frac{0}{2}\end{array}$ & $\begin{array}{l}\frac{0}{0} \\
\frac{0}{2}\end{array}$ & $\begin{array}{l}\frac{0}{0} \\
\frac{0}{2}\end{array}$ & $\frac{.0}{\frac{0}{2}}$ & $\frac{\circ}{\frac{0}{0}}$ \\
\hline 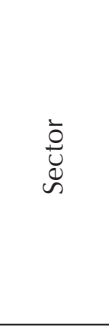 & 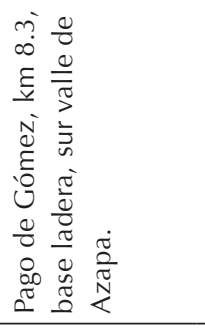 & 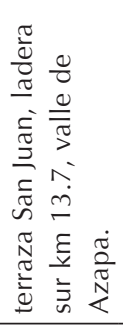 & 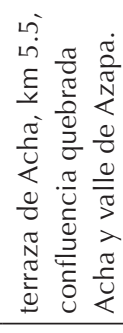 & 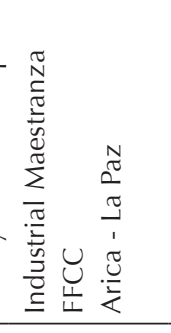 & 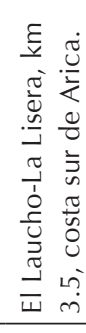 \\
\hline$\stackrel{\ominus}{\stackrel{\Xi}{n}}$ & 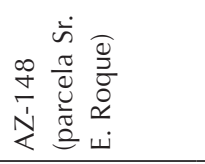 & 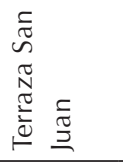 & 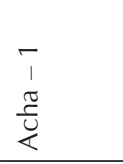 & 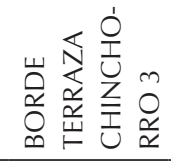 & 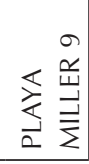 \\
\hline
\end{tabular}




\section{Discusión en torno a los asentamientos prospectados}

\author{
La relación entre asentamientos y \\ recursos hídricos
}

Los asentamientos humanos prospectados se hallan espacialmente cercanos a los recursos de agua, especialmente a filtraciones subterráneas que conducen a la formación de vertientes (Figuras $\mathrm{N}^{\circ} 2, \mathrm{~N}^{\circ} 3$ y $\mathrm{N}^{\circ} 4$ ). La condición de alta permeabilidad que caracteriza al lecho del río San José, facilitó la intensa infiltración de las aguas hacia las napas subterráneas, haciendo desaparecer el débil flujo superficial del río San José. En su desplazamiento subsuperficial hacia el nivel de base oceánico, estos recursos afloran en la parte baja del valle de Azapa, en especial en los sectores comprendido entre quebrada del Diablo y Las Llocllas. Estos recursos de agua fueron básicos para el asentamiento de las poblaciones de pescadores del período Medio en el valle, recordemos que la condición agrícola del valle de Azapa, hasta principios del S. XX, estaba sustentada por el aporte de las vertientes y el cultivo en paños de tierras aislados. Así lo señalan documentos del Período Colonial, como es el caso de la descripción realizada por Fray Antonio Vázquez de Espinosa a partir de la visita realizada en 1618 (Keller, 1946).

Un análisis de la vinculación asentamiento/vertiente-humedades de mar a cordillera, vemos que los humedales de la costa (Chinchorro, La Chimba y el Morro) se hayan relacionados a asentamientos como el sitio Borde Terraza Chinchorro 3, donde se han encontrado piezas cerámicas y fragmento de textiles que asemejan formas e iconos del periodo Medio, vinculados a la cultura Tiwanaku. Luego en el sector del cerro San Miguel a $5 \mathrm{~km}$ de la costa y asociado al humedal del mismo nombre se concentraron los asentamientos Az-25, Az-26, Az-27, Az-97 y Az-105 correspondientes a agricultores que construyeron sus viviendas y enterraron a sus muertos en el sector, sin embargo, también se desplazaron hacia la costa en búsqueda de recursos del mar. Entre el km 7 al km 12 se ubican los humedades y vertientes como El Gallito, La Media Luna y la Mita Chica, estas vertientes están conectadas con el sector de las Animas, donde se concentró un gran humedal y en sus alrededores hallamos los asentamientos Az-19, Az-20, Az-95, Az-96, ahora bien, las poblaciones asentadas en el sector de San Lorenzo, Maitas y Alto Ramírez, también usufrutuaron de estos recurso hídricos, entre los sitios registrados tenemos a Az-80, Az-83, $\mathrm{Az}-14$, grupos de agricultores vinculados con el proceso aldeano en su fase experimental y posterior desarrollo del trabajo de la tierra. Entre el km 12 al 16 se hallan la mayor cantidad de vertientes, entre ellas, La Noria, Socavón, Caniviri, los asentamientos asociados a estos recursos de agua corresponden a un gran número de sitios como Az-115, Az-69, Az-13, Az-75, Az-71, Az-6, Az-11, Az-102.

El espacio que se ubica entre el $\mathrm{km} 7$ al 16 está delimitado por dos quebradas la del Diablo y las Llocllas, la confluencia de estas con el río principal San José hicieron que la presencia de materiales finos interrumpiera el flujo del acuífero, originando un conjunto de vertientes como las descrita por Muñoz y Zalaquett (2011).

Otros sector con asentamientos se distribuyen entre la quebrada del Diablo y el sector de Cabuza, allí se hallan los asentamientos Az-74, Az-4, Az-5 y Az-3 vinculado con el sector de Sobraya, estos asentamientos tienen una relación directa con las vertientes La Noria, Socavón, Caniviri. Finalmente entre el km 17 al 21 se halla el sector de Cabuza donde hemos registrado los sitios Az-1, Az-2, Az-101 y Az-141. En el sector alto de Cabuza se halla una pequeña quebradilla, la cual nos sugiere que en sus alrededor debió existir un pequeño humedal que alimentó de agua a los agricultores que se enterraron en los sitios antes mencionado.

En síntesis, la presencia de vertientes distribuidas desde la desembocadura hasta el km 22 hicieron que el poblamiento humano de Azapa se focalizara en este espacio, sin embargo, hay dos sectores en el valle que concentran el poblamiento humano y los recursos hídricos. En primer lugar, el sector entre la quebrada del Diablo y las Llocllas y el segundo lugar el sector de la quebrada de las Llocllas y la quebrada de Acha. En este sentido, algunas vertientes y humedales explotados por estas poblaciones habrían sido: según Muñoz y Zalaquett (2011), El Gallito, Mita Chica, Media Luna, cerro San Miguel, Pago Gómez, entre otros. 
Figura $\mathrm{N}^{\circ} 2$

Ubicación de los principales sitios arqueológicos del periodo Medio

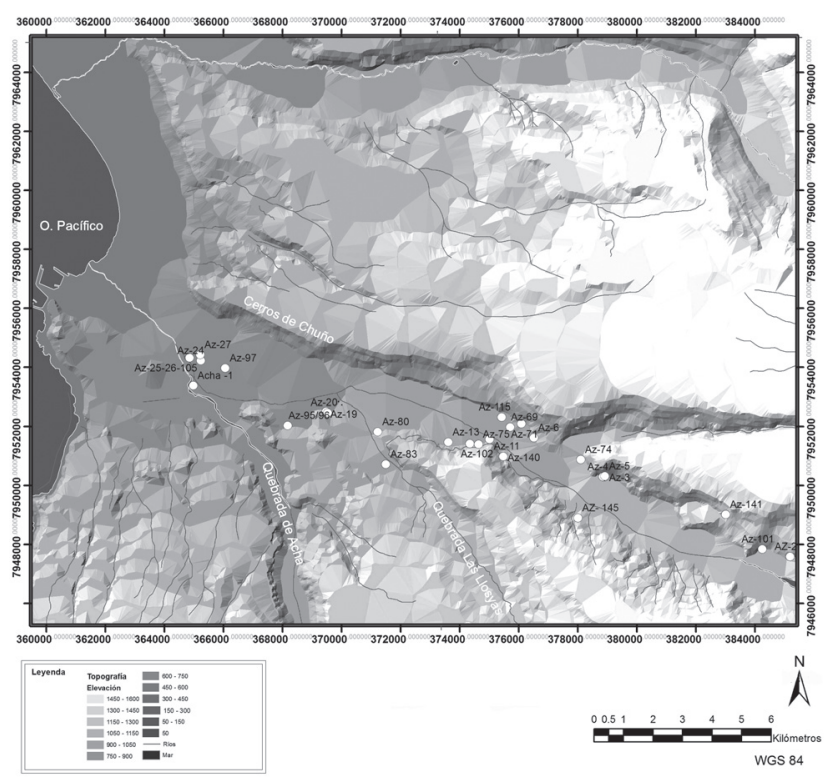

Fuente: Elaboración propia.

Figura $\mathrm{N}^{\circ} 3$

Ubicación de los principales sitios durante el periodo Medio y su relación con las vertientes en el valle de Azapa

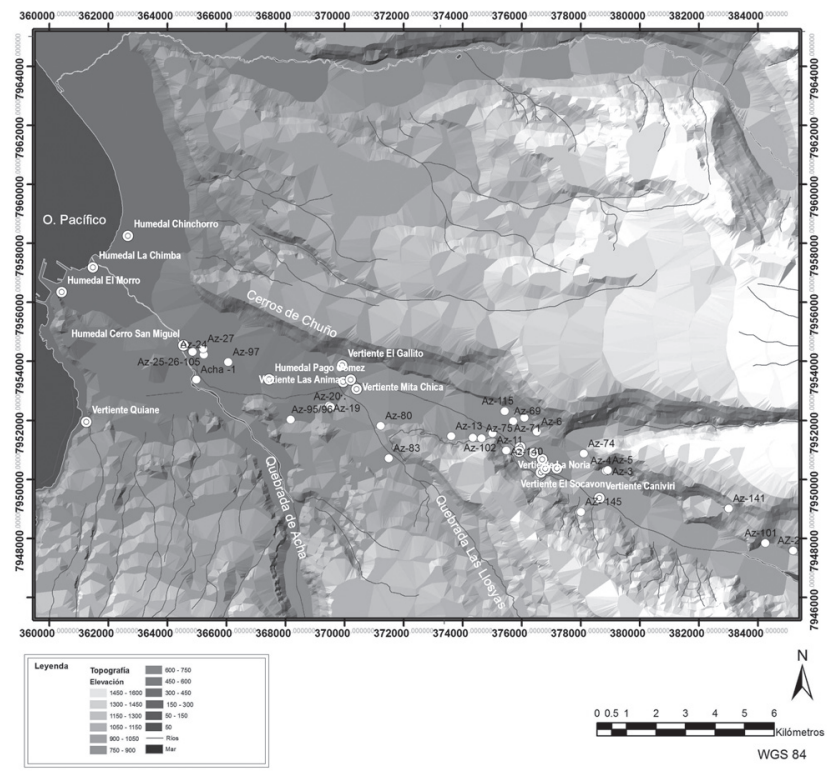

Fuente: Elaboración propia. 
Figura $\mathrm{N}^{\circ} 4$

Concertación de los principales sitios a corta distancia de vertientes durante el periodo Medio en el valle de Azapa

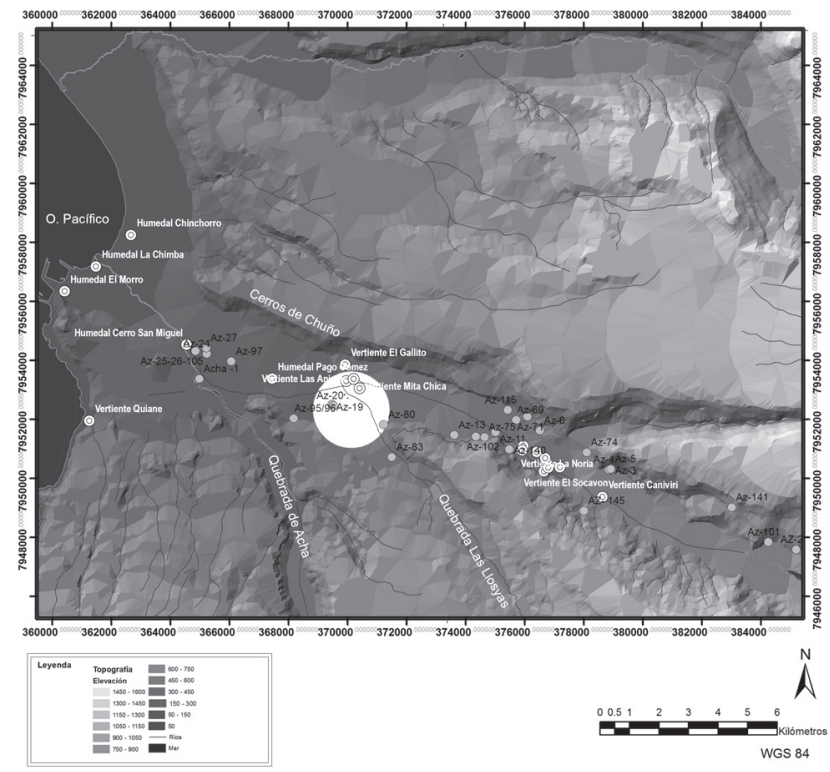

Fuente: Elaboración propia.

\section{Patrón de visibilidad}

Desde Az-115 (Figura $N^{\circ}$ 5) se tiene un amplio dominio visual del valle, sin embargo, son los sitios más cercanos ubicados en el km 10 y 12 en ambas laderas lo que hacen que se formen una gran unidad de asentamientos destacándose entre otros en la ladera sur Az11, Az-71, Az-40 y en la ladera norte Az-71, Az-76. Estos sitios corresponden a los asentamientos más emblemáticos estudiados para el período Medio, sin embargo, también debemos mencionar que en este sector se hallan los primeros campamentos vinculados con las primeras experimentaciones agrícolas como Az-71, nivel bajo, así como la máxima expresión arquitectónica desde el punto desde el punto de vista habitacional como el poblado de San Lorenzo, el cual lo hemos vinculado a un centro administrativo propio de los valles occidentales sobre el cual se estructuró la Cultura Arica (Muñoz y Focacci, 1985, Muñoz, 2004a y 2004b).

Desde Az-71 y Az-6 (Figuras $N^{\circ} 6$ y $\mathrm{N}^{\circ}$ 7), la visibilidad alcanza gran parte del valle, por la ladera norte se alcanza hasta la Waka (cementerio) Az-145 y por el oeste hasta los cementerios de cerro San Miguel, esta amplia visibilidad integró los recursos de agua (vertientes) ubicados en el sector medio del valle. Esta ubicación estratégica sumada al alto número de entierros encontrados sugiere que en este sector conocido en la actualidad como poblado de San Miguel de Azapa se había concentrado una población de agricultores representativos del periodo Medio. Ellos habrían ocupado la terraza mayor de este sector, construyendo sus viviendas (recintos de caña) y sus cementerios, los que se caracterizaron por enterramientos en fosas donde fueron depositados los cuerpos una vez que fueron envueltos en mantas y camisas y enfardados.

Desde Az-3 nos encontramos con una amplia visibilidad que involucró la ladera sur desde Az-140 pasando por Az-145 y el interior del valle entre ellos los sectores de Chamarcusiña y Ausipar donde hay registros de redes viales y un parque de petroglifos. En este sector del valle es importante la pre- 
Figura $\mathrm{N}^{\circ} 5$

Patrón de visibilidad desde Az-115

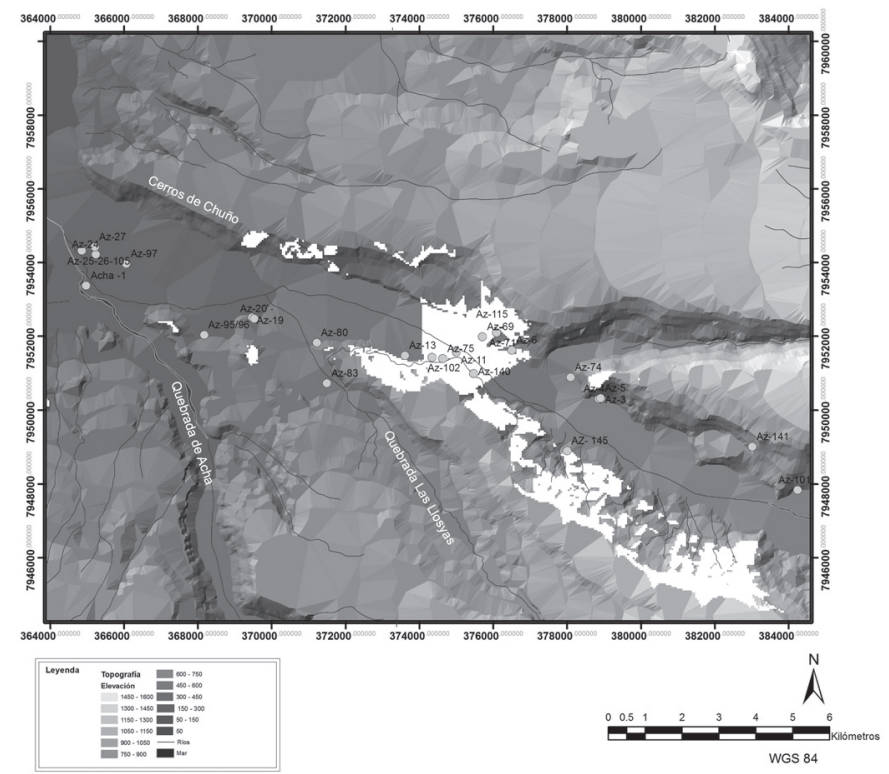

Fuente: Elaboración propia.

Figura $\mathrm{N}^{\circ} 6$

Patrón de visibilidad desde Az-71

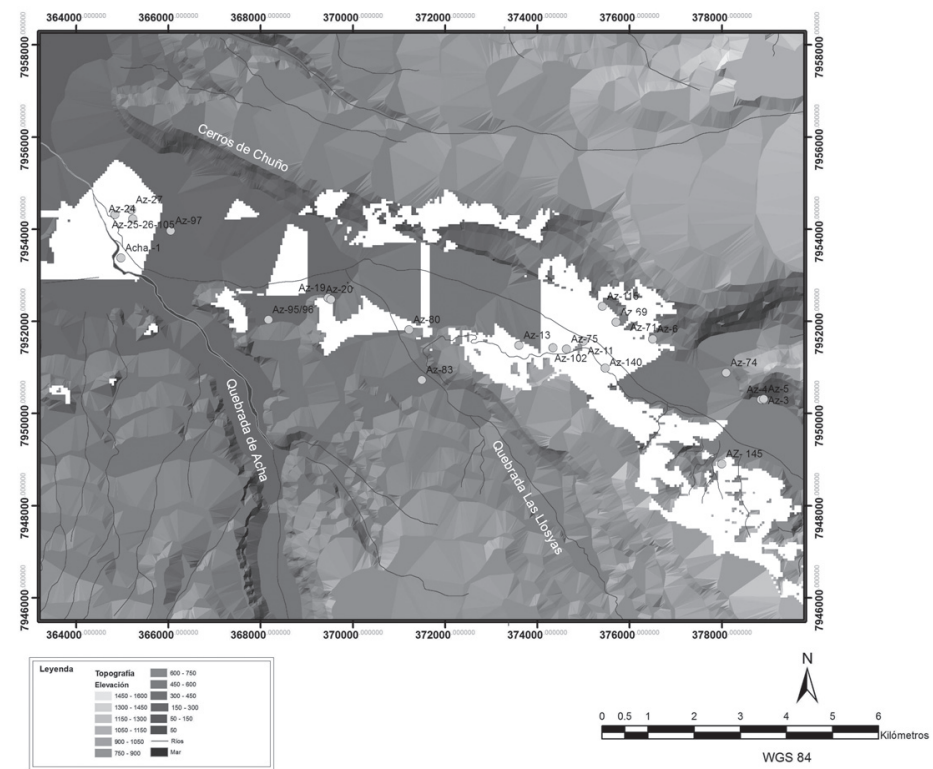

Fuente: Elaboración propia. 
Figura $\mathrm{N}^{\circ} 7$

Patrón de visibilidad desde Az-6

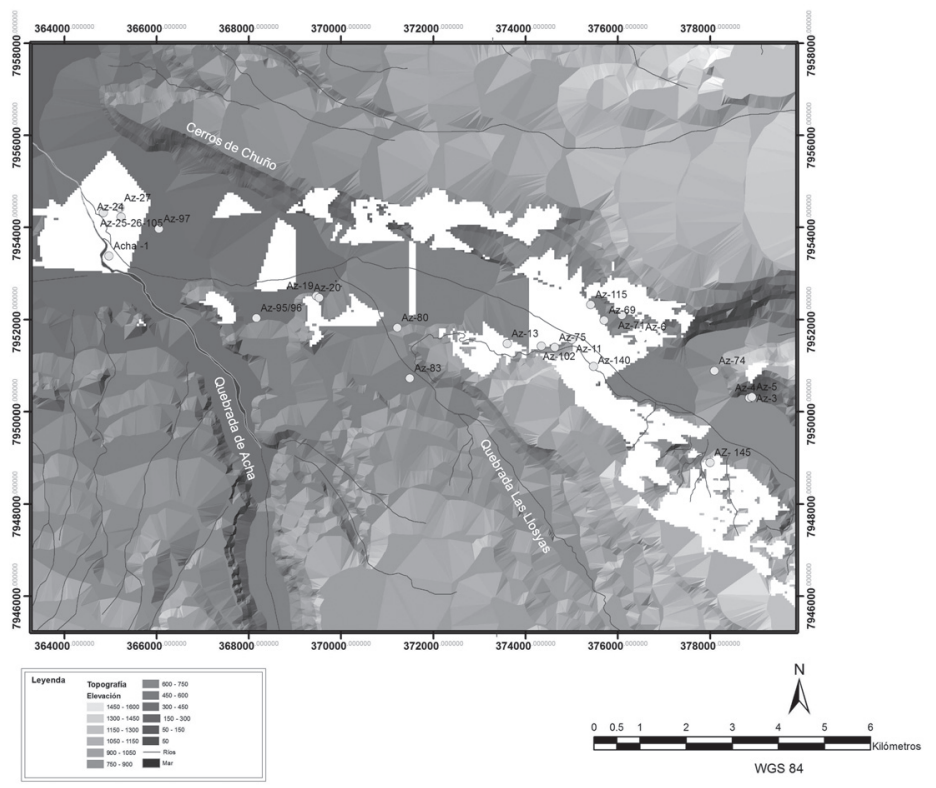

Fuente: Elaboración propia.

sencia de vertientes entre ellas: El Pejerrey, Matavaca, La Noria, San Miguel, El Socavón, La Concepción y Caniviri quienes, al parecer habría nutrido de agua a los agricultores enterrados en los cementerios de Az-145 y Az140. A su vez, Az-2 presenta una visibilidad que se expresa desde Az-145, este espacio es un sector de quebradillas que desembocan en la cuenca del río San José, por lo tanto es un lugar adecuado para la formación de "ojos de agua" los que se situarían en la ladera norte y sur. Por su parte Az-1 presenta una visibilidad que abarcó la ladera norte desde Az-145 hacia el sector de cerro Blanco. En general, estos cementerios de Az-1, Az-2 y Az-3, presentan una visibilidad similar concentrándose en el área más extrema del sector bajo del valle de Azapa que involucra un espacio territorial que va desde el km 18 al 35 (Figuras $\mathrm{N}^{\circ}$ $8, N^{\circ} 9$ y $\left.N^{\circ} 10\right)$. Otro cementerio Az-141, por ubicarse en un sector de la ladera más alta que el resto de los cementerios descritos, presenta una visibilidad que abarca desde los asentamientos del sector de San Lorenzo, por la ladera sur hasta el sector de cerro Blanco (Figura $\mathrm{N}^{\circ} 11$ ). En la ladera norte la visibili- dad abarca la cadena de cerros denominada cerro Chuño, donde se sitúa una quebrada de cauce secundario que tiene curso en cotas de cima y desagua en la caja del valle.

En la ladera sur la visibilidad que nos presenta Az-145, incluye el sector central de la ladera norte donde se concentran los asentamientos que se ubican entre la quebrada del Diablo y el pueblo de San Miguel, incluido la parcela 27 donde se halla el Museo Arqueológico de San Miguel de Azapa (Figura $N^{\circ} 12$ ). El límite por el oeste alcanza hasta el sector de las Animas y por el este hasta el área donde se ubica el cementerio Az-141. Reiteramos que este es uno de los sectores donde se concentró mayoritariamente el poblamiento prehispánico del período Medio. Sobre el patrón de visibilidad que nos presenta Az-140, este alcanza la ladera norte, el sector de la terraza de San Juan hasta el sector de Sobraya-Cabuza; también se tiene visión hacia el interior de la quebrada del Diablo, en la ladera sur se tiene una visión del asentamiento de San Lorenzo y de los cañaverales que circundan 
Figura $\mathrm{N}^{\circ} 8$

Patrón de visibilidad desde Az-71

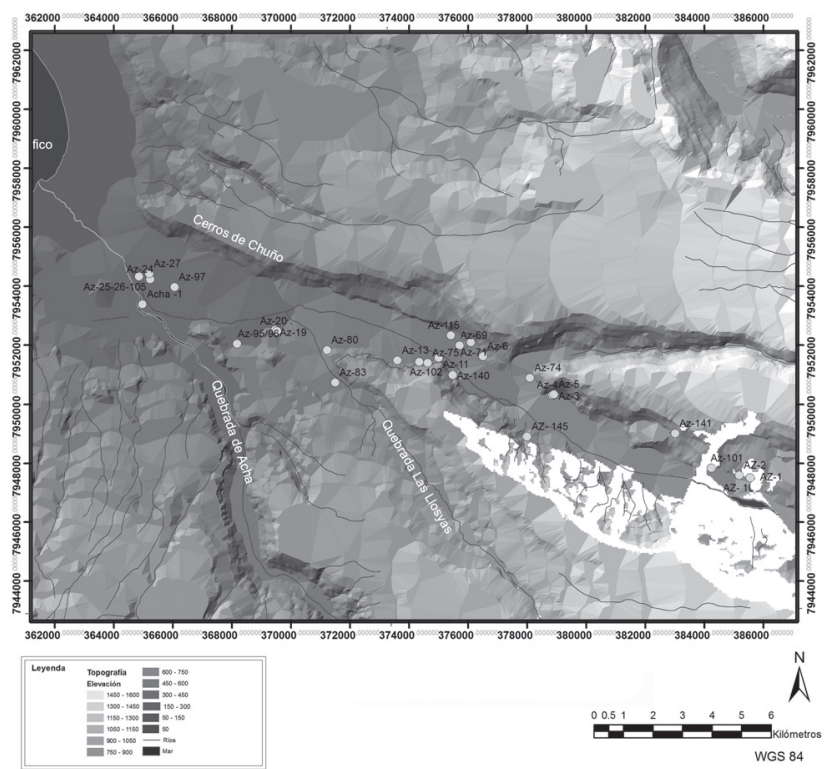

Fuente: Elaboración propia.

Figura $\mathrm{N}^{\circ} 9$

Patrón de visibilidad desde Az-2

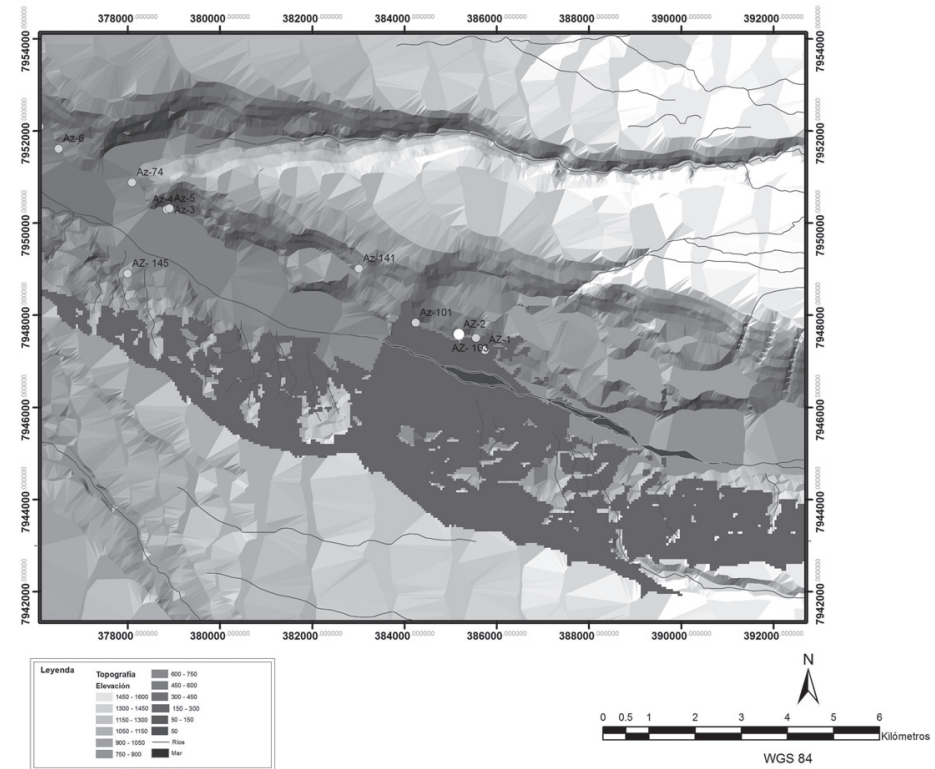

Fuente: Elaboración propia. 
Figura $\mathrm{N}^{\circ} 10$

Patrón de visibilidad desde Az-3

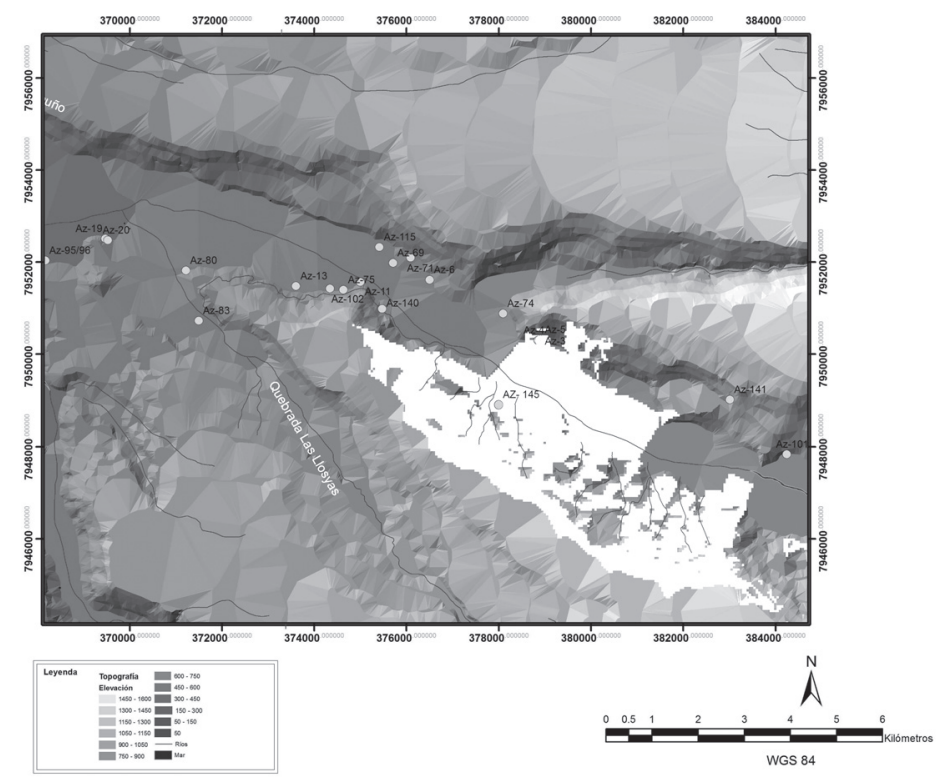

Fuente: Elaboración propia.

Figura $\mathrm{N}^{\circ} 11$

Patrón de visibilidad desde Az-141

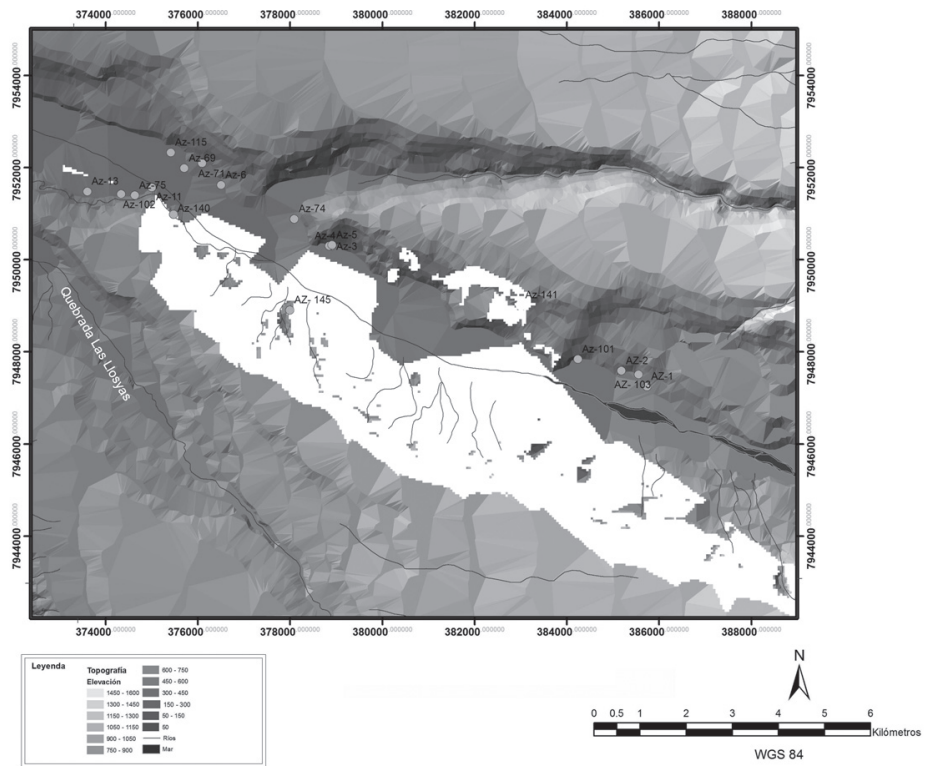

Fuente: Elaboración propia. 
este asentamiento (Figura $N^{\circ} 13$ ). Respecto al patrón de visibilidad que nos presenta Az-11, en el sector de San Lorenzo, esta es similar a la de Az-145, en donde resalta como hito geográfico determinante la quebrada del Diablo y su entorno, como complemento presenta una visión hacia el interior del valle hasta la altura del km 20 y hacia la costa la visibilidad alcanza hasta el km 4 (Figura $N^{\circ} 14$ ). Este es uno de los sectores más estratégicos en el valle con un abrupto montículo que sobresale de la geomorfología que caracteriza la ladera sur, por lo tanto fue allí donde se construyó el mayor asentamiento con características de centro administrativo a fines del periodo Medio (Muñoz, 2004a y 2004b). Del asentamiento de Az-13, se tiene visibilidad de la ladera norte desde el cordón de cerros Chuño hasta la quebrada del Diablo, inclusive alcanzando el asentamiento Az-74, ubicado en la terraza de Sobraya-Cabuza (Figura $N^{\circ}$ 15). En la ladera sur la visibilidad alcanza el sector de Las Maytas y San Lorenzo. Tal como lo hemos señalado anteriormente corresponde al sector medio del valle, donde se concentran un gran número de vertientes tales como: El Gallito, La Mita Chica y la Media Luna.

En la pampa de Alto Ramírez, la visibilidad que nos presentan los asentamientos (cementerios) como Az-80 alcanza por la ladera norte hasta cerro Chuño en dirección al mar, y hasta la quebrada del Diablo hacia el interior del valle, por la ladera sur, la visibilidad se concentra en la pampa de Alto Ramírez y el sector de Las Maitas, un sector menor de Atoca, cerro San Miguel y Saucache (Figura $\left.N^{\circ} 16\right)$. De este sector de pampa de Alto Ramírez, se tiene una visibilidad directa con las vertientes del sector de Las Ánimas, El Gallito, La Mita Chica, la Media Luna, que nutrieron de agua a las poblaciones asentadas en la pampa de Alto Ramírez y su entorno. Desde Az-20, asentamiento que se caracteriza porque en uno de los cerros se halla un geoglifo bastante particular por su diseño de camélidos, su visibilidad alcanza la ladera norte, desde el sector de Las Ánimas hasta la terraza de San Juan (Figura $N^{\circ} 17$ ). Una visibilidad similar es la que nos presenta la imagen desde los sitios Az-95 y Az-96, aunque con una mayor amplitud puesto que se obtiene una visión del núcleo poblacional de lo que es el sector de San Miguel (Figura $N^{\circ}$ 18). Una mayor visibilidad en torno al valle lo observamos de los sitios Az-24, Az-25 y Az-26 y Az-97, enclavados en los alrededores del cerro San Miguel (Figuras $N^{\circ} 19, N^{\circ} 20$ y $\left.N^{\circ} 21\right)$. La visión espacial que se tiene de estos asentamientos involucra la costa, gran parte de la ladera norte hasta la quebrada del Diablo y por la ladera sur distintos lugares que involucran el sector de confluencia entre quebrada de Acha y Azapa, Saucache, cerro San Miguel, parte del sector de Atoca, pampa de Alto Ramírez, Las Maitas y San Lorenzo. En síntesis, hay un patrón visual bastante amplio que más allá de los asentamientos, también se conjugaron algunos hitos geográficos relevantes, los recursos hídricos y los ecosistemas de vertientes, todos ellos conformando una unidad integral del paisaje durante el período Medio.

Adicionalmente a lo señalado, a continuación se hace mención de algunos antecedentes complementarios relativos a las fuentes de aprovisionamiento de material lítico en el área de estudio. Estos antecedentes fueron recogidos en una prospección paralela a la nuestra por Faundes (2013). Se describen los principales sectores de aprovisionamiento lítico y sus características generales. 
Figura $\mathrm{N}^{\circ} 12$

Patrón de visibilidad desde Az-145

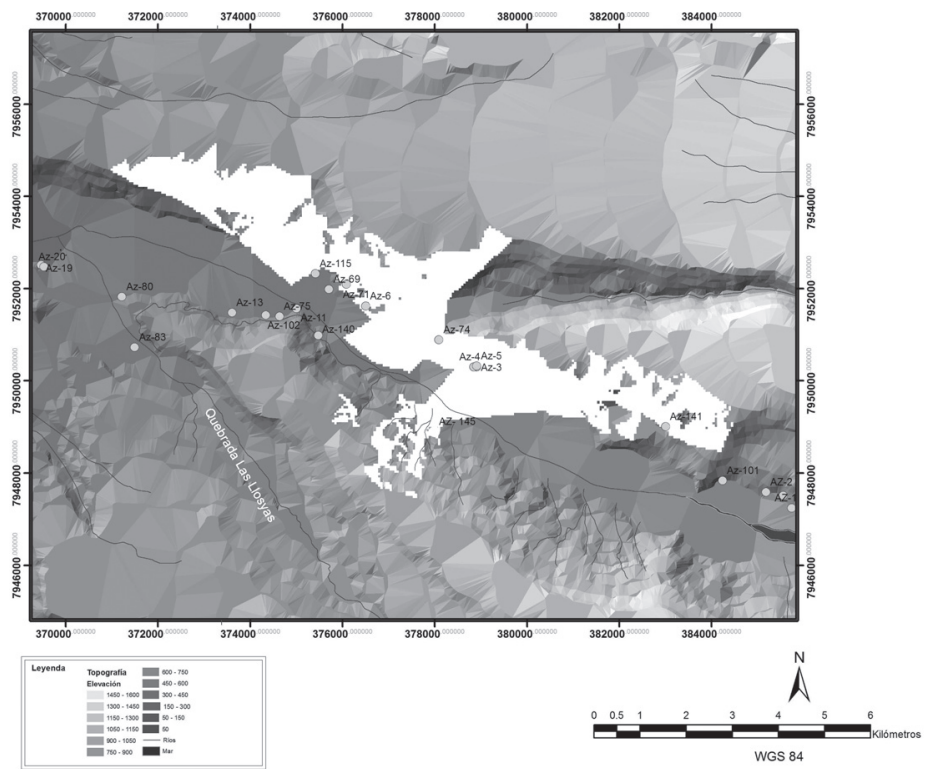

Fuente: Elaboración propia.

Figura $\mathrm{N}^{\circ} 13$

Patrón de visibilidad desde Az-140

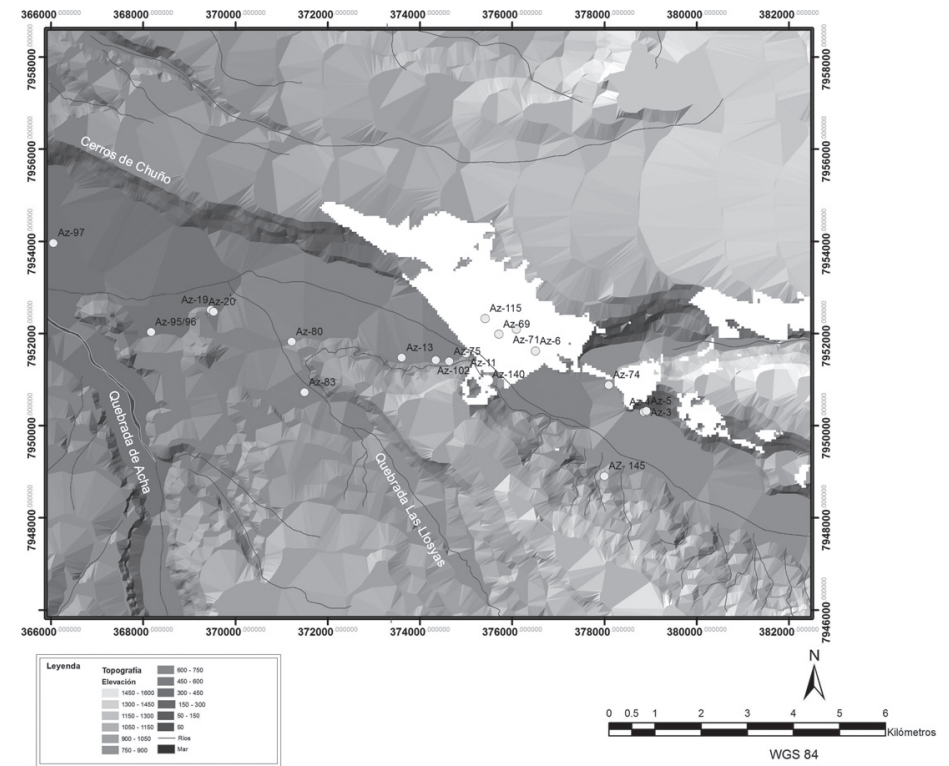

Fuente: Elaboración propia. 
Figura $\mathrm{N}^{\circ} 14$

Patrón de visibilidad desde Az-11

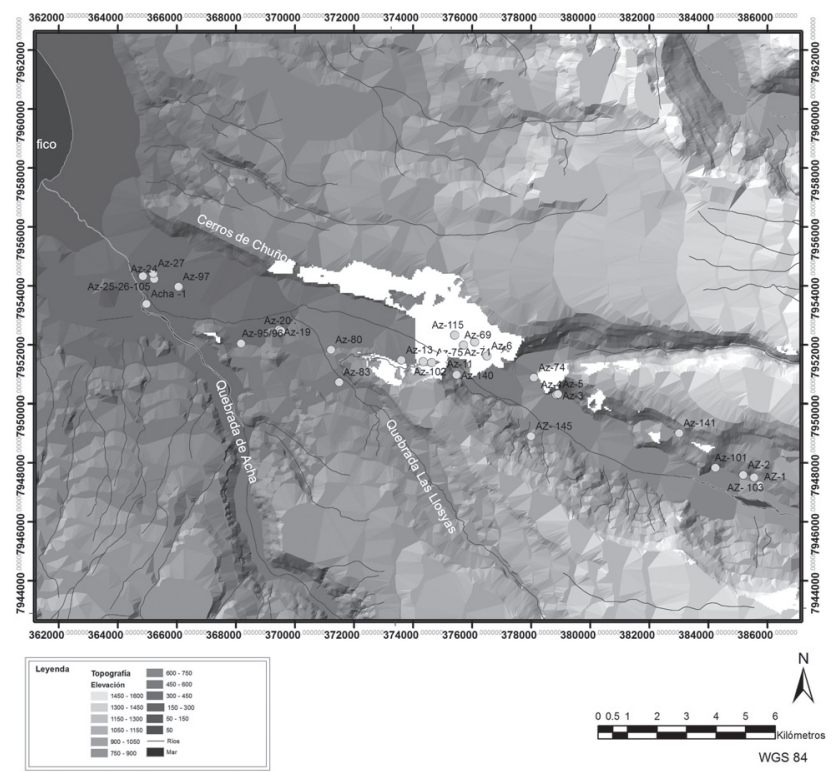

Fuente: Elaboración propia.

Figura $\mathrm{N}^{\circ} 15$

Patrón de visibilidad desde Az-13

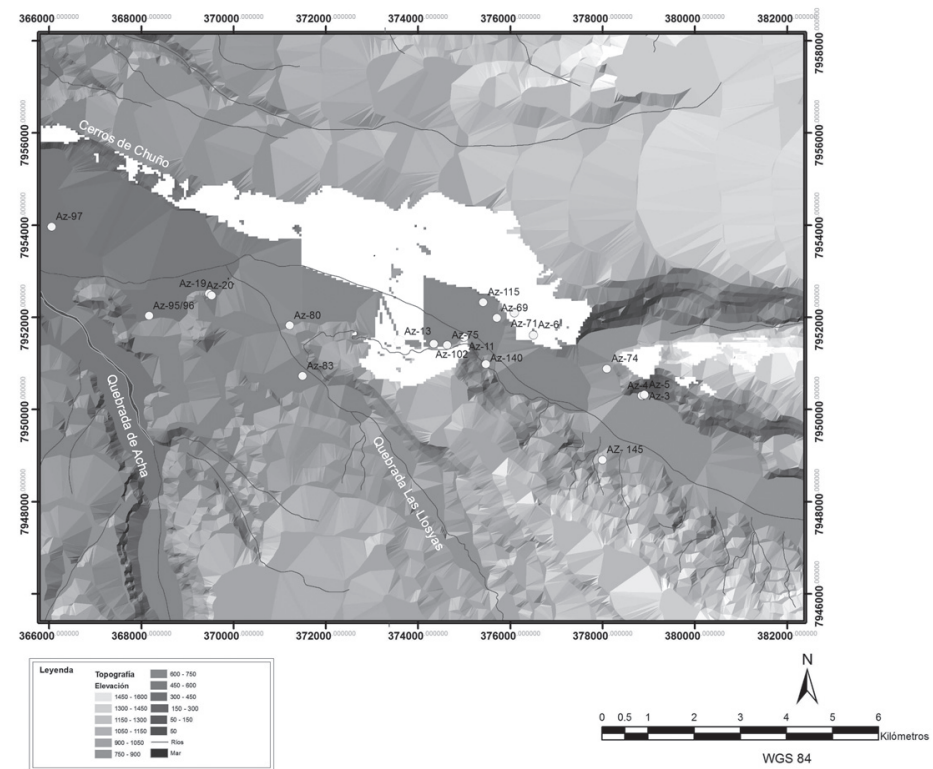

Fuente: Elaboración propia. 
Figura $\mathrm{N}^{\circ} 16$

Patrón de visibilidad desde Az-80

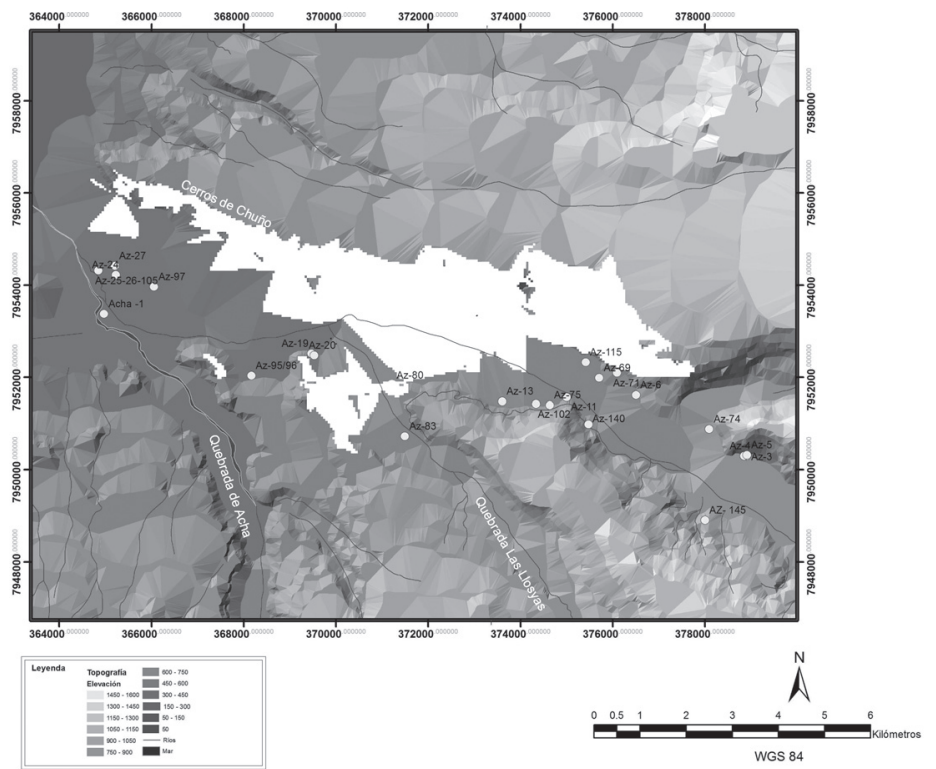

Fuente: Elaboración propia.

Figura $\mathrm{N}^{\circ} 17$

Patrón de visibilidad desde Az-20

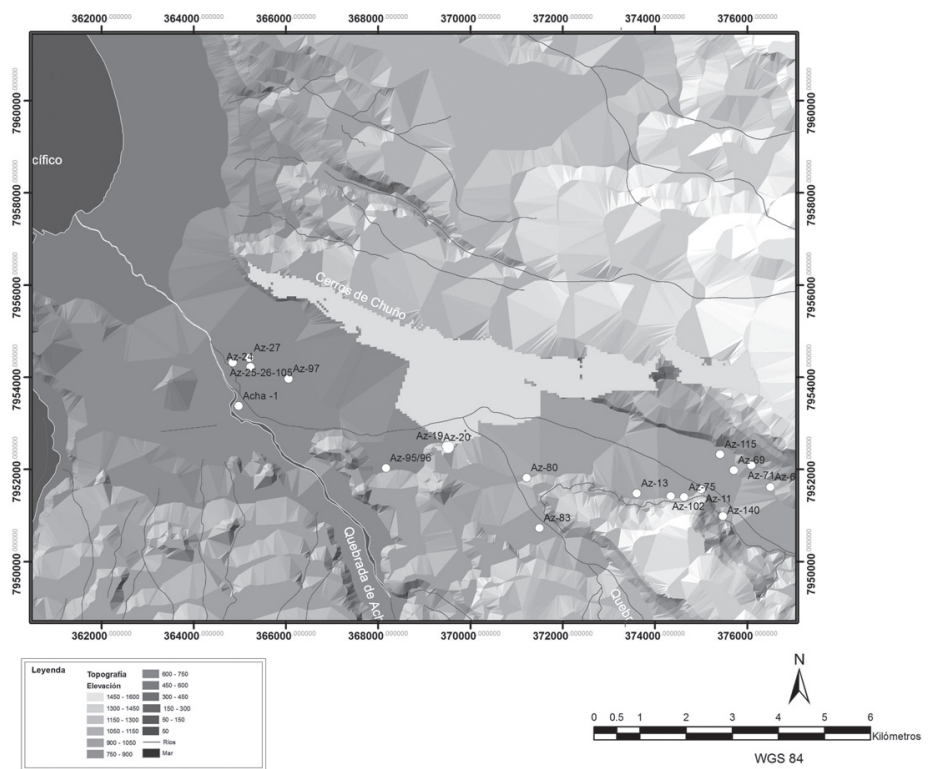

Fuente: Elaboración propia. 
Figura $\mathrm{N}^{\circ} 18$

Patrón de visibilidad desde Az-95-96

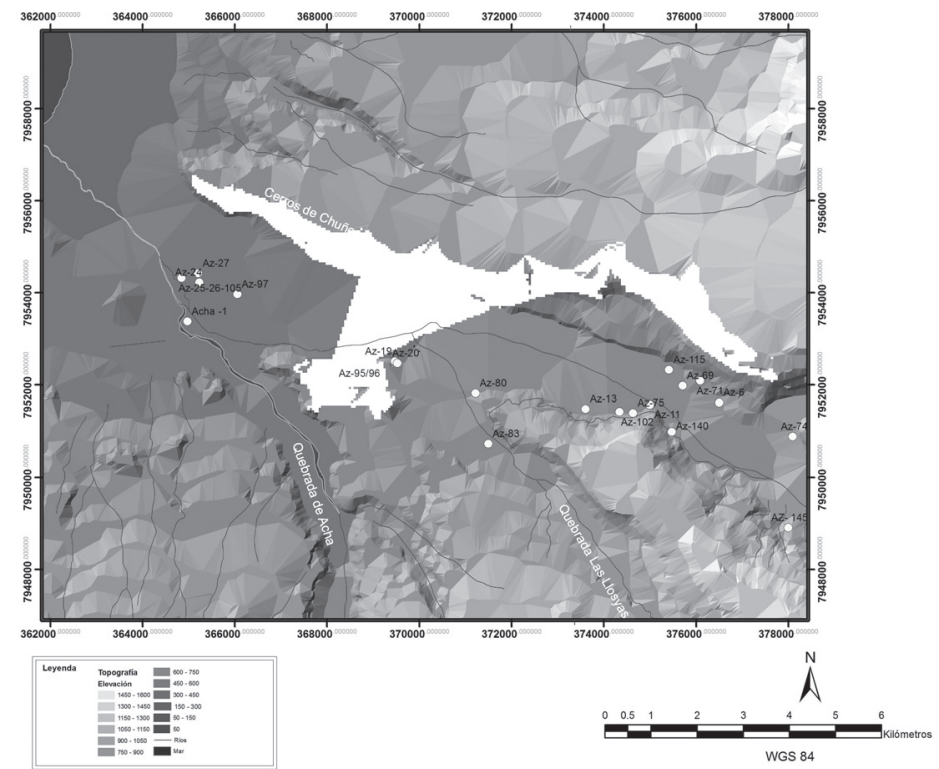

Fuente: Elaboración propia.

Figura $\mathrm{N}^{\circ} 19$

Patrón de visibilidad desde Az-24

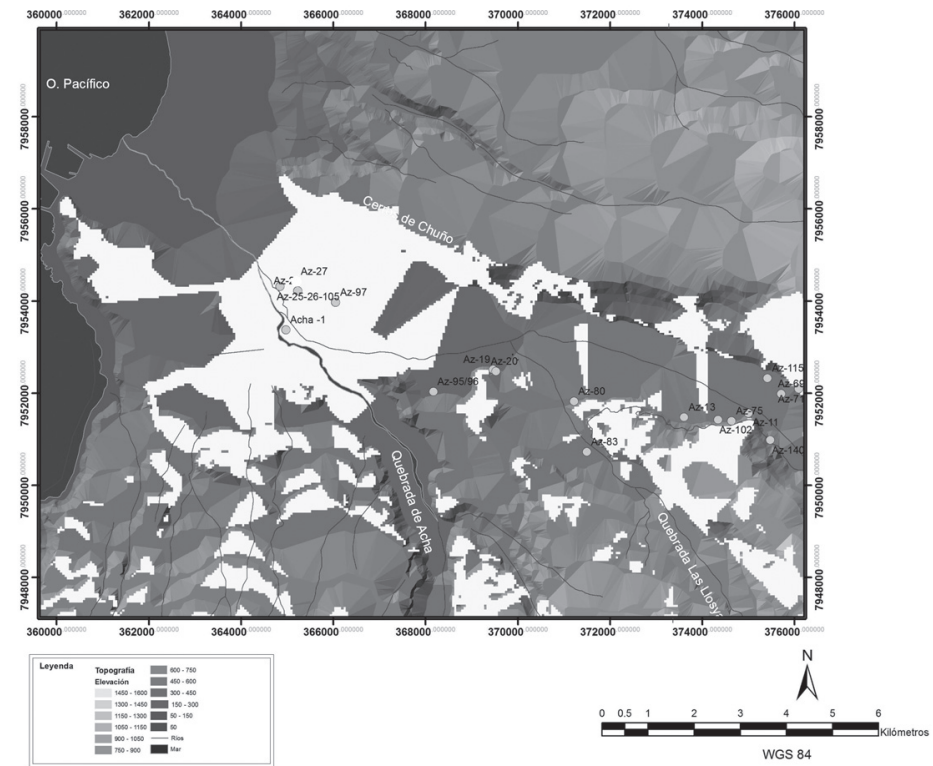

Fuente: Elaboración propia. 
Figura $\mathrm{N}^{\circ} 20$

Patrón de visibilidad desde Az-25-26

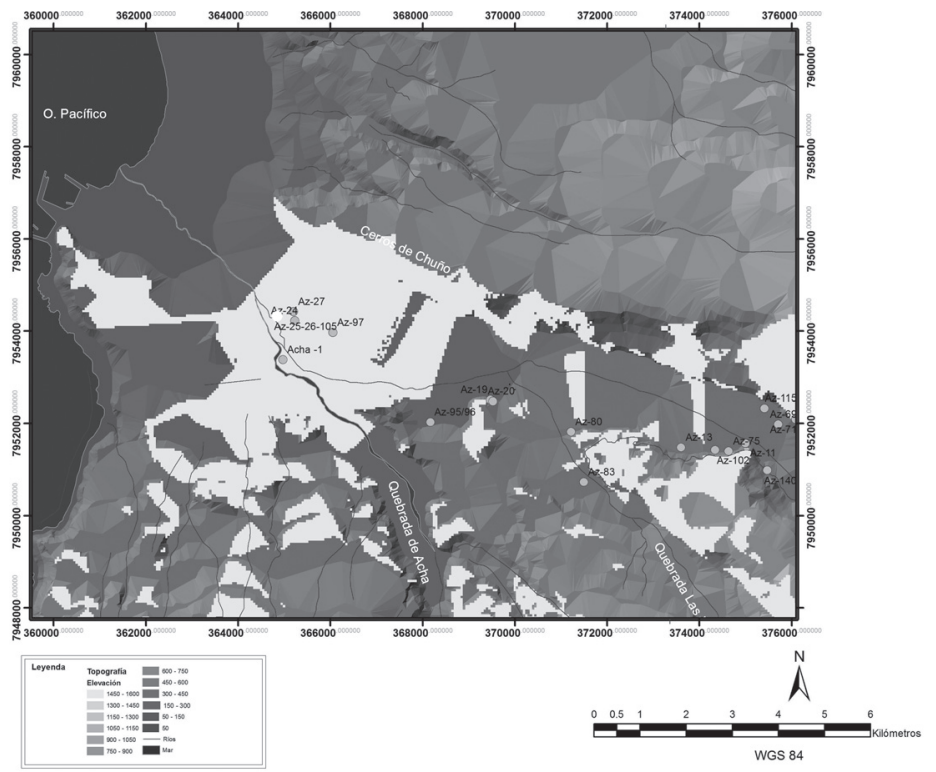

Fuente: Elaboración propia.

Figura $\mathrm{N}^{\circ} 21$

Patrón de visibilidad desde Az-97

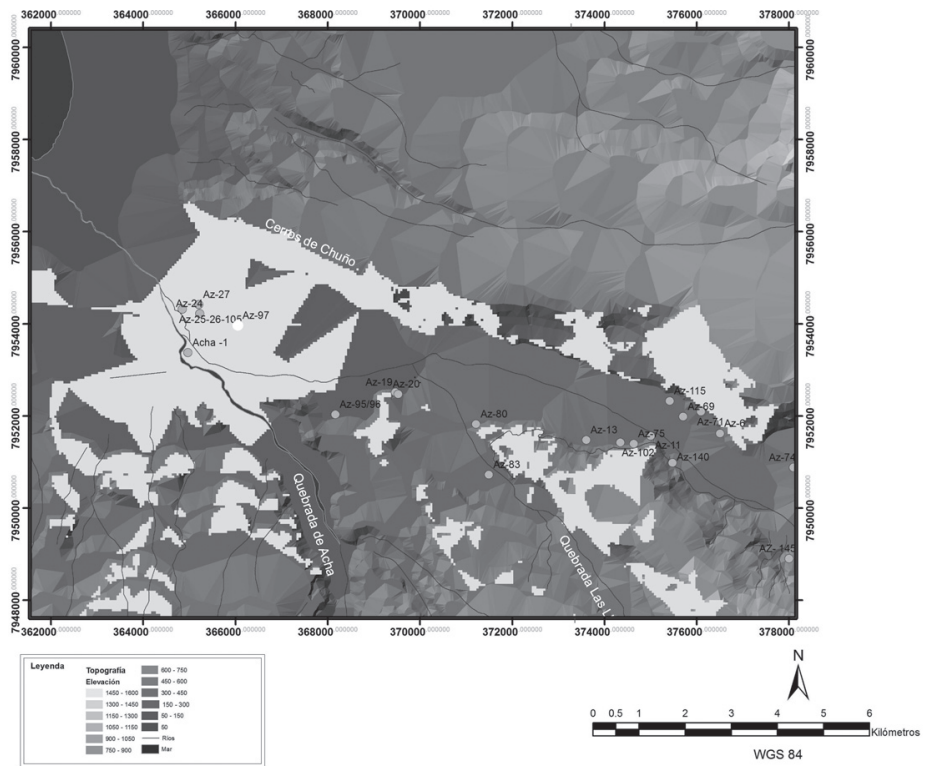

Fuente: Elaboración propia. 
Fuente de aprovisionamiento

Faundes (2013) reconoce tres sectores como fuente de aprovisionamiento de material lítico a) cerro Blanco (valle de Azapa), b) pampa Pan de Azúcar, también Ilamada pampa de Acha y c) playa Corazones (borde costero sur), ubicados en un radio de movilidad no mayor de los 25 km (Figura N²2).

Figura $N^{\circ} 22$

Ordenamiento territorial del poblamiento humano a partir de las fuentes de agua, recursos vegetales y aprovisionamiento de material lítico. Periodo Medio, sector bajo del valle de Azapa y costa de Arica

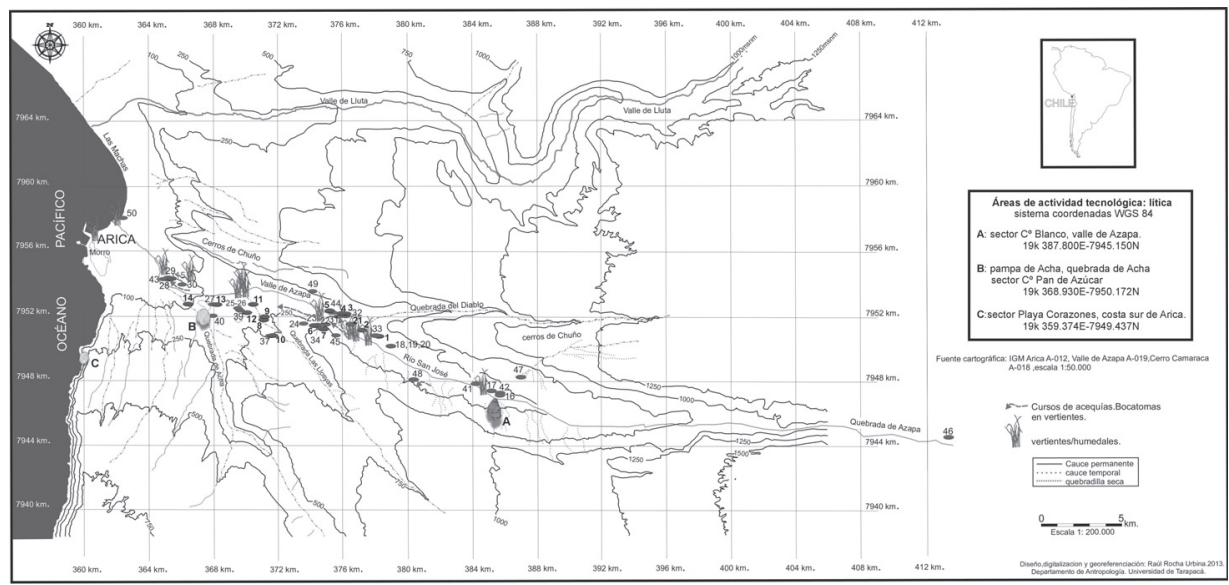

Fuente: Elaboración propia.

\section{Cerro Blanco}

Desde el punto de vista de la prospección fue el lugar que presentó mayor desechos de talla lítica, corresponde a una extensa terraza en cuya superficie se encuentra una cantidad significativa de derivados y desechos de talla lítica de filos óptimos para el corte, derivándose de esta observación una muy buena factura de formatización instrumental. Desde la perspectiva superficial se observa una alta frecuencia depositacional de lascas primarias y secundarias de tamaño mediano, microlascas e hipermicrolascas lo que indican una extracción mediante percusión dura directa llevada a cabo con percutor duro, de tamaño medio con un peso y constitución formal tendiente a oval extendido. Mediante el diag- nóstico macroscópico de las lascas primarias y nodulares se reconoce que estas provienen de un nódulo relativamente mediano con tendencia a grande del cual se extraen lascas primarias (con presencia de corteza) y secundarias (menor porcentaje de corteza y mayor número de extracciones dorsales) mediante técnica de extracción directa multidireccional, contándose en algunos casos con extracción unidireccional (presencia de láminas o lascas alargadas). Las microlascas e hipermicrolascas se observan en menor medida y corresponden a efectos de talla marginal obtenidas mediante percusión directa dura, y no a extracción marginal por retoque blando (en algunos casos es producto de la extracción de lascas de tamaño mayor, produciendo incluso hipermicro fragmentos angulosos aberrantes). 
Algunas lascas revisadas presentan hueIlas de uso, es decir microastillamientos sobre filos vivos, así como filos romos producto del paso intenso del filo natural a manera de cuchillo o raspador sobre un soporte relativamente más duro como puede ser hueso o maderas (Faundes, 2013). Respecto de los focos de extracción es necesario reconocer que en la terraza se reconocen concentraciones de material lítico en diversa graduación de distribución espacial que van desde media a alta, con grados de dispersión acotado y extendido, esta última situación espacial se evidencia coherentemente con efectos de arrastre (tafonomía) sobre arenas no consolidadas en sector de ladera de pendiente. Se identifican pocos nódulos fracturados mediante técnica de percusión bipolar y algunos con presencia de extracción unidireccional.

\section{Sector Pan de Azúcar}

En la cima de los cerros denominados Pan de Azúcar se registraron un número considerable de eventos de talla acotados y dispersos en el espacio. El registro de eventos de talla aislados nos hizo referencia a un uso logístico específico de nódulos muy pequeños. Los eventos de talla identificados más bien correspondían a dispersiones líticas que no sobrepasan los dos metros de ancho, consignándose más bien dispersiones superficiales que concentraron desechos de talla compuestos por lascas primarias (corteza) y secundarias (ausencia de corteza), no lográndose identificar láminas o lascas alargadas. Sin embargo se constató la presencia de instrumentos aislados de manufactura unifacial caracterizados por raspadores y raederas de dorso alto.

Mediante una reevaluación de la situación lítica en el área se reconocen dos sectores de eventos de talla extendidos, corresponden a puntos de alta e intensa concentración y dispersión de material lítico con extensiones diametrales que van desde $1 \times 1 \mathrm{~m}$ a $3 \times 4 \mathrm{~m}$. Las materias primas corresponden a sílices cristalinos de variada coloración como: blanquecino cristalino y opaco, rojizo cristalino, opaco y veteado, gris cristalino y opaco veteado.

\section{Playa Corazones}

Corresponde a un área de afloramiento de calcedonia beige opaca de grano medio a fino, de fractura regular. Se presenta como un afloramiento con efecto de arrastre desde la parte superior de la cornisa del talud de la cordillera de la Costa hasta la base o pie de ladera. La dispersión de material lítico se encuentra asociada a concentraciones y afloramiento natural de calcedonia. La presencia de extracciones líticas obtenidas mediante acción antrópica se caracterizan por lascas primarias (presencia de corteza en cara dorsal) y secundarias (baja presencia de corteza), algunas de las cuales presentan retoques y denticulados laterales producto de percusión dura directa. Desde la perspectiva morfofuncional se identifican instrumentos unifaciales sobre lascas de dorso alto, caracterizados como raederas frontolaterales semicirculares levemente extendidas y raspadores sobre lascas irregulares.

\section{Conclusiones}

Del reconocimiento de sitios arqueológicos en el sector medio del valle de Azapa, se desprende que los lugares preferidos donde se asentaron las poblaciones del periodo Medio, tanto como para construir aldeas como cementerios, fueron los faldeos de cerros, espolones rocosos y sobre todo terrazas fluviales, distribuidas en ambas laderas del valle de Azapa. Por la ladera norte los espacios (terrazas) mayormente ocupados, incluso desde antes del periodo Medio, fueron las que se ubican los sectores de Cabuza, Sobraya, cerro Moreno, San Miguel, San Juan, Las Ánimas y Cerro Chuño, en cambio en la ladera sur las terrazas más ocupadas fueron cerro Blanco, Las Riberas, San Lorenzo, Las Maitas, pampa de Alto Ramírez, Atoca, cerro Sombrero, cerro San Miguel y Saucache. Estas terrazas aunque están localizados en distintos lugares del curso bajo del valle, presentan una situación geográfica común, en cuanto a las relaciones de un lugar específico con el entorno próximo y lejano. Hay una proximidad a las vertientes, están ubicados por sobre el piso del valle y presentan similares posibilidades de control y defensa de los espacios de interés. Además, fueron lugares que ayudaron a la protección contra ambientes malsanos y fenómenos naturales, por hallarse en mayor altura que el cauce del río. De tal manera que la existencia de estas terrazas habrían facilitado la existencia de asentamientos humanos, espacios que fueron intervenidos 
y modificados periódicamente originando con ello, verdaderos paisajes geográficos. En cuanto a los lugares de aprovisionamiento lítico, estos se hallan dentro del entorno de la conformación del valle pero no inmediatamente contiguos a los sitios, y tienen la particularidad de ubicarse en la cima de cerro que conforman la ladera como afloramientos de la roca. Por lo tanto la interacción y acceso a ellos se desarrolló a través de senderos, lo que demostraría un conocimiento de los recursos potenciales del valle.

Con la práctica de la agricultura y el sedentarismo en Azapa, podría señalarse que se inicia la transformación del paisaje natural en paisaje geográfico, cuya condición desde entonces ha sido la de cambios acordes a los intereses de la sociedad que se ha asentado (Muñoz y Chacama, 2012).

La gran mayoría de sitios prospectados correspondieron a cementerios, en él vemos una estrecha relación espacial entre los cementerios de túmulos del periodo Formativo y los cementerios en fosas del periodo Medio, esta situación permitió que estas últimas poblaciones reutilizaron los túmulos, cuando estos dejaron de tener vigencia como cementerios, a fines del período Formativo, transformándolos en centros ceremoniales para acciones de culto que se manifestaron a través de ofrendas depositadas en los bordes y cimas de estos. Esta idea de ofrendar a los antiguos cementerios monticulares al parecer estuvo relacionada a rendir culto o reconocimiento a los antepasados que se enterraron en los túmulos, responsables además de haber realizado las primeras prácticas agrícolas. De tal manera que estas ceremonias de ofrendar a antiguas wakas o cementerios, tuvieron una larga vigencia histórica en el valle de Azapa, su complejidad la observamos en el caso de Atoca, a fines del período Medio donde a un imponente cerro le fue construido un geoglifo, y en sus faldeos fueron depositados entierros con ofrendas cerámicas cuyo estilo decorativo se vincula al horizonte Wari-Tiwanaku.

Desde el punto de vista de la visibilidad la mayor construcción registrada en el valle de Azapa, a fines del período medio, corresponde al asentamiento de San Lorenzo, el que se sitúa sobre dos montículos y faldeos de cerros. Superficialmente se observan una serie de áreas de actividad, ligadas con la preparación y cocimientos de alimentos, trabajo de manufacturas, descanso y ceremonias llevadas a cabo donde se ofrendaron animales. Esta organizada estructura del espacio habitacional, sumada a una planificada construcción del poblado y los materiales utilizados nos hacen sugerir que los recintos habitacionales fueron más complejos que los espacios habitacionales de los agricultores del período Medio y Formativo, sin embargo, para lograr la construcción de este gran emplazamiento, tuvo que existir un mecanismo gradual de asentamientos en el tiempo, partiendo por sencillos campamentos semiestable como lo fueron Az-115 y que posteriormente se transformaron en pequeñas aldeas como A-75, Az-29 y Az-6. En la medida que se conseguía la estabilidad del proceso agrícola, a fines del período Medio emerge el asentamiento Az-11 San Lorenzo, el que llegó a constituirse en el mayor centro administrativo en el valle con una vigencia de 300 años aproximadamente (Muñoz y Focacci, 1985) (Figura $\mathrm{N}^{\circ} 22$ y $\mathrm{N}^{\circ} 23$ ).

En relación a la gran concentración de sitios arqueológicos ubicados en el sector medio del valle, esto se explicaría en base en factores ecológicos y culturales. La existencia de recursos hídricos permanente mediante afloramientos de aguas subterráneas habrían permitido un ecosistema vegetacional, que atrajo animales para la caza mayor y menor como guanacos (Aucheni guanacus), vizcachas (Lagidium viscociacuviere), roedores menores, etc. lo cual habría ayudado a la obtención de carnes rojas. Otros animales que se habrían sumado a esta cadena conformada a partir de estos sistemas acuosos, fueron las aves como: flamencos, garzas y variedades de patos, los que emigran especialmente en invierno de los climas lluviosos de la cordillera andina hacia la costa. La llegada temporal de estas especies habría permitido que aumentara localmente los recursos de caza terrestre y recolección como los camarones de río. De tal manera que, como consecuencia del conocimiento del medio, los agricultores habrían escogido este lugar del valle porque constituiría el mayor espacio para cultivar, allí las tierras agrícolas formadas esencialmente por terrazas fluviales alcanzan una extensión de ladera a ladera de 800 a 1.000 m, 
Figura $\mathrm{N}^{\circ} 23$

Organización de los asentamientos habitacionales durante el período Medio en el valle de Azapa

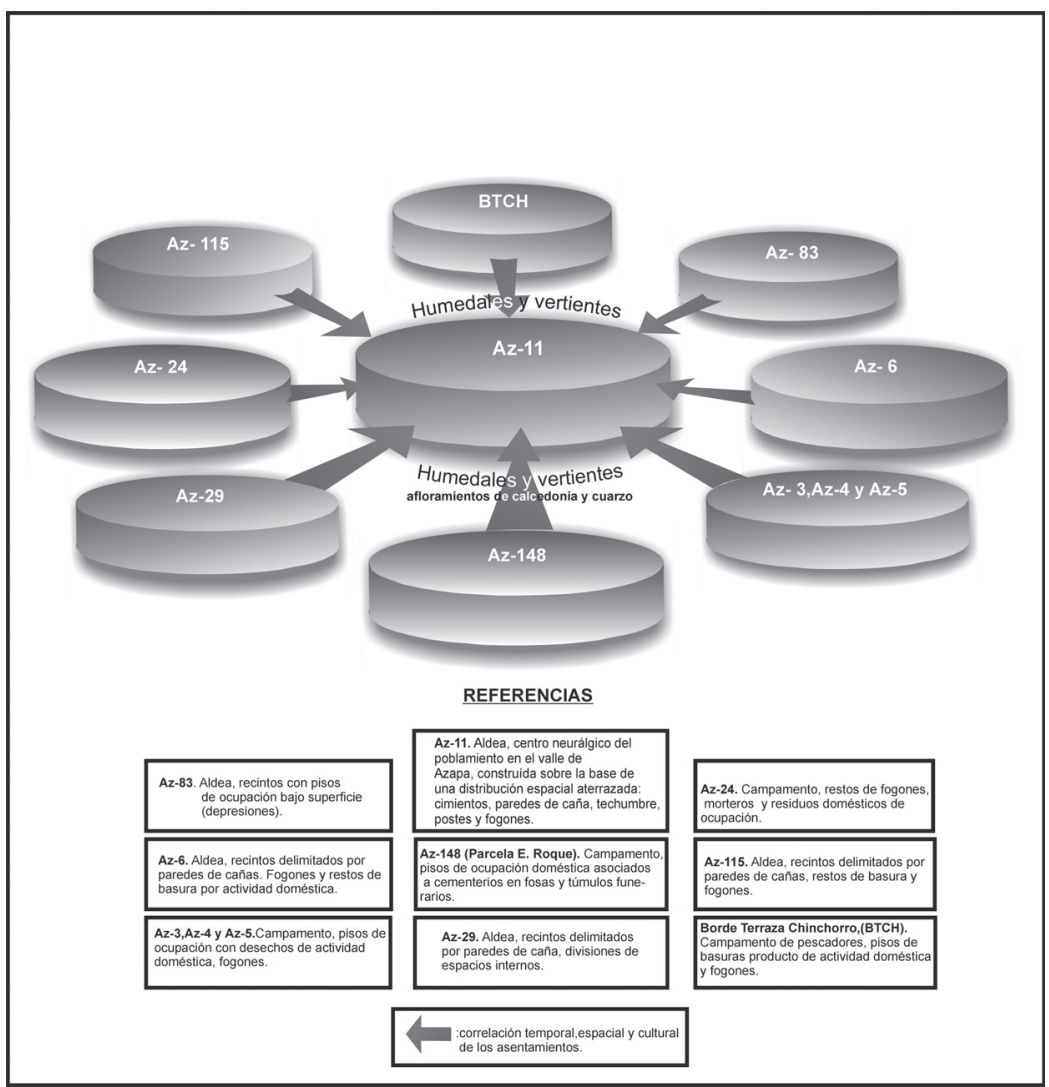

Fuente: Elaboración propia.

lo cual les habría permitido utilizar el riego por acequia llevando las aguas que brotaban de las vertientes. Su cercanía a la costa, 10 a $14 \mathrm{~km}$, aunque no haya sido una razón preponderante, fue importante ya que constituía un recurso complementario en la dieta de estos agricultores aldeanos.

En cuanto a la interacción del valle medio con la costa observamos una estrecha relación que se manifiesta por evidencias económicas y la visibilidad que presentan los asentamientos ubicados en distintos sectores del valle y que lo comunican con la costa. Otro indicador de conexión son las redes viales (senderos) que se desplazan por las laderas norte y sur del valle hacia la costa. Un sendero clave por la ladera norte para explicar esta conexión es la ruta que comunica los sectores de Cabuza, Sobraya, cerro Moreno, San Miguel, Parcela 27 (MASMA), Las Ánimas, Parcela Eusebio Roque, cerro Chuño y desembocadura del río San José, en estos sectores se hallan asentamientos poblacionales del periodo Medio, los cuales están interconectados con las vertientes: El Socavón, Pejerrey, Conchalique, Matavaca, La Noria, San Miguel, La Concepción, Peña Blanca y Canaviri. (Muñoz y Zalaquett, 2011). Por la ladera sur, lo sectores que están comunicados a través de senderos son cerro Blanco, Las Riberas, San Lorenzo, Las Maitas, pampa de 
Alto Ramírez, Atoca, cerro Sombrero, El Buitre, y Quiani en la costa, alcanzando varios de ellos una interconexión con las vertientes de Gallito, Media Luna, Las Ánimas y Mita Chica. Es interesante destacar que en estas laderas están ubicadas las mayores expresiones de arte rupestre en geoglifos donde un elemento a destacar son las figuras de camélidos y en el sector de cerro Sombrero la figura del pastor con su rebaño. En esta interacción costa-valle es importante destacar la presencia de restos de economía del mar en los asentamientos prospectados en el sector medio del valle, lo cual sería un indicador de permanentes desplazamientos de las poblaciones del valle a la costa en búsqueda de productos alimenticios como lo indica la presencia de Choromithilus, locos, lapas, corvinas, pescados, mamíferos marinos, etc.

De la información analizada podemos concluir que los tempranos agricultores que construyeron los túmulos fueron pescadores cuya historia milenaria los vinculaba con el manejo de la costa y el valle de Azapa, de tal manera que conocían profundamente los diversos espacios productivos de este valle, conjuntamente con sus características ecológicas y geográficas entre ellas los lugares de disponibilidad de agua, de aprovisionamiento de material lítico entre otros, lo cual pudo haber facilitado el mecanismo agrario temprano, en el sentido de buscar recursos permanentes de agua y lugares apropiados para prácticas de cultivos.

A diferencia de la etapa experimental ocurrida durante el periodo Formativo, durante el período Medio, la situación pudo ser controlada debido a que se logró encontrar una línea productiva en donde alcanzó importancia el cultivo del maíz, ají, calabazas, camote y mandioca entre otros productos, lo que hizo que estas tierras del valle se constituyeran en un espacio atractivo para los intereses tanto de los agricultores como de pescadores de la zona; como asimismo de poblaciones de otras áreas culturales, dentro de las cuales habría que considerar a Tiwanaku. Sin embargo, es a partir de la fase tardía de este periodo donde se observan cambios que van a cristalizar hacia una identidad propia como fue la Cultura Arica a comienzos del 1000 d.C. Al parecer todas las experiencia previas lograda en el trabajo agrícola conjuntamente con el aporte de los recursos del mar y los camélidos habrían contribuido económicamente a la emergencia de esta Cultura Regional permitido un mayor aumento de la población en el valle de Azapa con una estructura social más compleja como lo demostraría el poblado de San Lorenzo como espacio único de carácter administrativo situado en el valle (Figura $\left.N^{\circ} 24\right)$.

Recapitulando la historia del poblamiento aldeano a través de las evidencias mayoritarias como fueron los cementerios, planteamos que la construcción de montículos funerarios durante el periodo agrícola Temprano (Formativo) pudo haber estado vinculado con manifestaciones visibles que permitieron demarcar como estrategia política los espacios y accesos a los recursos, situación que habría cambiado en el periodo Medio debido a la estabilización del desarrollo agrícola y los contactos producidos con comunidades agrícolas entre ellas, grupos vinculado con la influencia Tiwanaku. El cambio de esta estrategia ideológica en el patrón funerario, con tumbas cavadas en el subsuelo, al parecer estuvo relacionada con la entrada al inframundo, el espacio de los muertos (Figura $\mathrm{N}^{\circ}$ 25 y N $\left.\mathrm{N}^{\circ} 26\right)$. Asimismo, estos espacios fueron lugares de origen, de concepción y comunicación con los ancestros, donde se realizaban ritos de paso y se legitimaba el poder y la territorialidad, insertando elementos externos, como materiales que asemejan rasgos Tiwanaku. 
Figura $\mathrm{N}^{\circ} 24$

Vista espacial del poblado de San Lorenzo, sitio Az-11

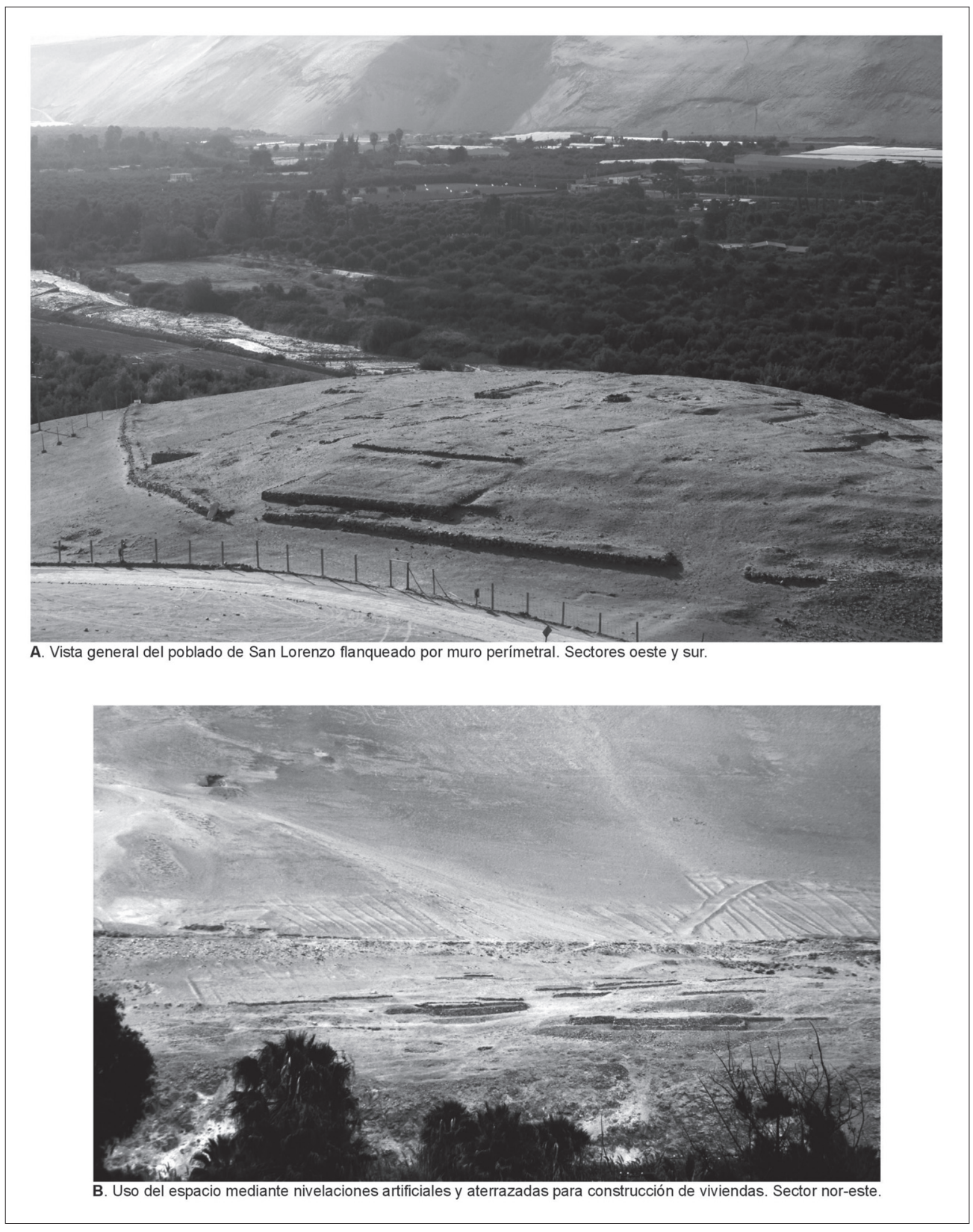

Fuente: Archivo personal de los autores. 
Figura $\mathrm{N}^{\circ} 25$

Aspecto de las condiciones actuales de preservación de las áreas funerarias en Az-19 y Az-141, valle de Azapa

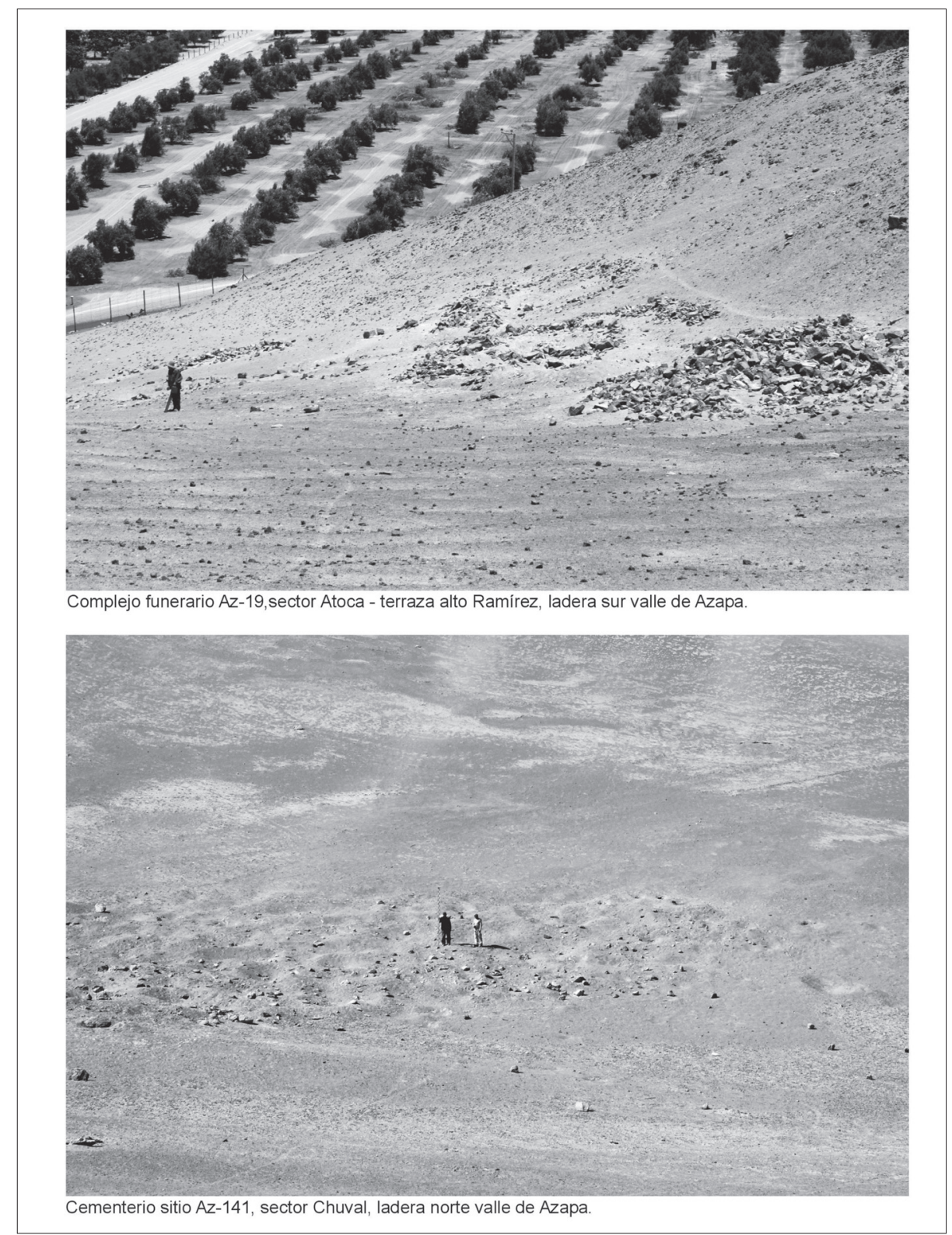

Fuente: Archivo personal de los autores. 
Figura $\mathrm{N}^{\circ} 26$

Enterratorios en fosas del período Medio, valle de Azapa

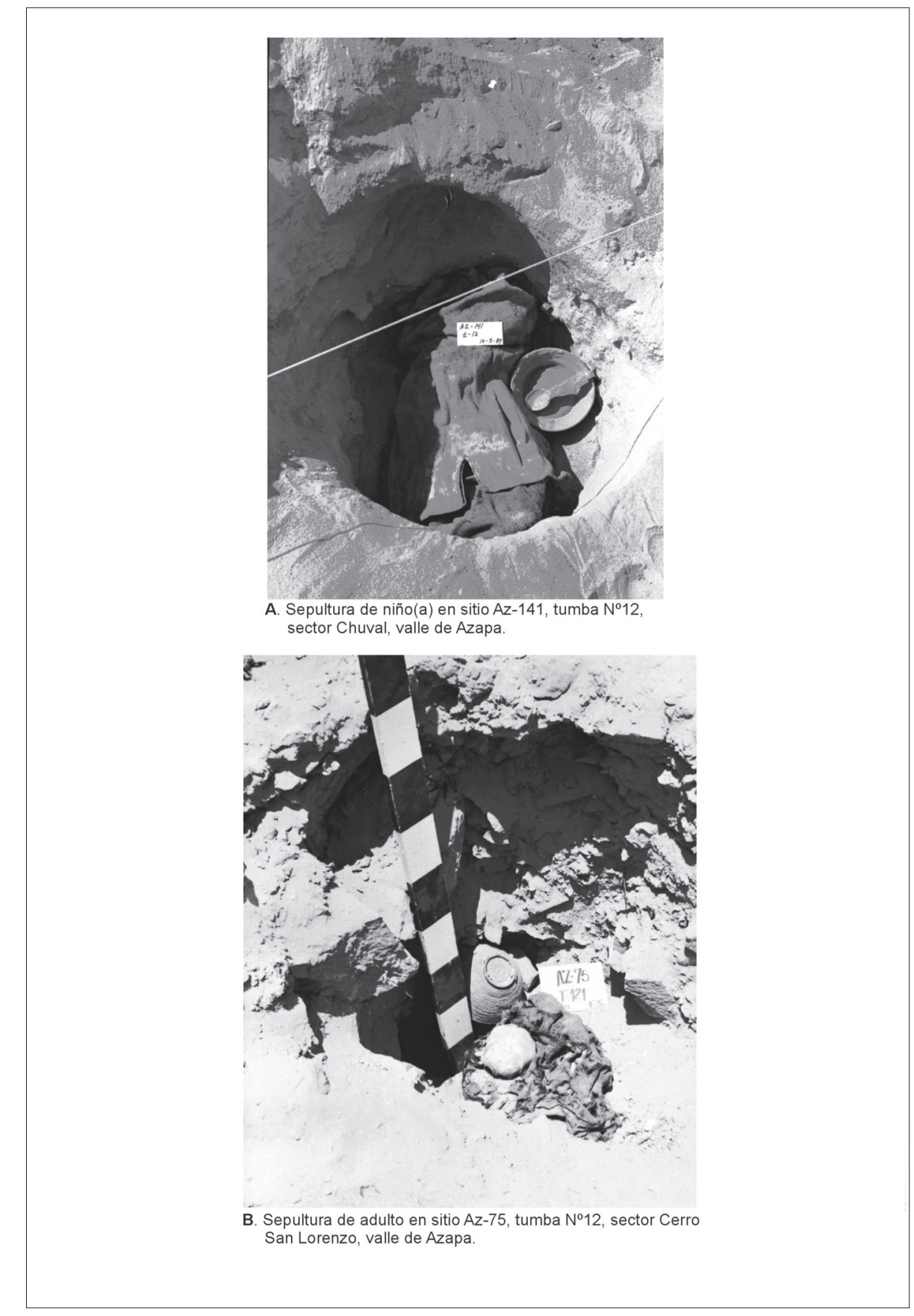

Fuente: Archivo personal de los autores. 


\section{Referencias bibliográficas}

ANSCHUETZ, K., WILSHUSEN, R. \& SCHEIK, CH. An Archaeology of Landscape: Perspectives and directions. Journal of Archaeological Research, 2001, No 9, p. 157-211.

BERENGUER, J. Tiwanaku. Señores del Lago Sagrado /Tiwanaku: lords of the sacred Lake. Santiago de Chile: Museo Chileno de Arte Precolombino/ Banco Santiago, 2000.

BERENGUER, J. y DAUELSBERG, P. El norte grande en la órbita de Tiwanaku (400 al 1200 d.C.). En: HIDALGO, J. (editor) Cultura de Chile: Prehistoria desde sus orígenes hasta los albores de la conquista. Santiago de Chile: Andrés Bello, 1989, p. 129-180.

BOURDIEU, P. Outline of a Theory of Practice. Cambridge: Cambridge University Press, 1997.

CHACAMA, J. El Horizonte Medio en los valles Occidentales del Norte de Chile. Chungará, 2004, Vol. esp., T. I, p. 227-233.

CRIADO BOADO, F. Límites y posibilidades de la arqueología del paisaje. Spal, 1993, $\mathrm{N}^{\circ} 2$, p. 9-55.

CRIADO BOADO, F. Del terreno al espacio: planteamientos y perspectivas para la arqueología del Paisaje. Santiago de Compostela: Capa 6. Grupo de investigación en arqueología del Paisaje, Universidad de Santiago de Compostela, 1999.

CROM, W. La interpretación geográfica de fuentes históricas: el ejemplo del valle de Azapa, Arica-Chile. Diálogo Andino, 1988/1989, No 7/8, p. 43-56.

DAUELSBERG, P. Contribución a la arqueología del valle de Azapa. Boletín Museo Regional de Arica, No 3, 1959, p. 17-24.

DAUELSBERG, P. Algunos problemas sobre la cerámica de Arica. Boletín de Museo Regional de Arica, № 5, 1961, p. 7-17.

DAUELSBERG, P. Sobre la problemática arqueológica de Arica. Carta respuesta a Luis Guillermo Lumbreras. Chungará, 1972, Nº 1-2, p. 32-37.
DILLEHAY, T. Paisaje cultural y público. El monumentalismo holístico y circunscripto de las comunidades araucanas. En: DURÁN, A. y BRACCO, R. Arqueología de las Tierras Bajas. Montevideo: MEC. Imprenta americana, 2000, p. 449-466.

ESPINA, L. Estudio agroeconómico del vaIle de Azapa. Santiago de Chile: Universidad de Chile, 1971.

ESPOUEYS, O. Archivo: Inventario de sitios arqueológicos en los valles de Arica. Arica: Oficina de Registro, Museo San Miguel de Azapa, Departamento de Antropología, Universidad del Norte, 1973.

FAUNDES, W. Fuentes aprovisionamiento lítico en la costa de Arica. Resultados de una propuesta metodológica de reconocimiento por prospección. Informe Fondecyt 1130249 , 2013.

FOCACCI, G. Síntesis de la Arqueología del Extremo Norte de Chile. Chungará, 1980, No 6, p. 3-23.

FOCACCI, G. Nuevos fechados para la época del Tiahuanaco en la arqueología del norte de Chile. Chungará, 1982, Nº 8, p. 6378.

FOCACCI, G. El Tiwanaku Clásico en el vaIle de Azapa. Arica: Documentos de Trabajo, Instituto de Antropología y Arqueología, Universidad de Tarapacá, 1983, № 3, p. 94-113.

FOCACCI, G. Excavaciones Arqueológicas en el Cementerio Az-6. Valle de Azapa. Chungará, 1990, № 24-25, p. 69-124.

GOLDSTEIN, P. Tiwanaku settlement patterns of the Azapa Valley. Diálogo Andino, 1995/1996, No 14-15, p. 57-73.

GOLDSTEIN, P. y MUÑOZ, I. Inventario de sitios arqueológicos en los valles de Arica. Arica: Oficina de Registro, Museo San Miguel de Azapa, Departamento de Antropología. Universidad de Tarapacá, 1991.

ISBELL, W.H. Mummies and Mortuary Monuments. A postprocessual Prehistory of Central Andean Social organization. Austin: University of Texas Press, 1997. 
KAULICKE, P. Vivir con los ancestros en el Antiguo Perú. En: MILLONES, L. y KAPSOLI, W. La memoria de los Ancestros. Lima: Editorial Universitaria, p. 9-24, 2001.

KELLER, C. El Departamento de Arica. Santiago de Chile: Editorial Zig-Zag, 1946.

KNAPP, B. \& ASHMORE, W. Archaeological Landscape: Constructed, Conceptualized and Ideational. In: KNAPP, B. \& ASHMORE, W. Archaeologies of Lanscape. Contemporary Perspectives. Oxford: Blackwell Malden, 1999, p. 1-30.

MUÑOZ, I. Investigaciones arqueológicas en los túmulos funerarios del valle de Azapa. Chungará, 1980, № 6, p. 57-95.

MUÑOZ, I. Poblamiento humano y relaciones Interculturales en el valle de Azapa: Nuevos hallazgos en torno al periodo Formativo y Tiwanaku. Dialogo Andino, 1995/1996, No 14-15, p. 241-278.

MUÑOZ, I. Estrategias de Organización Prehispánicas en Azapa: El Impacto de la Agricultura en un Valle del Desierto Costero. Arica: Ediciones Universidad de Tarapacá, 2004a.

MUÑOZ, I. Ocupación del espacio doméstico y áreas de actividad generadas en el asentamiento prehispánico de San Lorenzo. Diálogo Andino, 2004b, № 24, p. 53-98.

MUÑOZ, I. Agua y Monumentalidad en el valle de Azapa: indicadores del uso del espacio en las poblaciones Alto Ramírez, periodo Formativo, norte de Chile. Chungará, 2012, Vol. 44, No 4, p. 571-592.

MUÑOZ, I. y FOCACCI, G. San Lorenzo: Testimonio de una comunidad de agricultores y pescadores post-Tiwanaku en el valle de Azapa (Arica-Chile). Chungará, 1985, № 15, p. 7-30.

MUÑOZ, I. y SANTOS, M. La waka de Atoca, ¿alfarería Wari en Arica? Actas del XIII Congreso Nacional de Arqueología Chilena, 1995, Vol. 2, p. 69-80. Antofagasta.

MUÑOZ, I. y ZALAQUETT, F. El paisaje en la distribución de los túmulos funerarios del valle de Azapa, durante el periodo Formativo, norte de Chile. Revista de Geografía Norte Grande, 2011, № 50, p. 23-43.

MUÑOZ, I. y CHACAMA, J. Transformación del paisaje social en Arica: De pescadores arcaicos a agricultores incipientes, norte de Chile. Estudios Atacameños Arqueología y Antropología Surandinas, 2012, No 44, p. 123-140.

MUÑOZ, I.; FERNÁNDEZ, M.S. y ROCHA, J.R. Nuevas Dataciones de 14 C para los Túmulos Funerarios: Una breve discusión en torno a la cronología de túmulos y la antigüedad del proceso formativo en Arica. En: MUÑOZ, I. y FERNÁNDEZ, M.S. Mil años de Historia de los constructores de Túmulos de los valles desérticos de Arica: Paisaje, Monumentos y Memoria. Arica: Ediciones Universidad de Tarapacá, 2014, p. 163-175.

NOGUÉ, J. y SAN EUGENIO VELA, J. La Dimensión comunicativa del paisaje. Una propuesta teórica y aplicada. Revista de Geografía Norte Grande, 2011, No 49, p. 25-43.

RIVERA, M. Patrones prehistóricos y contemporáneo del uso de la tierra en el valle de Azapa, norte de Chile. Diálogo Andino, 1983, $\mathrm{N}^{\circ} 2$, p. 9-26.

RIVERA, M. y KOLATA, A. Tiwanaku, aproximaciones a sus contextos históricos y sociales. Santiago de Chile: Ediciones Universidad Bolivariana, 2004.

ROTHHAMMER, F. y SANTORO, C. EI Desarrollo Cultural en el valle de Azapa, extremo norte de Chile y su vinculación con los desplazamientos poblacionales altiplánicos. Latin American Antiquity, 2001, Vol. 12, Nº. 1, p. 59-66.

SANTORO, C. Fase Azapa, Transición del Arcaico al desarrollo agrario inicial en los valles bajos de Arica. Chungará, 1980, № 6, p. 46-56.

SANTORO, C. Estudios de un yacimiento funerario arqueológico del extremo norte de Chile, 1300 a.C. 1300 d.C. Antofagasta: Tesis de pregrado en Arqueología, Universidad del Norte, 1981. 
SUTTER, R. Prehistoric Genetic and Culture Change: A Bioarchaeological Search for Pre-InkaAltiplano Colonies in the Coastal Valleys of Moquegua, Peru, and Azapa, Chile. Latin American Antiquity, 2000, Vol. 11, № 1 , p. 43-70.

URIBE, M. y AGÜERO, C. Alfarería, textiles y la integración del norte grande de Chile a Tiwanaku. Boletín de Arqueología PUCP, 2001, No 5, p. 397-426.
VÁSQUEZ DE ESPINOZA, A. Compendio y descripción de las Indias Occidentales. Madrid: Atlas, 1969.

VILLAFÁÑ̃EZ, E.A. Entre la geografía y la arqueología: el espacio como objeto y representación. Revista de Geografía Norte Grande, 2011, No 50, p. 135-150. 